GOVERNED BY OPPORTUNITY 


\section{GOVERNED BY OPPORTUNITY}

How can the vanishing trades of Singapore be conserved

through the integration of architecture and social inclusion?

Angelina Shu Chien Ang

A research portfolio submitted to the School of Architecture and Design,

Victoria University of Wellington, in fulfilment of the requirements for

the degree of Master of Architecture (Professional). 
Acknowledgements ave helped me gain the confidence I seek for.

Oscar Ho - Even though we rarelv see eye to eye, vour comfort and

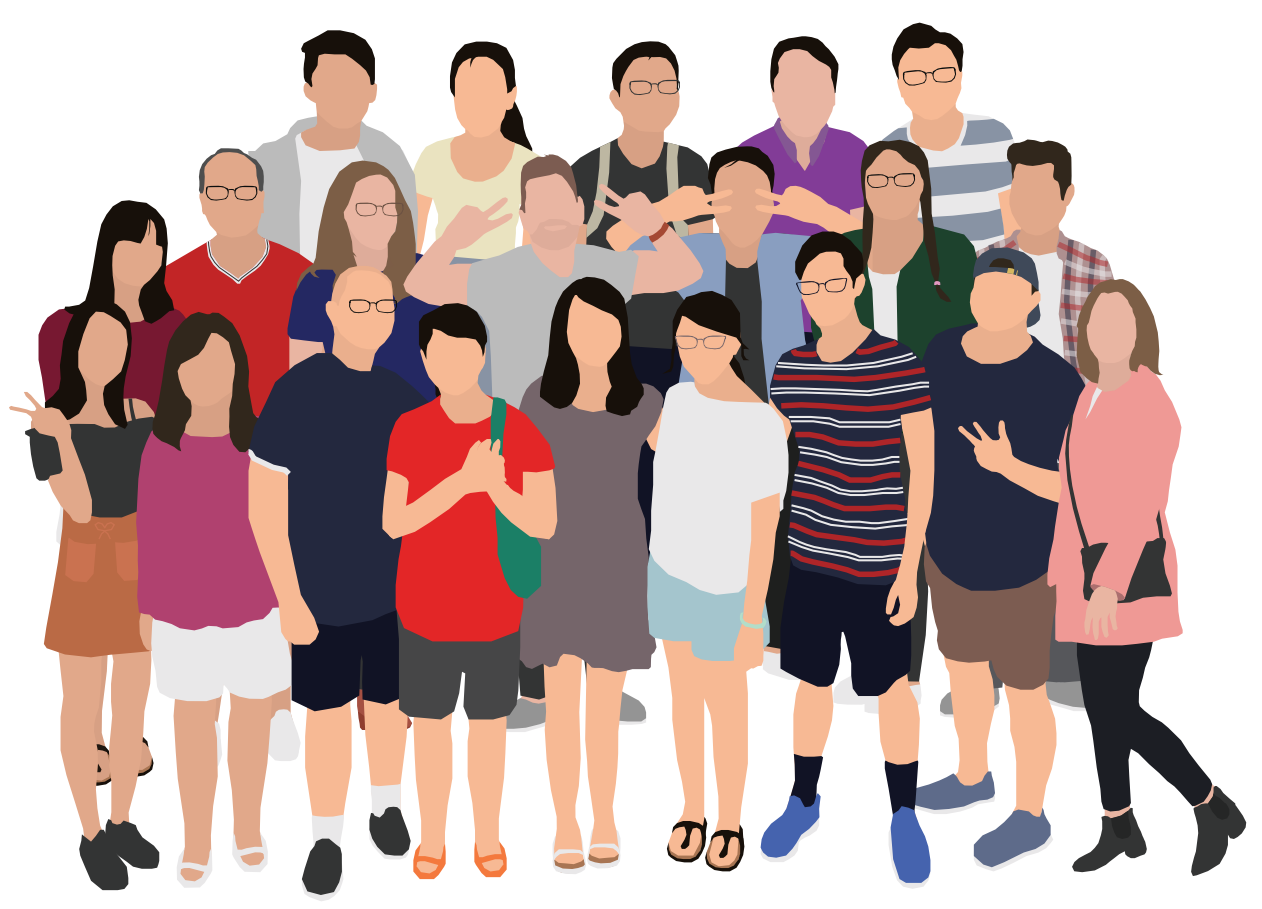
your construction knowledge. $\mathrm{Oh}$ - and for building my easel and cork not for you.

Emma Cunningham \& Allie Hennessv (otherwise known as basic bitch / illustrator queen) - You guys never fail to make me laugh. I am so proud of all the challenges we faced and overcomed together!

Kelsey Flett \& Kenneth Claudio - Thank you for still wanting to hang out with me even though I disappear for months. I promise I will be back to normal now!

Phoebe, Feng, Shin, the Ng Family \& everyone else I met in Singapore Thank you for your great hospitality and food recommendations. Your friendliness and generosity made my trip very fulfilling I hope to vec

Lastly, Mum, Dad, Andrew \& Adeline - Your endless love and support

It has been a challenging $b$ ee what the future holds 


\section{Abstract}

Singapore is known as an advanced industrialising city-state with the aspiration to be a global city in the international economy (Yuen, 2005). With the rapid economic growth; the country's population has been increasing alongside the high demand of: housing, commercial areas,
industries, transport and infrastructure (Yuen, 2005). Having an area of industries, transport and infrastructure (Yuen, 2005). Having an area of only $720 \mathrm{~km}^{2}$, the country is forced to optimise their land by building vertically and closely together. Consequently, older buildings, activities and traditions are more prone to vanishing despite their cultural and historical significance. The loss of tangible and intangible heritage results in a highly modern country that is becoming more international in scale 2005). The aim of this research investigation is to explore how the traditional
trades can be conserved and integrated with the present and future development of Singapore. Through interviews and observations conducted in field research, it will provide a better understanding of the community and government's point of interest. This will develop social cohesion to promote a sense of belonging and identity in this metropolitan city. The design outcome of this research investigation will be an integration of the Sungei Road Market and the future development of the Singapore Johore-Express Bus Terminal. 
Contents

Acknowledgements

Abstract

Contents

Chapter One: Introduction

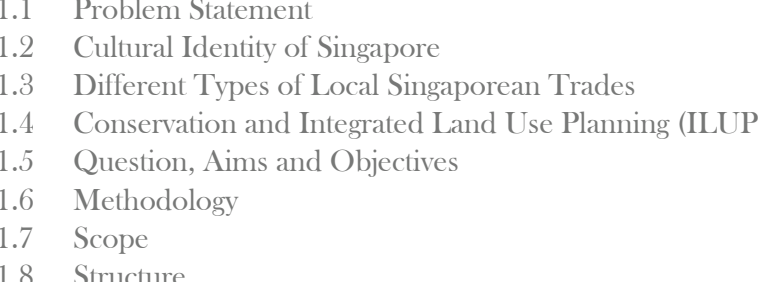

$18 \quad$ Stuct

4.1 Design Intentions and Proces

4.2 Design Outcome

1.3 Design Reflectio

Chapter Five: Developed Design

5.1 Design Intentions and Process

$\begin{array}{ll}5.2 & \text { Design Outcome } \\ 5.3 & \text { Design Reflection }\end{array}$

\section{Chapter Six: Conclusion}

$$
\begin{array}{ll}
6.1 & \text { Final Summary } \\
6.2 & \text { Bibliography } \\
6.3 & \text { List of Figures } \\
6.4 & \text { Appendix }
\end{array}
$$

2.1 Literature Review

.2.

$\begin{array}{ll}3.1 & \text { Quantitative Site Analysis } \\ 3.2 & \text { Qualitative Site Analysis }\end{array}$

3 Existing Site Problems

3.4 Design Guideline 


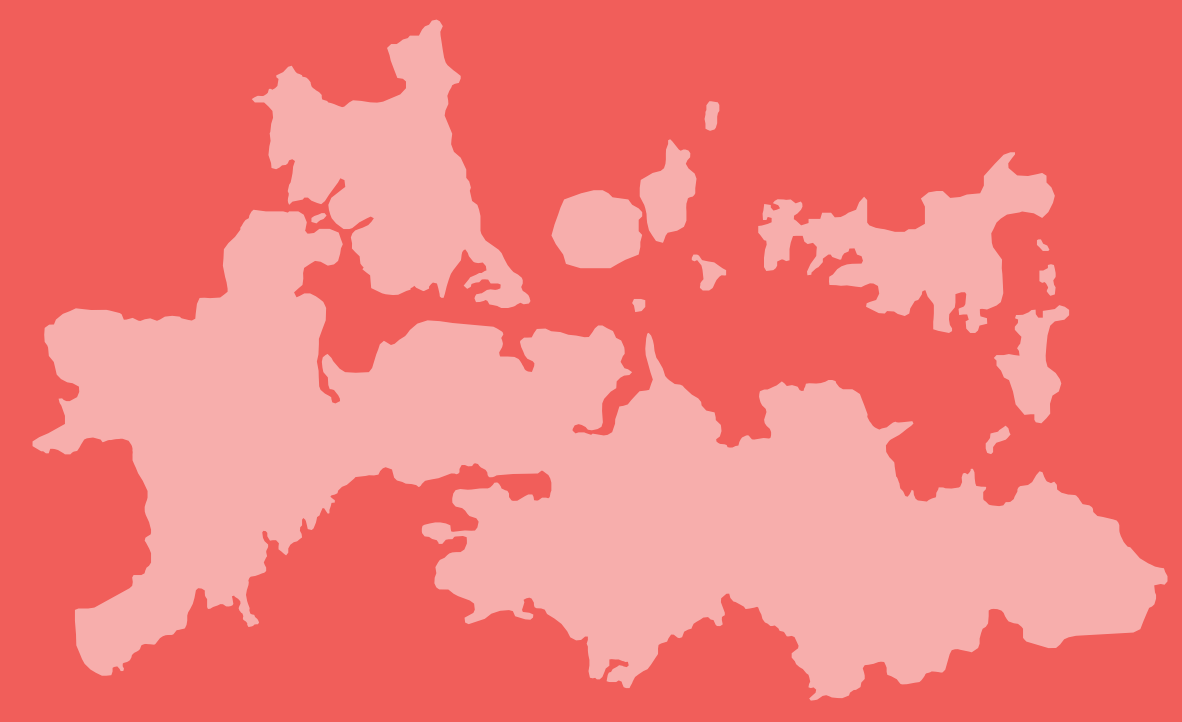

Auckland City, New Zealand

$290 \mathrm{~km}^{2}$

Population: 405,000

Population Density: 1396 people per km²

Wellington City, New Zealand

$1086 \mathrm{~km}^{2}$

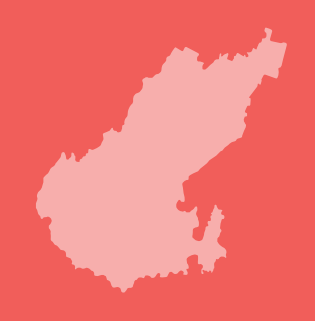

Population : 1,495,000 Density: 1376 people per $\mathrm{km}^{2}$
Poplo

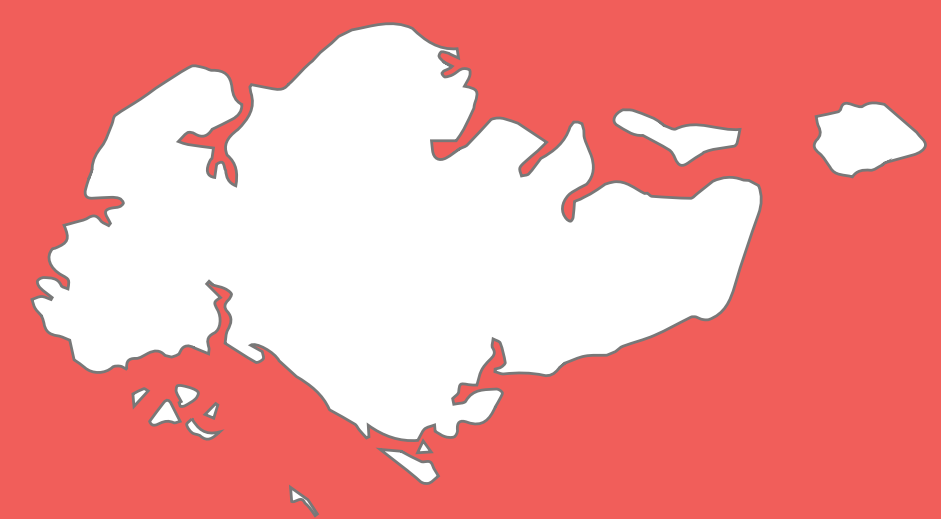

Singapore

$720 \mathrm{~km} 2$

Population: 5,610,000

Population Density: 7802 people per km²

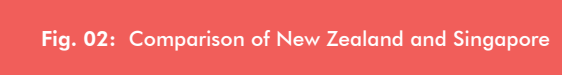

CHAPTER ONE:

INTRODUCTION 
"The loss of many tangible and intangible heritage results in a highly modern country that is becoming more international in scale and style but also evermore faceless and lacking in cultural identity."

Belinda Yuen

(Yuen, 2005, pg 199)

1.1 Problem Statement

What use to be a small fishing village of less than 150 people, Singapore grew into a modern city-state of one million people by the 1950s. This county has consciously reinvigorated its economy to its present status of the international economy (Yuen, 200.5). As a result, this caused a rapit ifflux of residents, housing commercial weas, industries, transport infrastructure (Yuen, 2005) With a land area of only $790 \mathrm{~km}^{2}$ Sing a is forced to optimise their use of land by building vertically and closely inger million people today.

From the fast pace and economic growth, the older buildings, activities and traditions are gradually forgotten despite their cultural and historica significance. Consequently, the loss of tangible and intangible heritage results in a highly modern country that is becoming more international in scale and style but also evermore faceless and lacking in cultural identity (Yuen, 2005).

Fig. 03 (Above): Singapore's CBD Fig. 04 (OPposite): Environmental Minists
workers demolishing morket stalls on workers dem
Sungei Road 


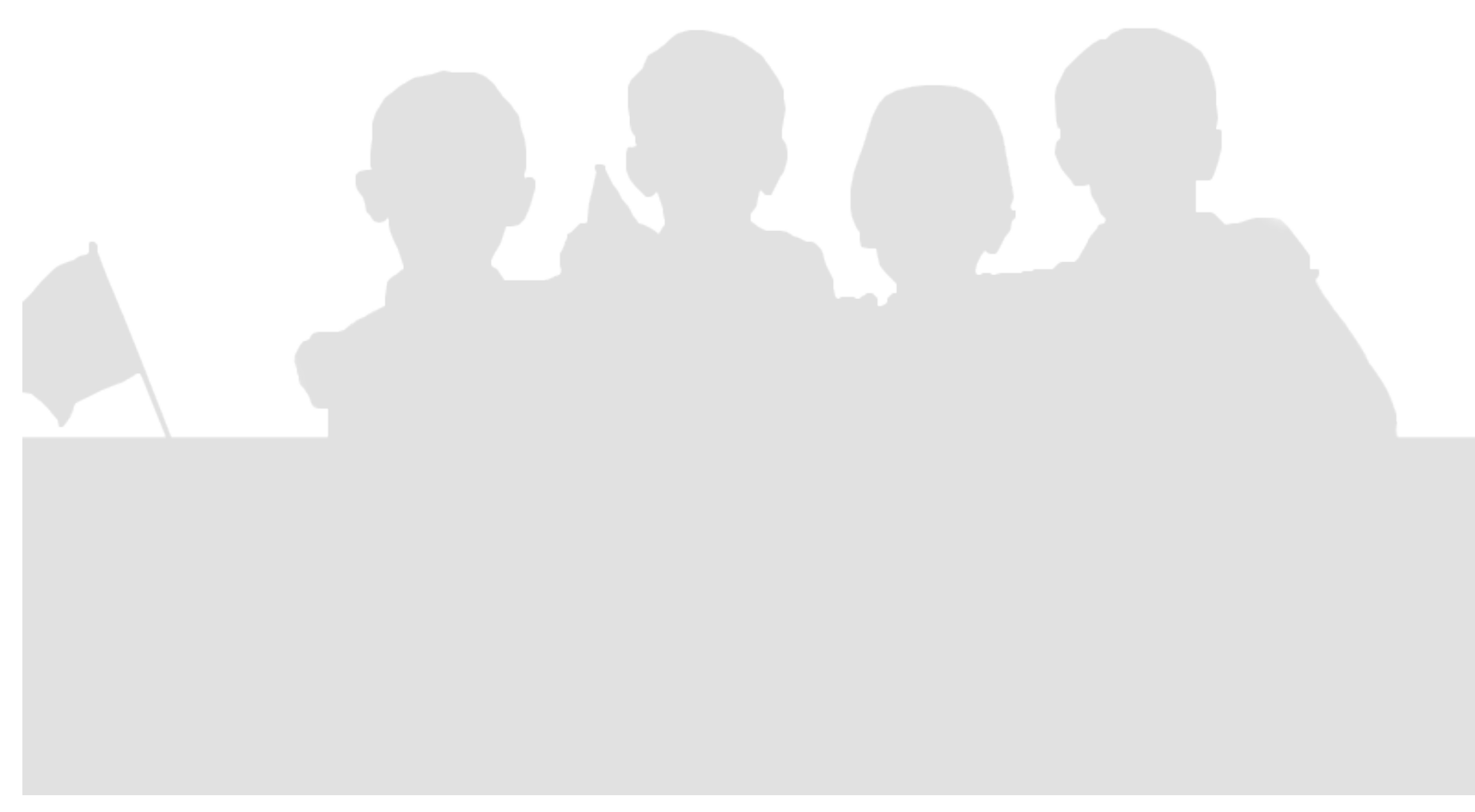

1.2

The cultural identity of Singapore is defined by the diversity and integration of various ethnicities (Chinese, Indian, Malay, European Peranakan and Eurasian). Over time, each ethnicity has retained an evolved is on cilure and heriage

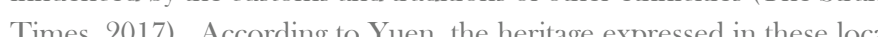

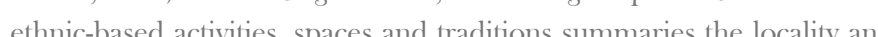
place identity of Singapore (Yuen, 2005).
Fig. 05 (Above): Local ethnicitities
found in Singagore

Fig. 06 (Opposite): Sungei Rood in
the 1970 s

"Things worth saving need not necessarily be beautiful or historic as long as they are familiar or well loved."

David Lowenthal

(Lowenthal, 1979, pg 555) 


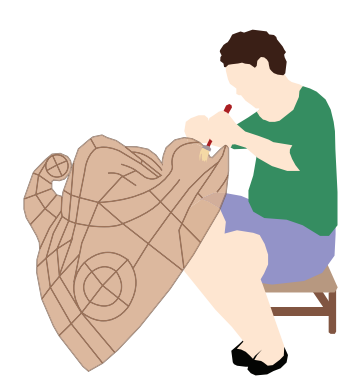

Lion Dance Costume Maker

Costumes that are made

for traditional Chinese lio

dance performances.
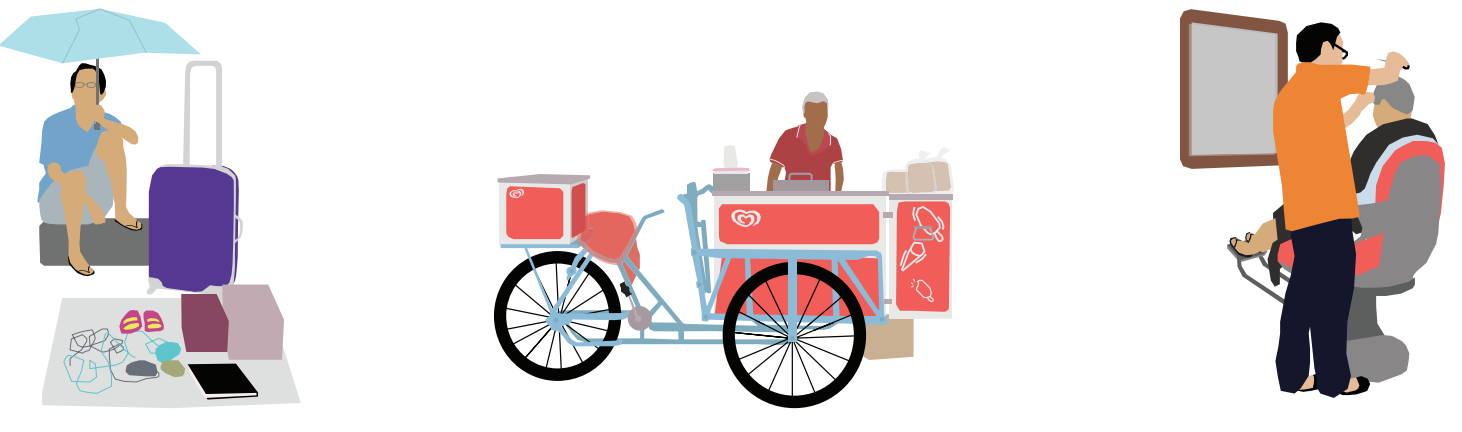

Roadside Barbe

Sungei Road Market Vendor

A street vendor that sells a

variety of second-hand good

A street vendor that sells ice cream

Barbers that are found along and vintage items.
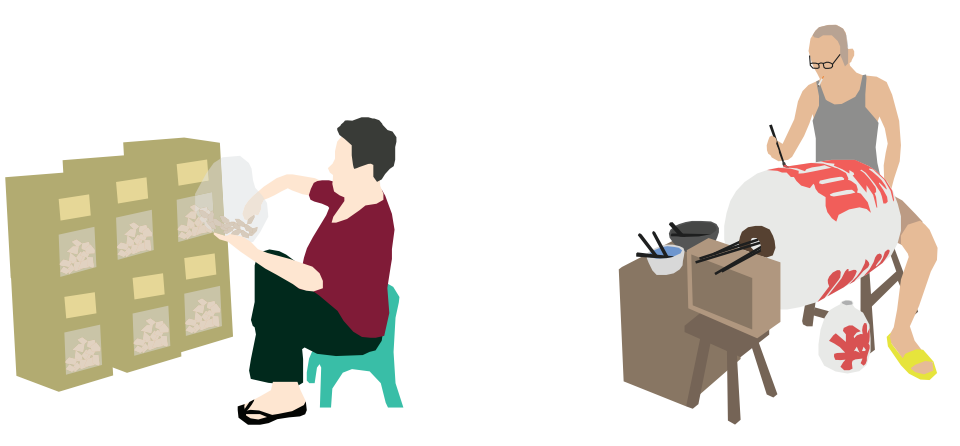

$$
\text { Biscuit Shop }
$$

Lantern Maker

A shop that sells a variety

of snacks and biscuits.
Paper lanterns that are made for traditional festivat a made

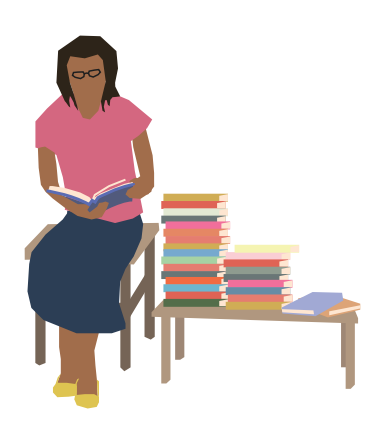

Second-hand Book Seller

A vendor that sells a variety

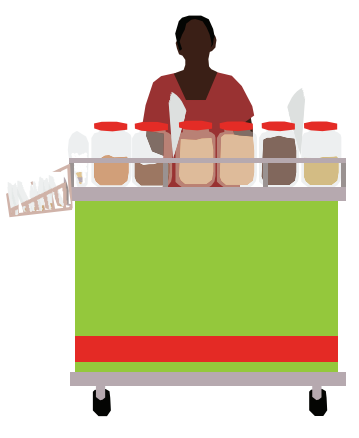

Kuchang Puteh Seller

A vendor that sells a variety in paper cones.

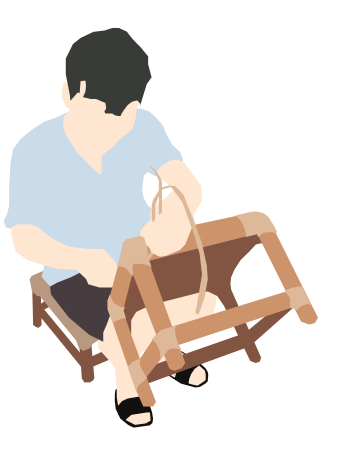

Rattan Weaver

Objects and furniture that are made by weaving
bamboo and rattan.

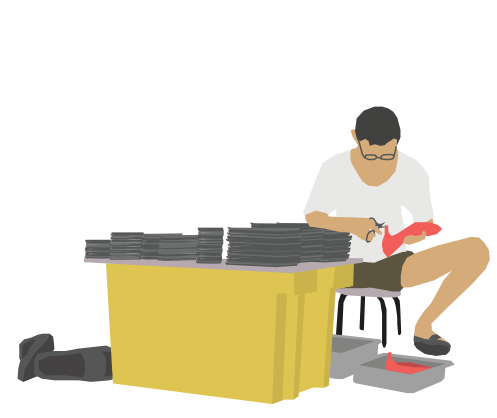

Shoe Cobbler

A vendor that repairs worn-out shoes.

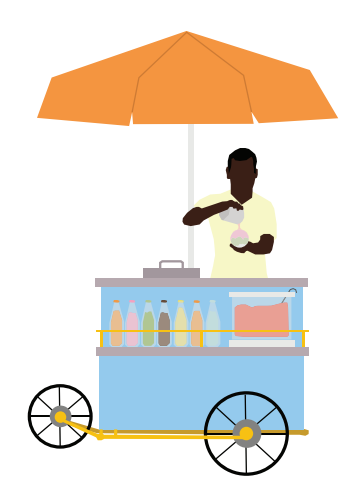

Ice-Ball Seller

A vendor that sells palm sugar and syrup laden ice-balls.

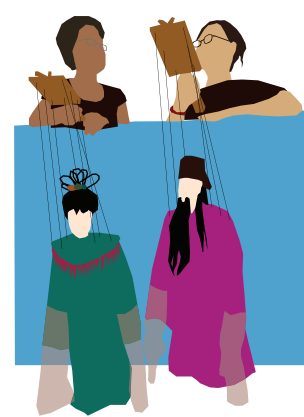

Chinese Puppet Theatre Puppet performances of

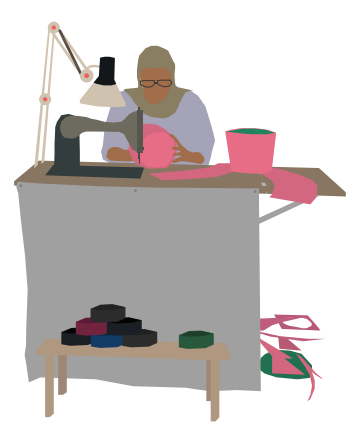

Songkok Maker

Custom-made caps that are formal Istumic events

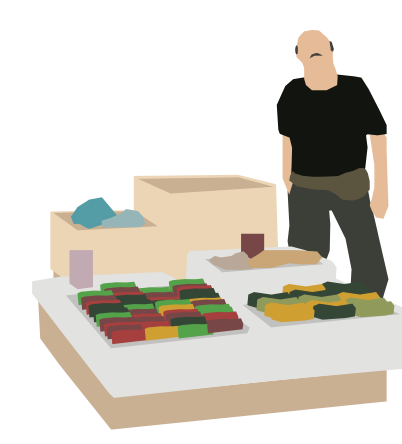

Provision/Mama Shop A 'mini-mart' that sells a range of groceries, grate and inems. 

Over time, local residents have been more aware and involved in onserving the cultural heritage of Singapore. According to the feedbac hile dlow $87 \%$ thount these builins should be conserved to retin toles .

"We need to build vibrant quality places. Singaporeans today want a more attractive and liveable city that meets more than just the functional need of the business community" (Yuen, 2005, pg 203).

For conservation plans to succeed alongside the development of the country, there needs to be an enforcement of integrated land us planning (ILUP), where there is a balance between the social, econom ond environmental growth (fig. 11) (Sum, 2013)

Why should it be conserved?
Integrated Land Use Planning (ILUP) for Sustainable Development

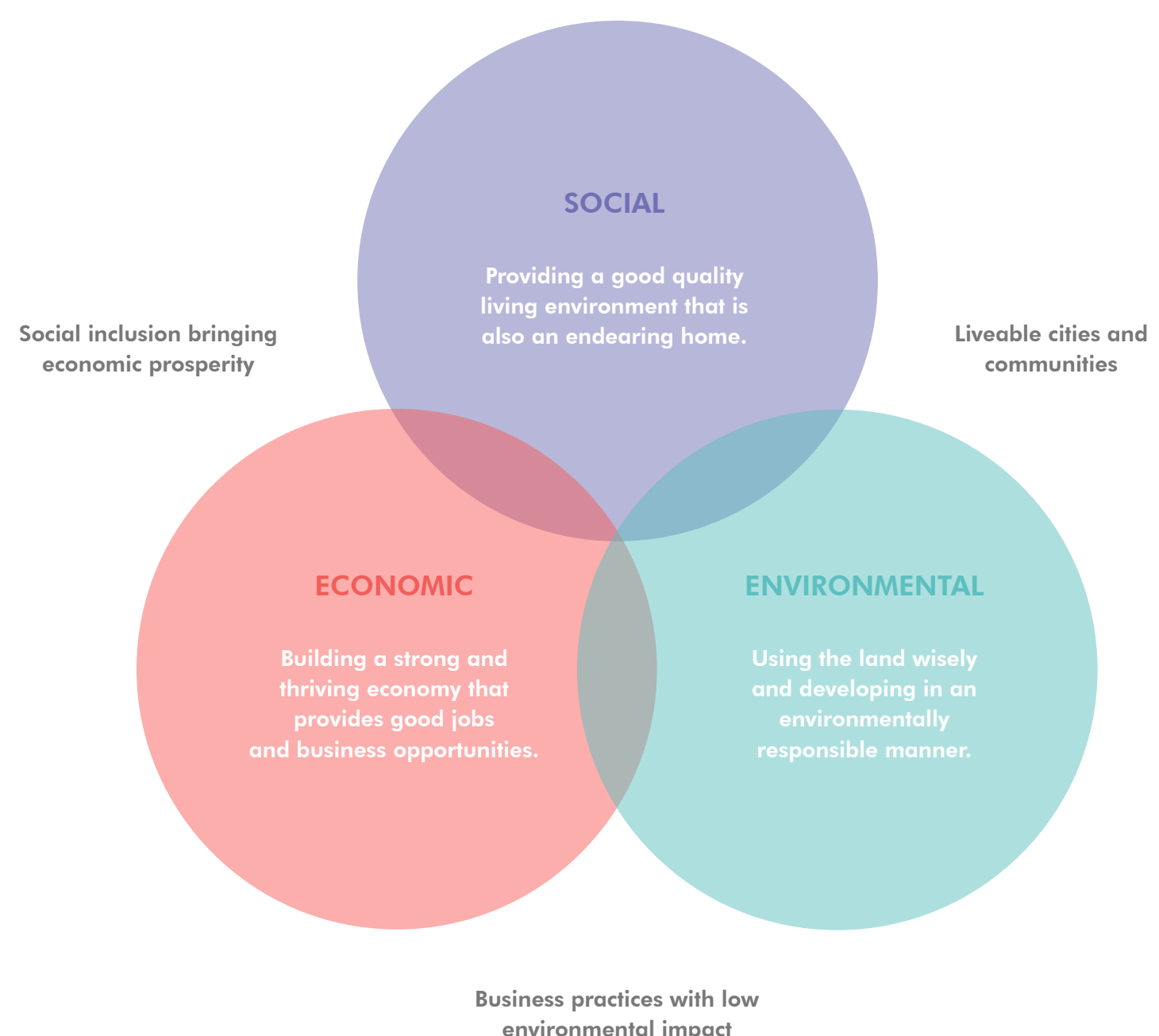

Retain trades and businesses that characterise the historic areas
Open and left to the market 
How can the vanishing trades of Singapore be conserved through the integration of architecture and social inclusion?
The aim of this research investigation is explore how architecture can:

Integrate the old and new development occurring in Rochor

Protect the users from Singapore's climatic conditions

Conserve and enhance the vanishing trades for fiture benertions

The objective of this research investigation is to implement the concept of social inclusion to:

Reduce alienation and enhance local ownership

Raise awareness of the historical and cultural significance 
This research investigation is approached in a visual design manner that shall be influenced and driven by the community. The engagement wit

the public through several qualitative research methods shall encourage

Fig. 12: Methodobog Dicagram (August - November)

studies will be reviewed in the early stages of this research investigatio

to help initiate possible ideas, approaches and solutions. The design

outcome will be formalised through a combination of sketches and dign
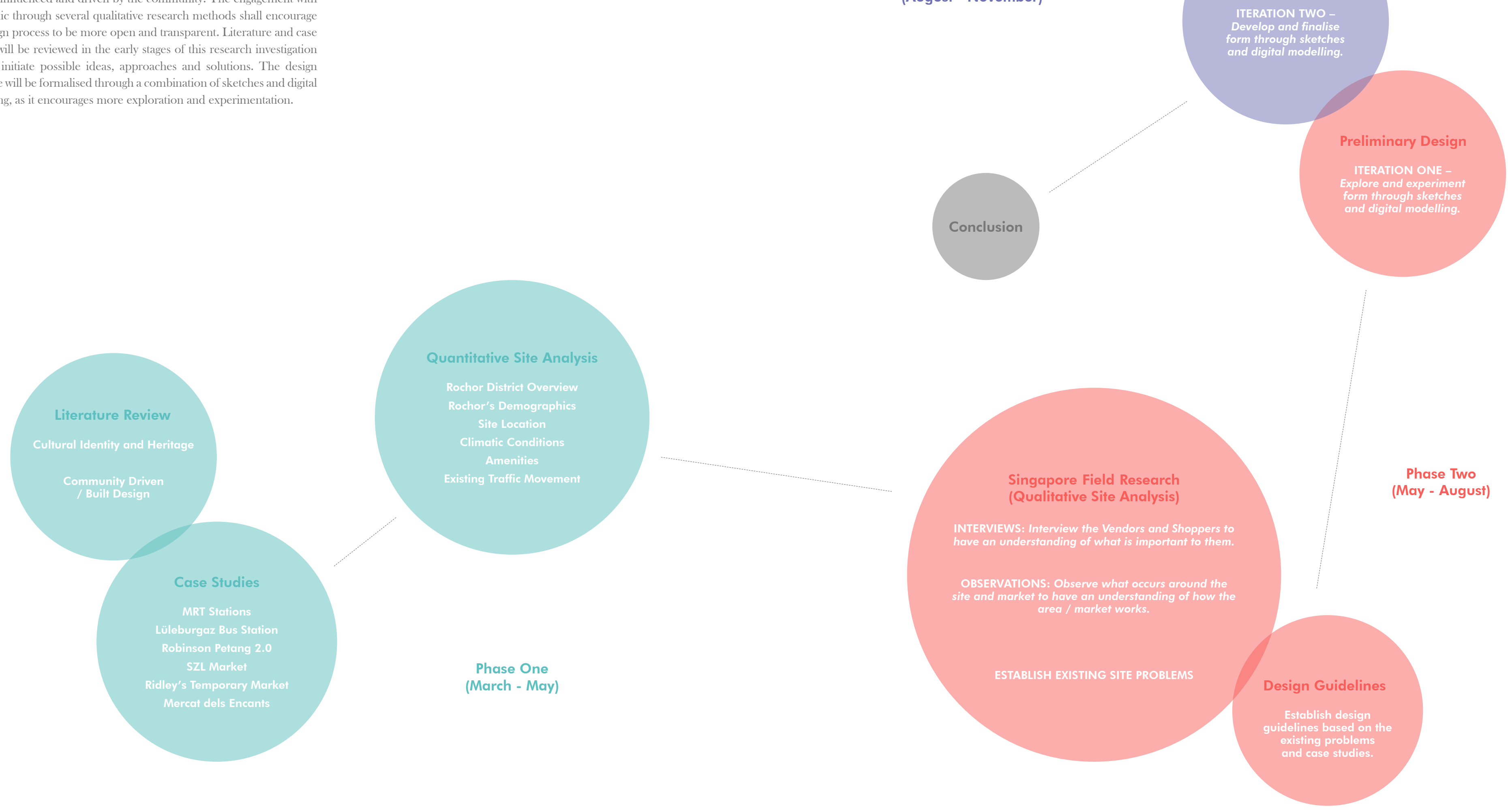


\section{$1.7 \quad$ Scope} This research investigation specifically focuses on understanding the Road Market. From observing and analysing both the people and the market, it shall provide a better understanding on how the market work and the community engagement that occurs within it. This will set up conditions that are required to develop a sense of cultural identity and belonging in Singapore.

The scope of this research investigation is to propose ways we can use architecture to conserve heritage that are intangitle in Singapore. Mis involves exploring various case studies, the location, formation and integration with the context. The bus station will be explored in the design process as the secondary and suppoting programme. This will help assist and justify the marketplace which is critical for this researc investigation

To achieve the amis and This research investagation is not about intensifation and maximisn

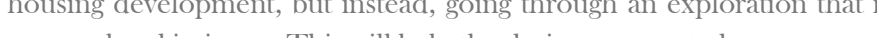
personal and intminate. This wilf help the design process to be more ope and trangers,

\section{Chapter One: Introduction}

This chapter introduces the topic, background and problem stateme wich

\section{Chapter Two: Literature Review \& Case Studies}

This chapter is a collation of theoretical research of cultural identity and heritage, as well as community driven and built design. The literature evien approached. Muttiple existing ase studies will also be reviewed to have

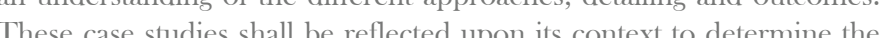
successful and unsuccessful factors.

\section{Chapter Three: Site Analysis}

This chapter is dedicated to understanding the context of this resear investigation through several quantitative site analysis methods. This includes; site location, demographics, climatic conditions, existing

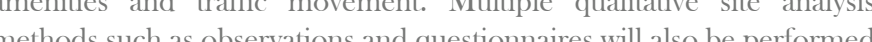
to gain a better understanding of the people and the community. The results of the site analvsis will help establish the existing site problems and design guideline

\section{Chapter Four: Preliminary Design}

This chapter focuses on establishing a conceptual design that are

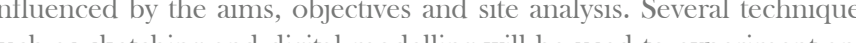
such as sketching and digital modelling will be used to experiment an

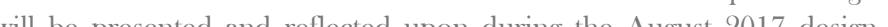

\section{Chapter Five: Developed Design}

his chapter will expand from the reflection of the preliminary design in hapter four. It will focus on developing the initial concept to articula

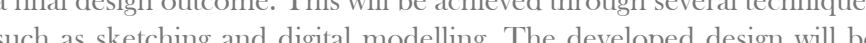

\section{Chapter Six: Conclusion}

This chapter will review the overall research investigation and how it was proached. Highlighting both positives and negatives to determine the 


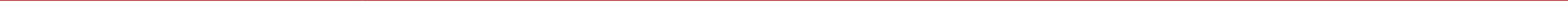


2.1 Literature Review

CULTURAL IDENTITY / HERITAGE

What is heritage? According to the English Oxford Dictionary, heritage is defined as "property that is or may be inherited; an inheritance" passed from one generation to the next - something that has historic and cultural value (Harrison, 2010). Saying that "things worth saving need

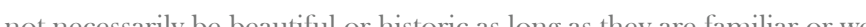
loved" (Lowenthal, 1979, pg 555.

The Singapore Heritage Society discussed how our heritare is more thu just the property we receive from previous generations it is the ties and connections that are associated with it. "If we value these objects todyy, in is not so much because they could be auctioned off for several thousants of dollars. We value these objects more for the memories they evoke " (Kwok, et al., 1999, pg 7). People use objects of heritage alongside their intangible memories to shape the ideas of their past, present and future (Harrison, 2010). It is our intangible memories which define the conte what tangible heritage is (Kwok, et al., 1999).
Despite the historic and cultural value, the general approach is that the past should serve the present (Yuen, 2005). The Chief Executive Office of the Uthan Relectop everything in time" (The Straits Times, 2002) Our woperties object and buildings must cater to the changes and new needs (The Stwis Times, 2002). The conservation that takes place will transorm thes objects into a beneficial toot for the environment - ane det will not incapactate the city into

But what do we choose to conserve? The Singapore Heritage Society emphasised that we must be selective in what we pass down. More importantly, we cannot dictate what our children choose to conserve - as a different time, place and memory will determine what heritage is (Kwok, et al., 1999). "Changing times and spaces will decide what traditions we conserve and how our ways of life will change. Our children and grand mildren will review and reinterpret the values underlying our traditions and way of life”" (Kwok, et al., 1999, pg 8).

\section{COMMUNITY DRIVEN / BUILT DESIGN}

Community-built projects often arise out of a specific need - whether it is caused by a natural disaster, economic downturn, or lack of government support (Stiefel, Faurest, \& Melcher, 2017). According to Turner and Fichter, "Governments have neither the will nor often the resources to provide sufficient shelter and/or amenities" (Turner \& Fichter, 1972, pg 3). Numerous buildings are being demolished to make way for new

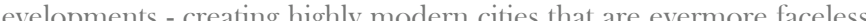
and lacking in cultural identity (Yuen, 2005).

Schneider discussed when a city appears somewhat unfinished and lessthan-perfect, it is far more attractive to young and creative people - as they feel they can leave their own individual mark (Schneider, 2014). This encourages more communitv-built projects to make better use of vacant lots, neglected public spaces and demolished buildings (Stiefel, Faurest, \& Melcher, 2017). The community's participation allows the images and meanings of places to develop from the bottom up - enhancing local ownership and tolerance to urbanity. (Rapoport, 1969).
According to Yuen, "inadequacies in the setting are far more tolerable the design process" Yuen, 2005, pg 202).

Community-built design can be driven through several quantitative an rialitative methods - this includes observations and questionnaire

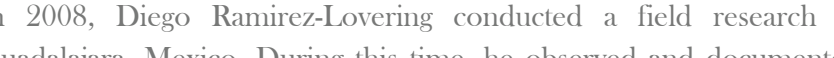
he informal settlements through photographs and diagrams. "We strove 10 understand a lot about a little. Rather than attempting to understand he city in any complete form, a focused enquiry into specific urba elements and environments were made" (Ramirez-Lovering, 2008, 11). Questionnarres and interviews can also be used to encourazc

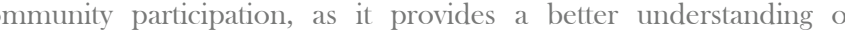
people's needs and interests (Participate in Design, 2018). "When this is based on real findings rather than assumptions, we have a higher chance in Design, 2018). 


\subsection{Transportation Case Studies}

\section{MRT Station(s), Singapore}

The MRT (Mass Rapid Transit) system is one of the most popular modes public transport in Singapore - taking over three million passengers day (Land Transport Authority, 2017). With 119 operating stations, station (Land Transport Authority, 2017).

The amenities around the area are easily accessible and link up to the MRT station(s).

to follow.

Pedestrians are protected from Singapore sclimatic conditions. Majority of the MRT stations lack in interior architectura teatures. If discourages pedestrians to meander and socialise, place for intereaction and socialisation?
Fig. 14 (Far Leff): Entrance to Tampines
MRT Station from Tampines Mall

(n)
Collective Architects \& Rasa Studio (2016)

"Transportation building is the entrance point of the city. Thus, it should

have not only symbolic value but also be memorable and unime. Our purpose is to design a functional and social transportation complex in Lüleburgaz - by using the potential of land and transforming it into a Landmark" (Collective Architects \& Rasa Studio, 2016).

A strong architectural statement was made through the canopy design. This makes the station more monumental drawing pedestrians in.

- The programme layout of the station was well executed. Restaurants, cafés and commercial spaces face towards the main road which work with the existing traffic movement. This widens the target audience as it is accessible for both passengers and the wider community.

- The different zones of the station are linked by the canopy and inishes of the interior space. The exposed structure allows the pace to feel more open and inviting.

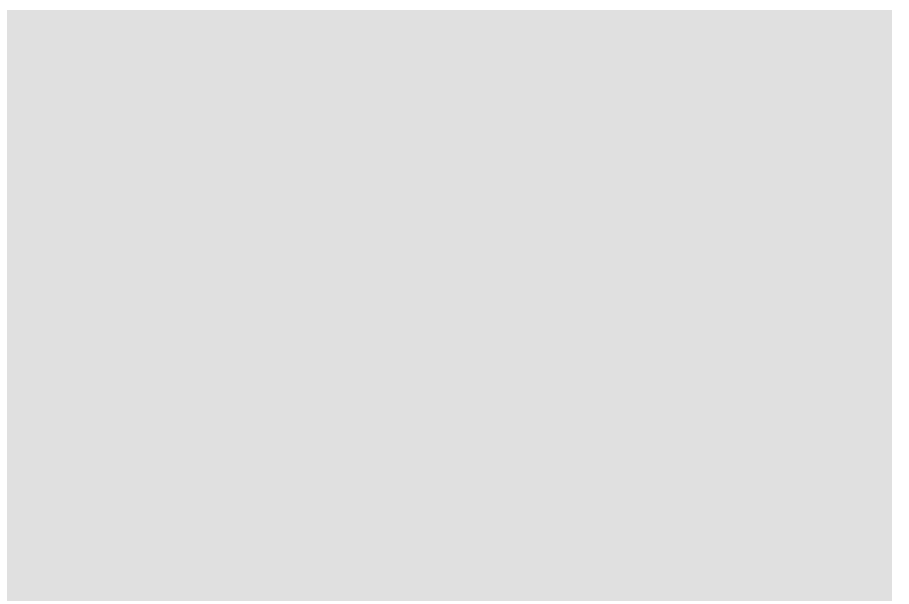

Fig. 16 (Far Leff): Exterior of
Livileburgaz Bus Station

Fig. 17 (Below): Departure Area of
Liuleburgaz Bus Station
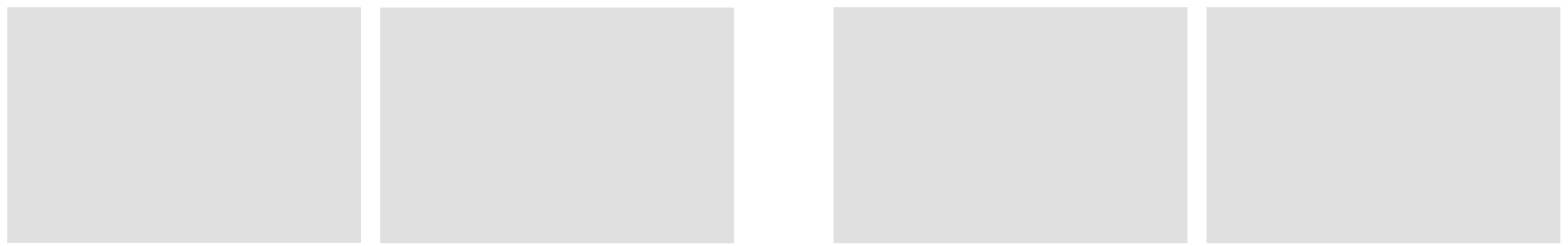


\subsection{Market Case Studies}

Save Sungei Road Campaign (2017)

During the 'Sungei Road Market: A Future for Street Culture Heritage' panel discussion, Faiz bin Zohri proposed a conceptual plan for 'Robinson Petang 2.0'. It involves relocating and revitalising the existing Sunger Road Market so it is "both a thriving marketplace of used good
- and a public space for community activities during the weekend" (Save Sungei Road Campaign, 2017, pg 3).

The proposed relocation areas will have good pedestria traffic from nearby MRT Stations

The proposed bold colours on stalls and umbrellas wil make the market place more vibrant - drawing pedestrians in. More storage space and rubbish bins will be provided to reduce the dis-amentities caused by the market.

The proposed retocation areas wilh be optimising underutilise space. However, without the ownership of the land, vendor are at risk of being evicted again.
Fig. 18 (Far Leff): Proposal inspiration.
local market tent typology Fig. 19 (Below): Proposal inspiration,
Deck Arr Gallery, Singapore

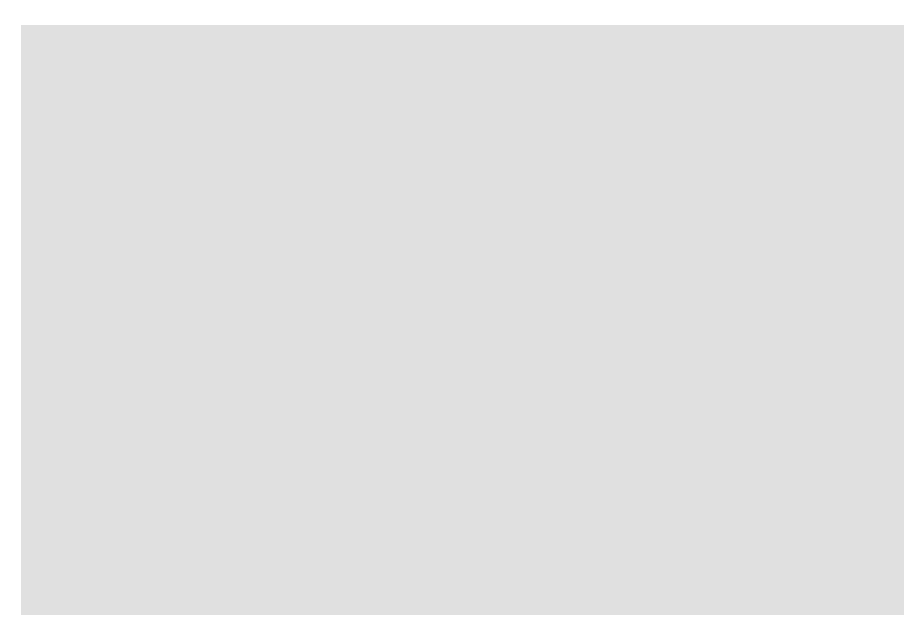

SZL Market, Bangkok, Thailand

all(zone) (2012)

"Open-air markets are the most common and simplest form of street business in Thiland With the expansion of Bangkok sity following the relocation of Bangkok Airport 6 years ago, the market transformed the physicality of the temporary market into a proper open-air market. Serving the new middle-class city" (all(zone), 2012).

20 (Far Leff): Street Vendors set up Fig. 21 ( Far Bottom): Canopy Design of
the Szl Market

- The market accommodates a mixture of Bangkok's economy by integrating street vendors, food and goods stalls, food court and a franchise 'mini-mart'. This reflects the diversity of the city by avoiding alienation and isolation.

- A strong architectural statement was made through the canopy design. It was inspired by the local tent typology which makes it more relatable. The canopy also protects the pedestrians from Thailand's climatic conditions - drawing more people in. The market uses a concrete structural system. Even though this is permanent, it is still able to accommodate for the fluctuation of the market without heavily influencing it.
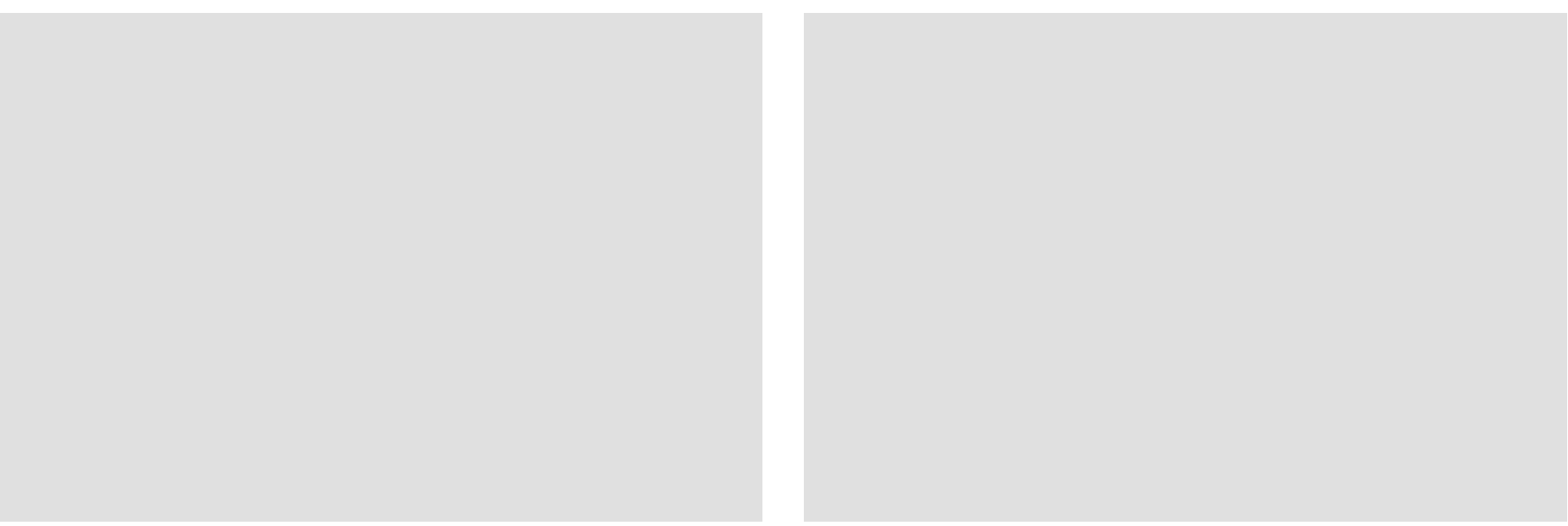
Ridley's was a public realm intervention that combined food and architecture by featuring a food-for-food exchange organism. Ideally located alongside a street market, Ridley's worked within the market's existing infrastructure to negotiate its social and economic contingencies" The Decorators, 2011).

The scaffolding used for the restaurant created a sense of openness and exposure to the rest of the market. This mad the restaurant more inviting and welcoming.

The temporary restaurant served as a device to stimulate local trades within Ridley's Market (The Decorators, 2011). By encouraged the pedestrians to engage with other stalls in the market.

This restautant desig was temporaty event though it was socially influential to the rest of the community. This raises the question of whether a proposal like this could be designed in way to become more permanen setting up a 'food-or--ood' exchange system, the restauran

\section{Fig. 22 (Far Leff): Ridley's Temporary
Restaurant in the Ridley's Market} Fig. 22 (Far Bottom): Rilley's Temporary
Restaurant's food-for-food exchange
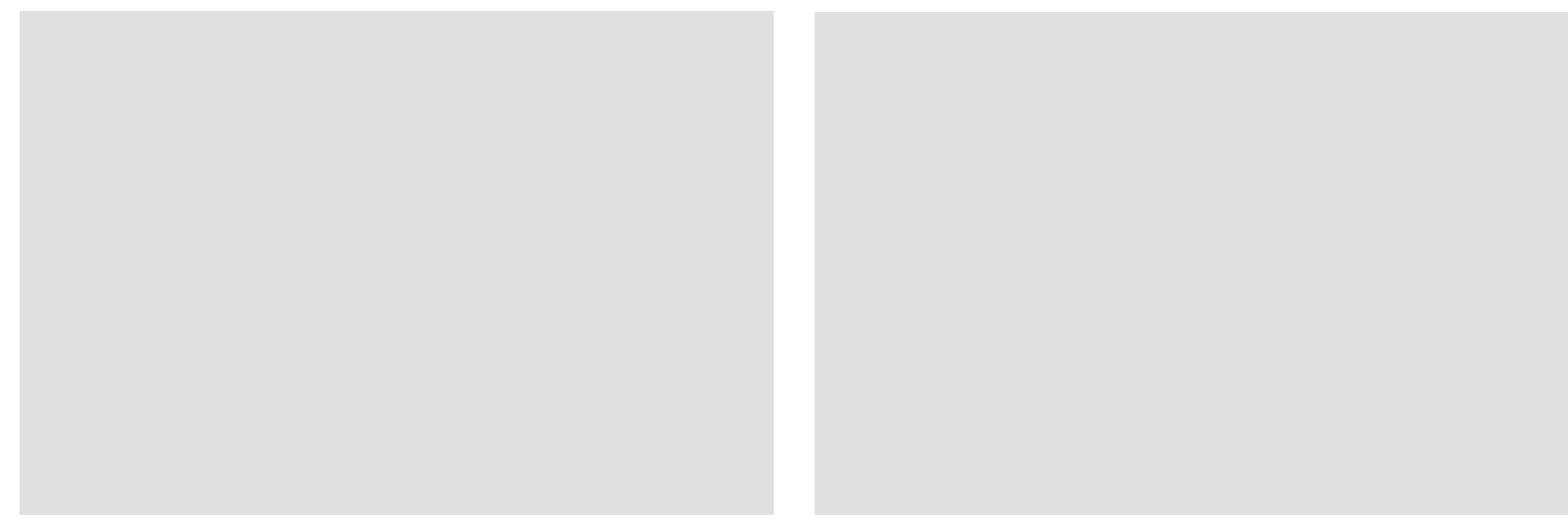

Mercat dels Encants, Barcelona, Spain "Els Encants in Barcelona is a centenarian marketplace, which has
traditionally been set outdoors in an informal way. Its original location was not far from the market's new grounds and is occupving the junction of Merdiana Avenue with Las Glorias Square" (b720 Fermín Vázquez Arquitectos, 2013).
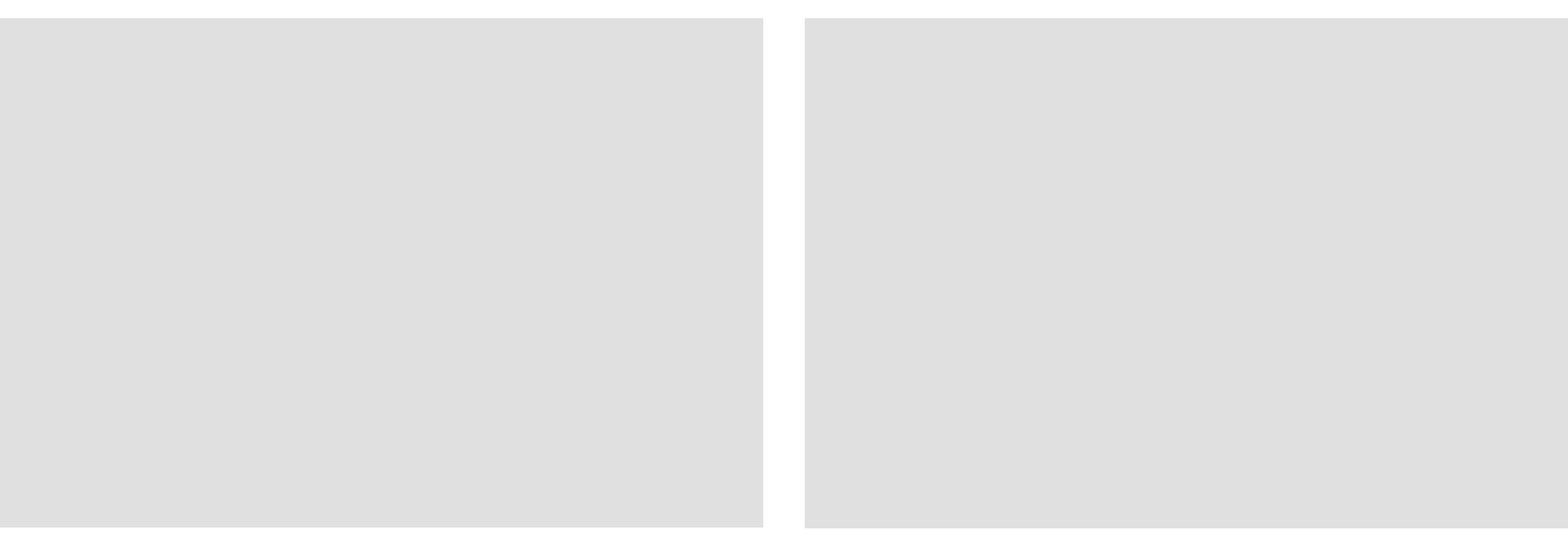


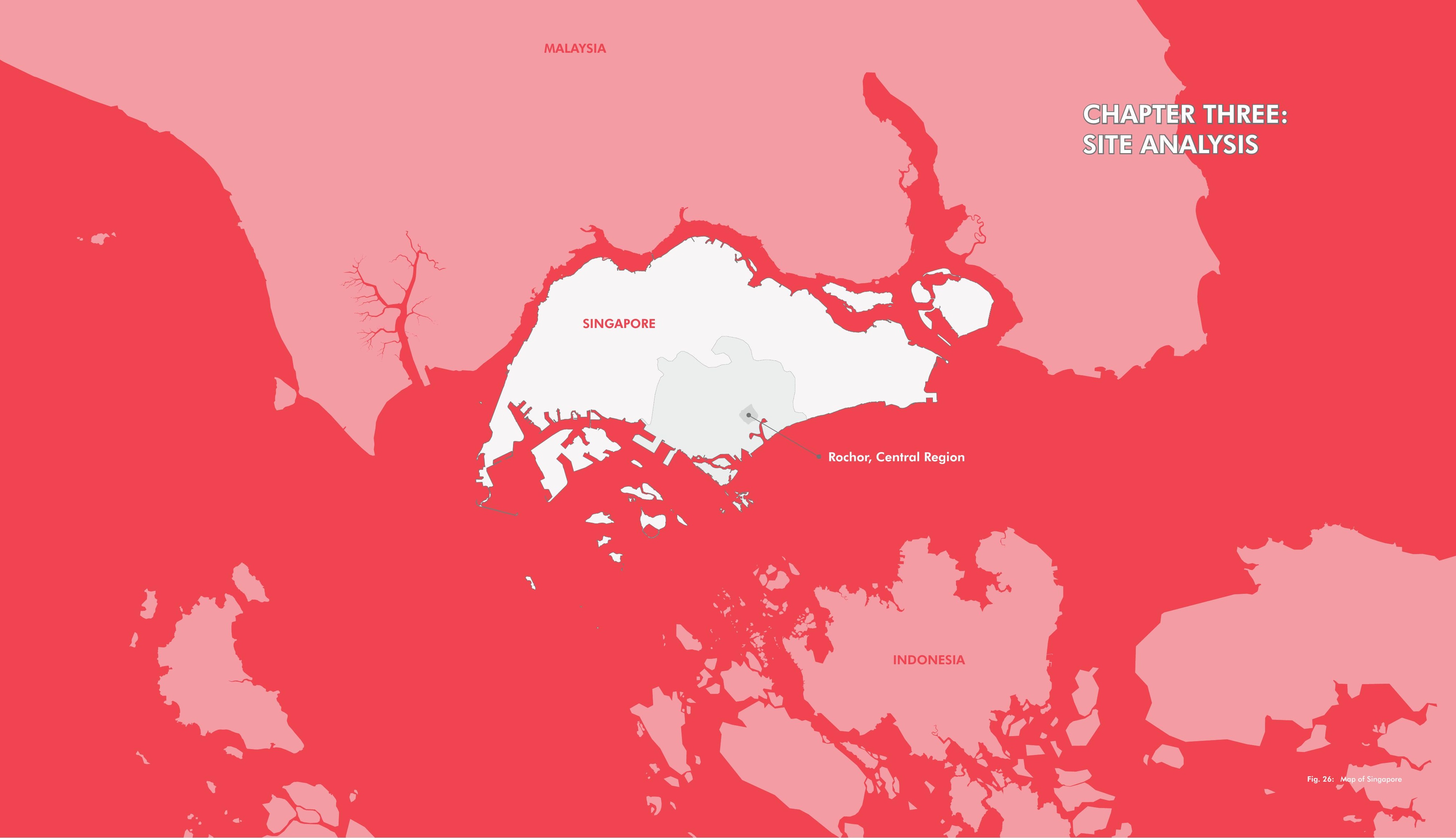


3.1 Quantitative Site Analysis Rochor District Overview

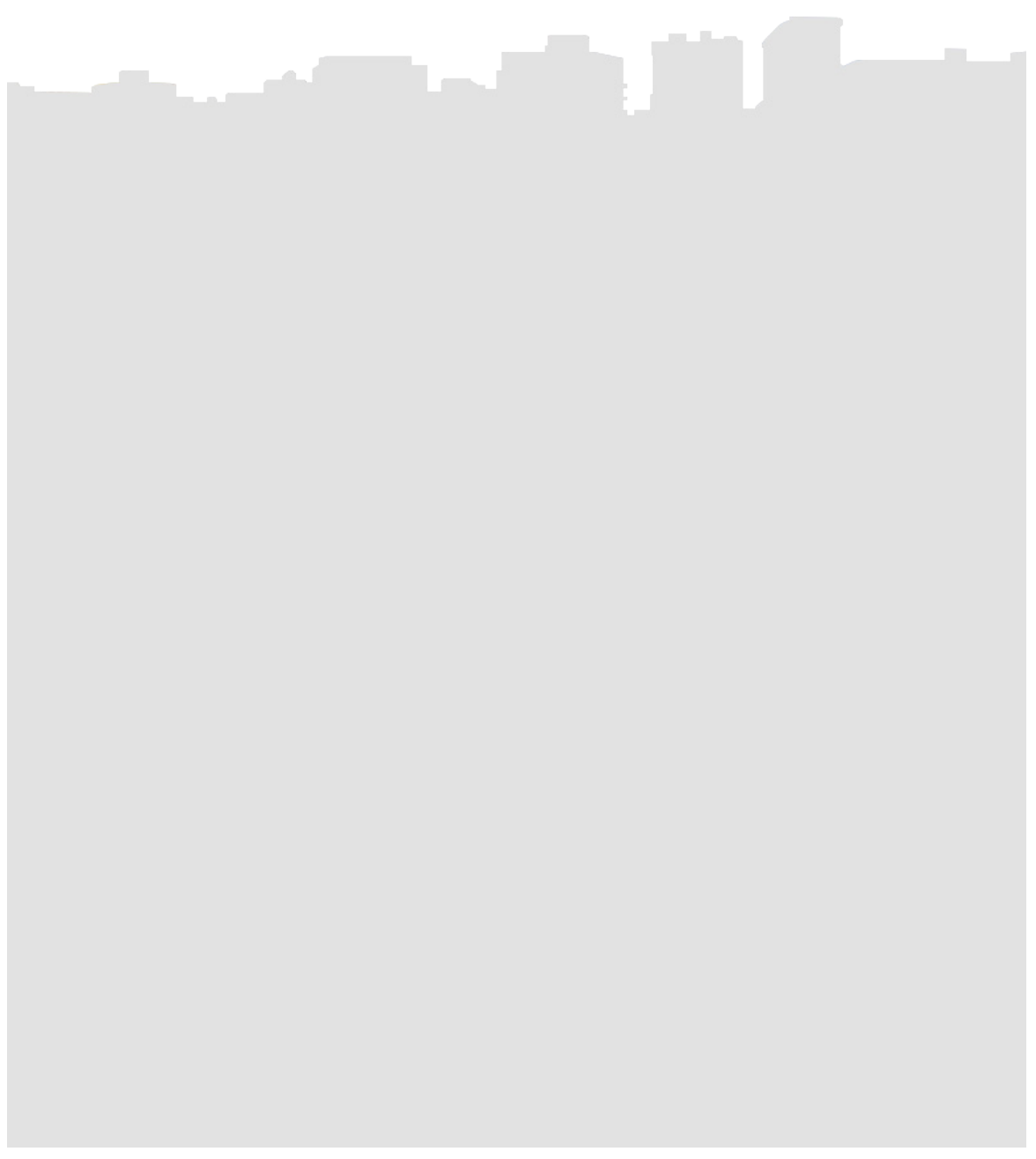

(1) Residential with Commercial on 1st Storey

2 Commercial and Residential

(3) Residential

(4) Conserved Shophouses for Commercial use

(5) Transport Facility

6 Open Green Space / Park

Rochor is located in the central region of Singapore which has a rich history and cultural background. Situated in between Bugis and Little India, this area attracts both residents and
tourists for the consumption of food, culture, goods and services.

Back in the colonial era, the Rochor Canal that runs along these districts played a major role for rades. It transported goods to and from Bugis - and supported the cattle trade in Little India (Chen, 2015). This fuelled other industres in the area and as a result, it turned into a busy

economic centre (Chen, 2015). The canal is now used for rest and recreational purposes as 
3.1 Quantitative Site Analysis

Rochor District Overview

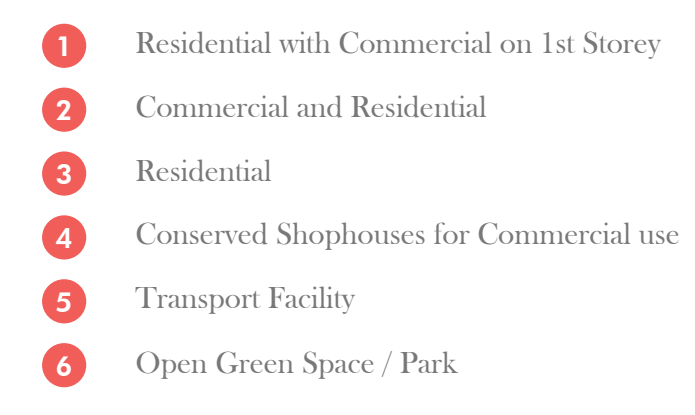

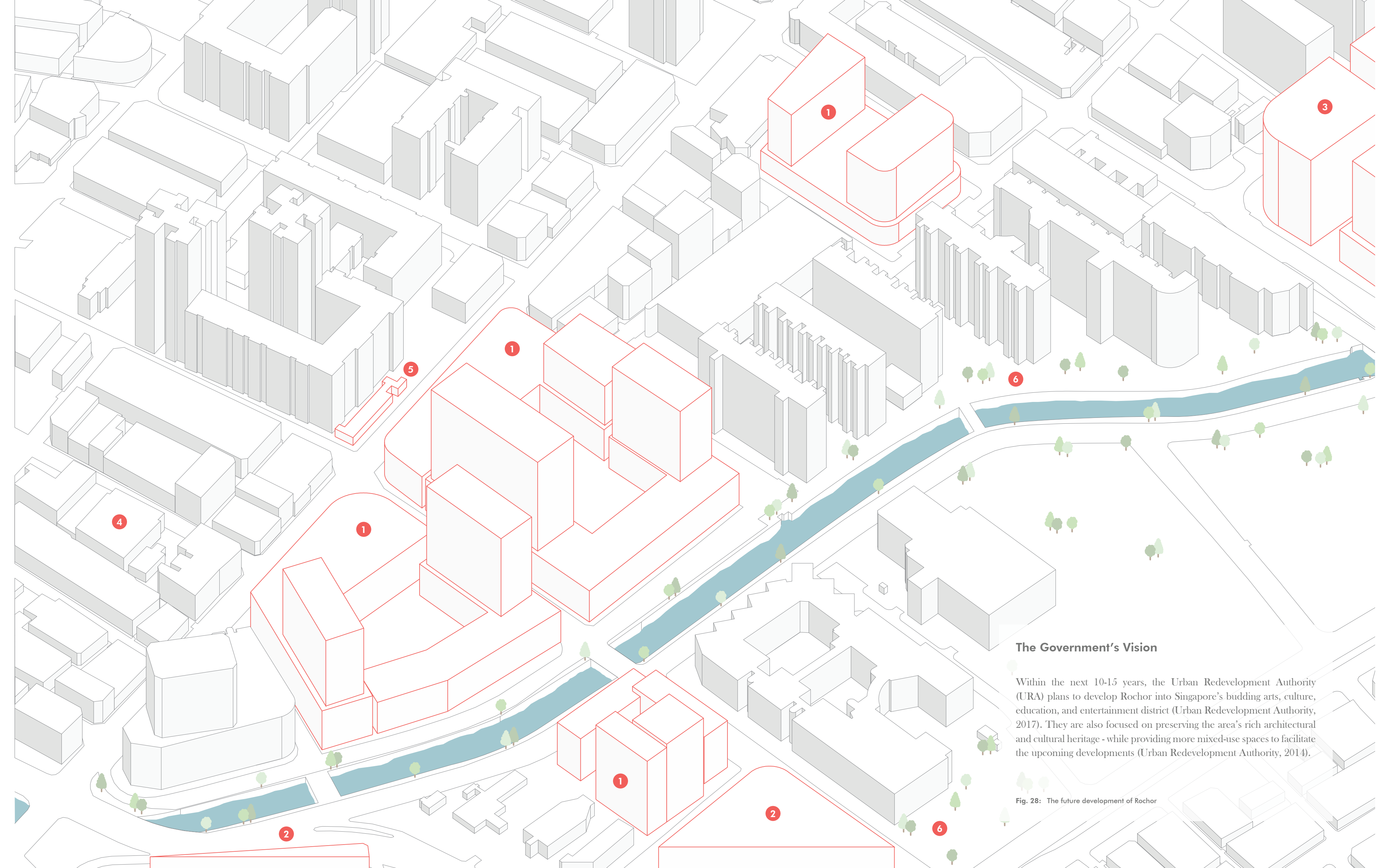


Due to the trading in the colonial era, Rochor represents a range of The majority of these residents earn between $\$ 1000$ to $\$ 3000$ per month ethnicities today. Majority of these ethnicities are made up of Chinese (Singapore Land Authority, 2017) (fig. 30). With an extremely high and Indian locals (Singapore Land Authority, 2017) (fir. 31) not economically support their own trading businesses.
Fig. 29 (Far Leff): Rochor's Age Grou Fig. 30 (Far Bottom Leff): Rochor's
Average Income per person (SGD)

Fig. 31 (Below): Rochor's Ethnic Groups Fig. 32 (Far Bottom): Rochor's Literacy

According to the Singapore Land Authority, Rochor supports an older

age group that ranges from 35 years old and over (Singapore Land

Authority, 2017) (fig. 29).

Age Groups (2016)

(Singapore Land Authority, 2017)

$11.3 \% \quad 9.0 \% \quad 12.8 \%$

$17.1 \%$

$15.2 \%$

$19.8 \%$

$0-14 \quad 15-24 \quad 25-34$

$35-44$

$45-54$

$55-64$

65 and over

Average Monthly Income per person SGD (2010)

(Singapore Land Authority, 20

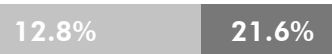

$20.7 \%$

$\$ 2000$ - $\$ 2999$

$\$ 3000-\$ 3999$

$\$ 4000-\$ 5000$

$16.3 \%$

Below $\$ 1000 \$ 1000-\$ 1999$

The average household size

in Singapore is three.

expenditure* in Singap

$\$ 4724.00$ (SGD).

The average monthly business

(Singapore Department of Statistics, 2016
The average monthly household erating expenditure* in Singapore is

$\$ 8750.60$ (SGD).

*Rent not included
(Singapore Department of Statistics, 2012) ～(New Zealand Trade and Enterprise, 2005)

Ethnic Groups (2015)

(Singapore Land Authority, 2017)

$71.6 \%$

One Language (2010)

Singapore Land Auth

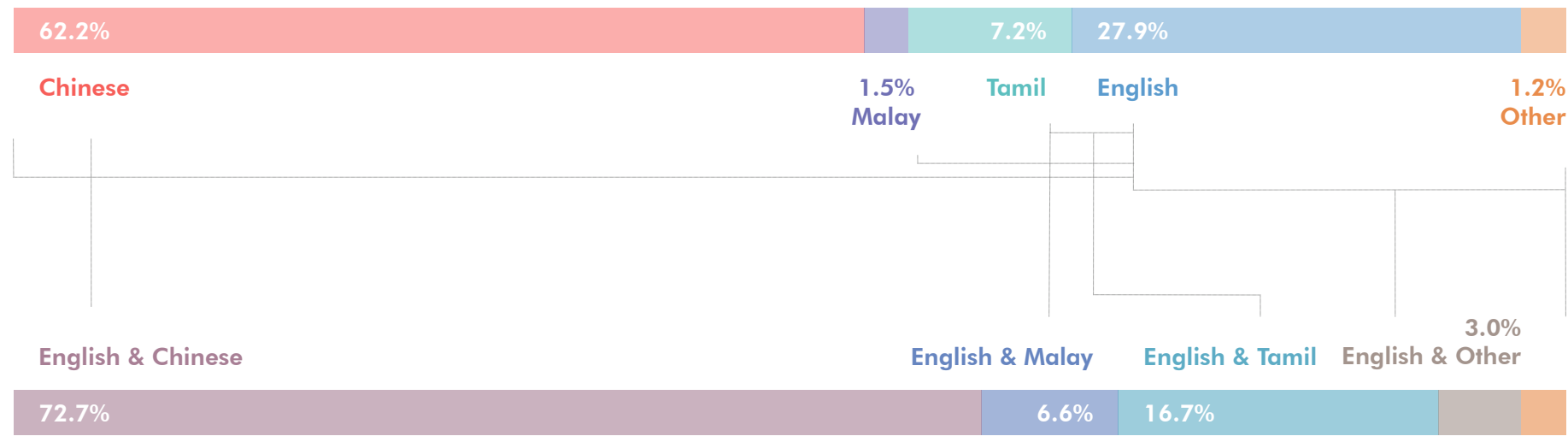

$73.2 \%$ of Singaporeans can literate

Two Other

(Lee, 2016 


\section{Site Location}

For this research investigation, the Sungei Road Market will be elocited to the Singapore - Johore Express Terminal.

Key:
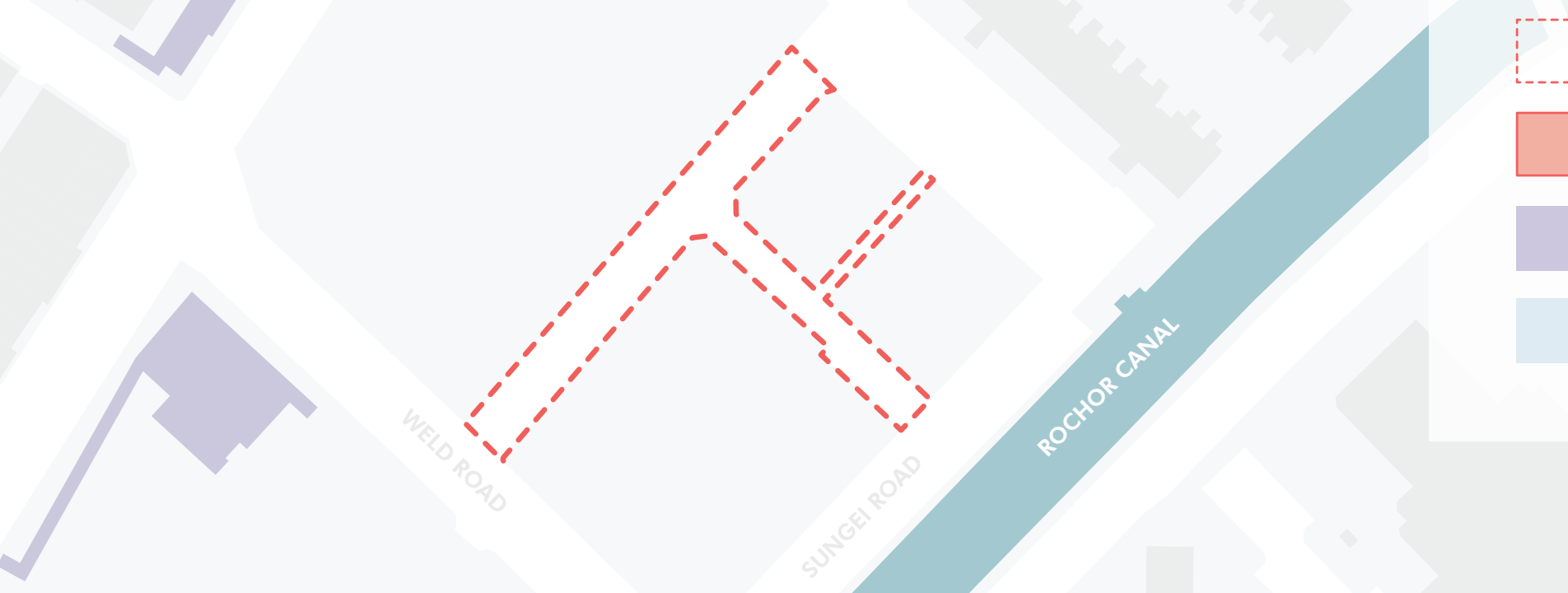

Original Sungei Road Market Locatio

Proposed Market Relocatio

(Singapore -Johore Express Terminal)

Jalan Besar MRT Station

Rochor Canal 

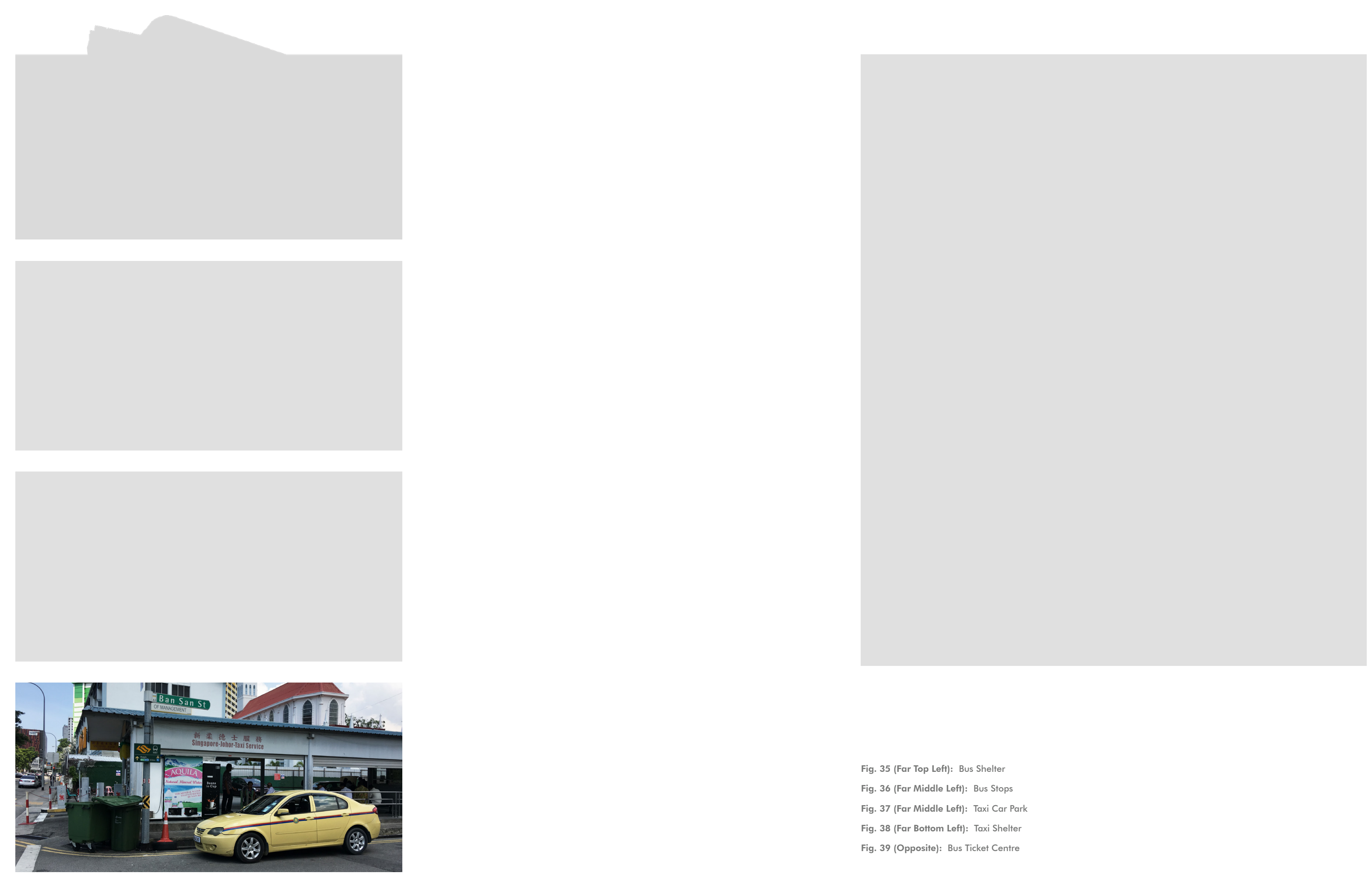

Fig. 35 (Far Top Leff): Bus Shelter

Fig. 36 (Far Middle Leff): Bus Stops

Fig. 37 (Far Middle Leff): Toxi Car Park

Fig. 39 (Opposite): Bus Ticket Centre 


\section{Climatic Conditions}

Like other tropical countries, Singapore has a hot climate - and four monsoon seasons per year. This includes: North-East Monsoon

the South-West Monsoon (Myy - July), the county has s Durng

the Sorature of $284^{\circ} \mathrm{C}$ (fis 41$)$ (Meteorological Service Singaper,

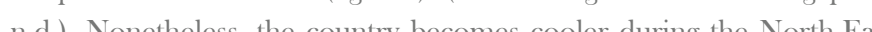

Mon

wind (fig. 40)(Meteorological Service Singapore, n.d.)

(Meteorological Service Simpore nd), (National Environment Agency, 2017), (Wind Finder, 2017 )
Fig. 40: Monsoon Seasons Graph

Fig. 41: Season Averages Graph
Seasonal Averages

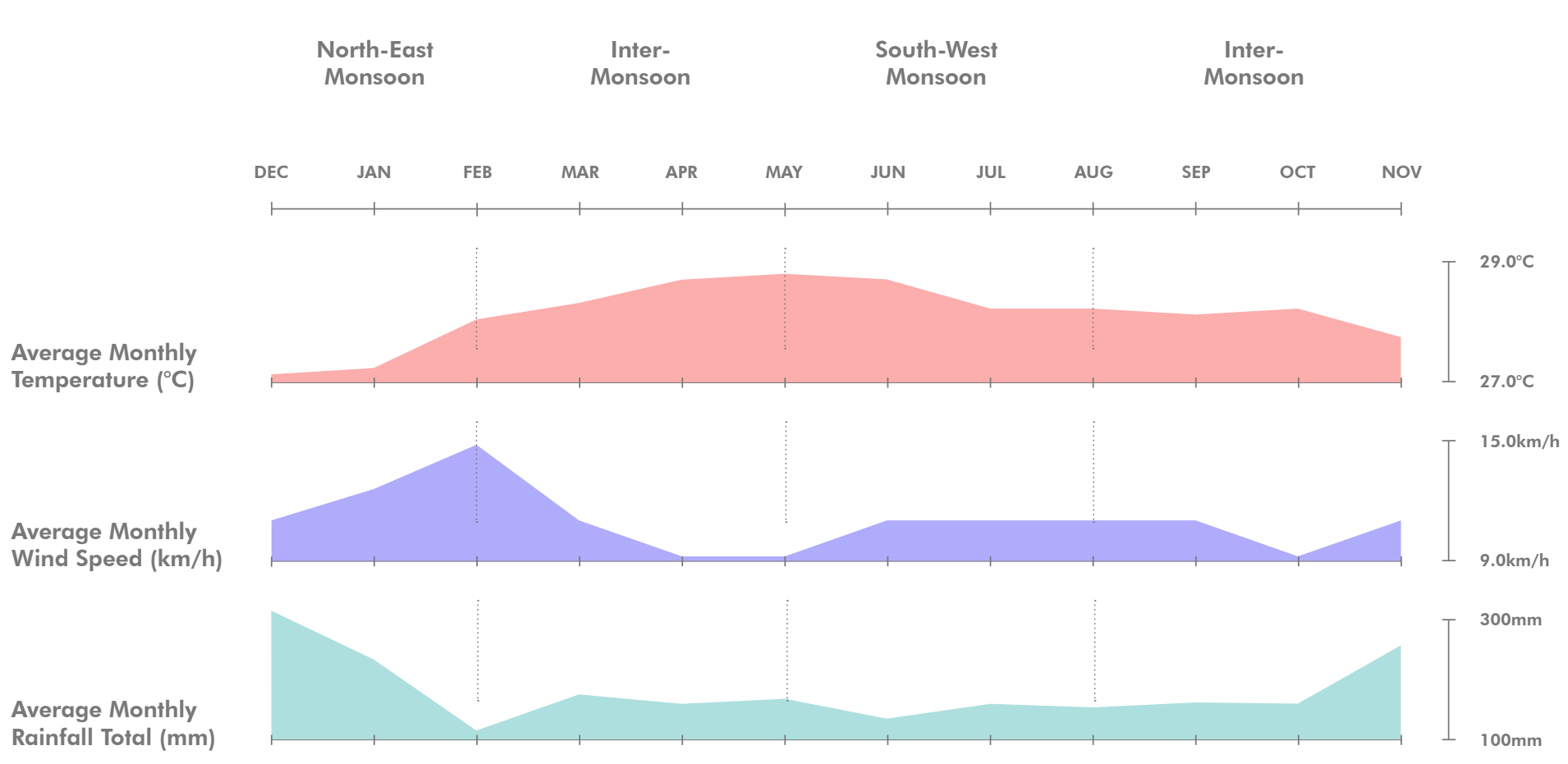

Temperature ( $\left.{ }^{\circ} \mathrm{C}\right)$

Wind Speed
$(\mathrm{km} / \mathrm{h})$

Rainfall Total (mm)

North-East

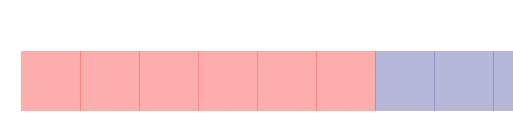

$27.4^{\circ} \mathrm{C}$

$12.9 \mathrm{~km} / \mathrm{h}$

$222 \mathrm{~mm}$

Monsoon

$\begin{array}{lll}28.6^{\circ} \mathrm{C} & 9.9 \mathrm{~km} / \mathrm{h} & 165.4 \mathrm{~mm}\end{array}$

South-West

Monsoon

$65.4 \mathrm{~mm}$

$\begin{array}{lll}28.4^{\circ} \mathrm{C} & 11.1 \mathrm{~km} / \mathrm{h} & 144.7 \mathrm{~mm}\end{array}$

Inter-

$\begin{array}{lll}28.0^{\circ} \mathrm{C} & 9.9 \mathrm{~km} / \mathrm{h} & 154.3 \mathrm{~mm}\end{array}$




$\begin{array}{ll}24^{\circ} \mathrm{C} & 25^{\circ} \mathrm{C} \\ 26^{\circ} \mathrm{C} & 27^{\circ} \mathrm{C} \\ 28^{\circ} \mathrm{C} & 29^{\circ} \mathrm{C} \\ 3 & 30^{\circ} \mathrm{C} \\ 31^{\circ} \mathrm{C} & \end{array}$

Average Hourly Variation of Temperature $\left({ }^{\circ} \mathrm{C}\right)$

Time Period (Hrs)

(Meteorological Service Singapore, n.d)

Sunshine

Sunshine Hours (Hrs)

The average daily sunshine hours in Singapore is 5.8 Hours

$$
4.0 \mathrm{Hrs}
$$$$
4.5 \mathrm{Hrs}
$$$$
5.0 \mathrm{Hrs}
$$

5 Hrs

$6.0 \mathrm{Hrs}$

$6.5 \mathrm{Hrs}$

$7.0 \mathrm{Hrs}$

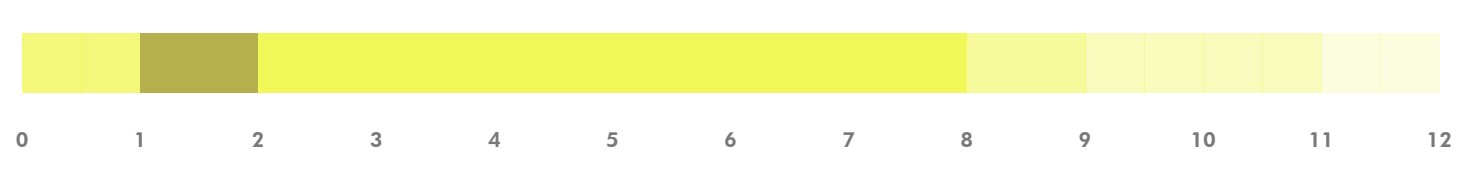

Average Monthly Variation of Sunshine Hours (Hrs)

Time Period (Month)
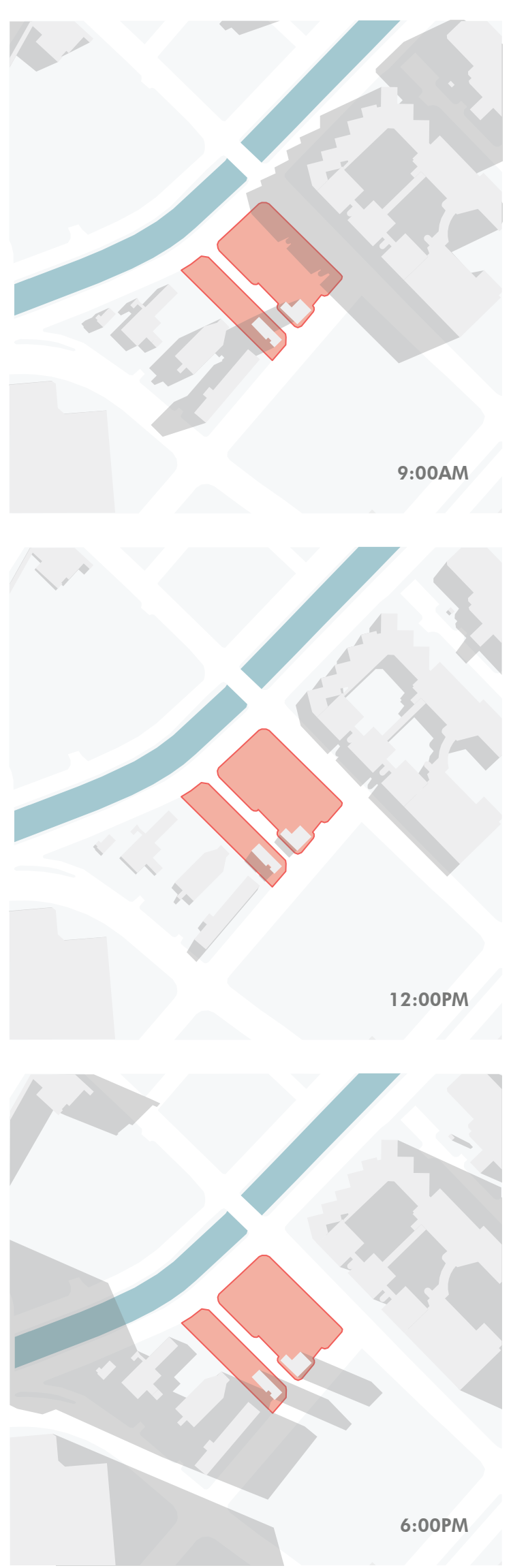

Sun Path

Majority of the site is exposed to the sun throughout the day (fig. 44). However, the site may be shaded in the afternoon when future .

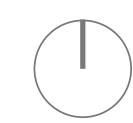

iig. 42 (Far Top Leff): Singapore's Average Temperature Fig. 43 (Far Bottiom Leff): Singapore's Average Sunshine Hours ig. 44 (Opposite): Siti's's Sun Path Analysis 


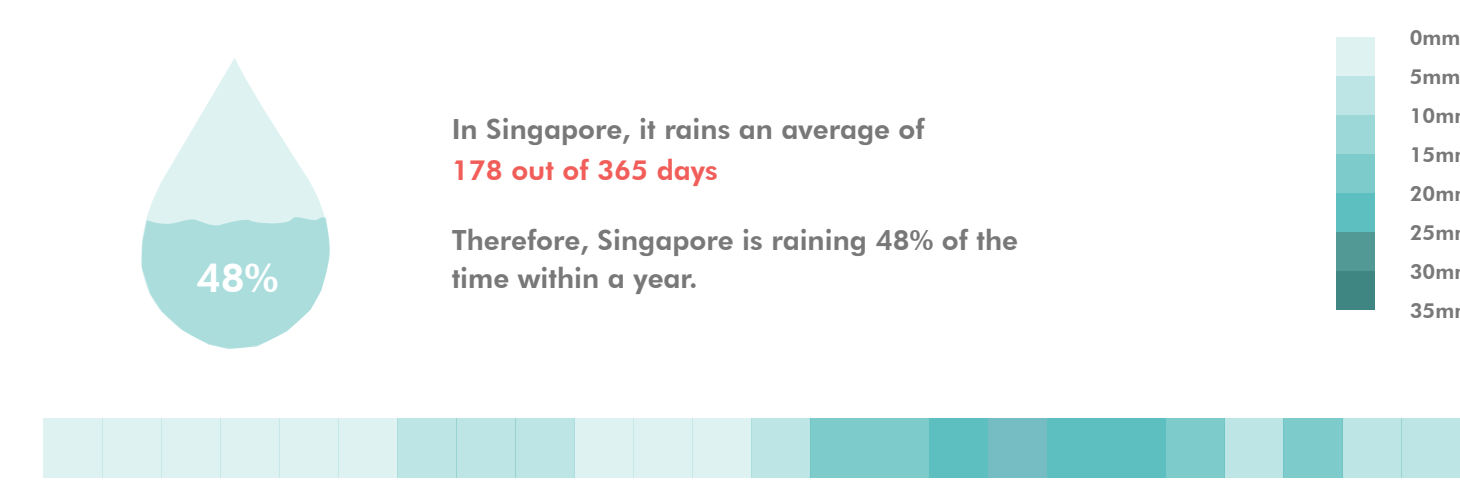

$\begin{array}{lllllllllllllllllllllllll}0 & 1 & 2 & 3 & 4 & 5 & 6 & 7 & 8 & 9 & 10 & 11 & 12 & 13 & 14 & 15 & 16 & 17 & 18 & 19 & 20 & 21 & 22 & 23 & 24\end{array}$ Average Hourly Variation of Rainfall (mm)

Time Period (Hrs) (Meteorological Service Singapore, n.d)

Wind

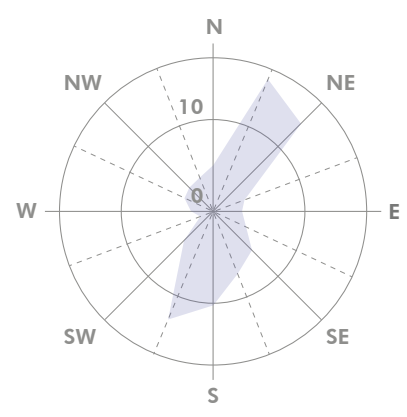

Annual Wind Direction

Frequency (\%)

Wind Finder, 2017)

Northeast Wind
is the most prominent wind in Singapore.

Wind Speed $(\mathbf{k m} / \mathbf{h})$

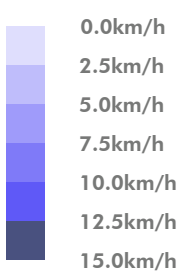

is the most prominent wind in Singapore. $\quad 12.5 \mathrm{~km} / \mathrm{h} / \mathrm{h}$

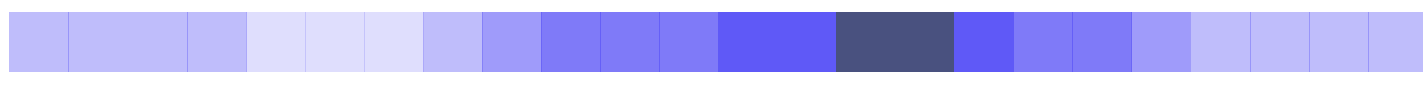

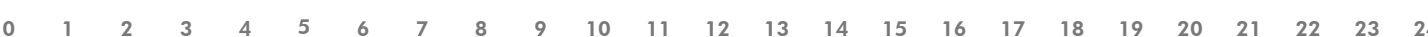

Average Hourly Variation of Wind Speed $(\mathrm{km} / \mathrm{h})$ (Meteorological Service Singapore, n.d)

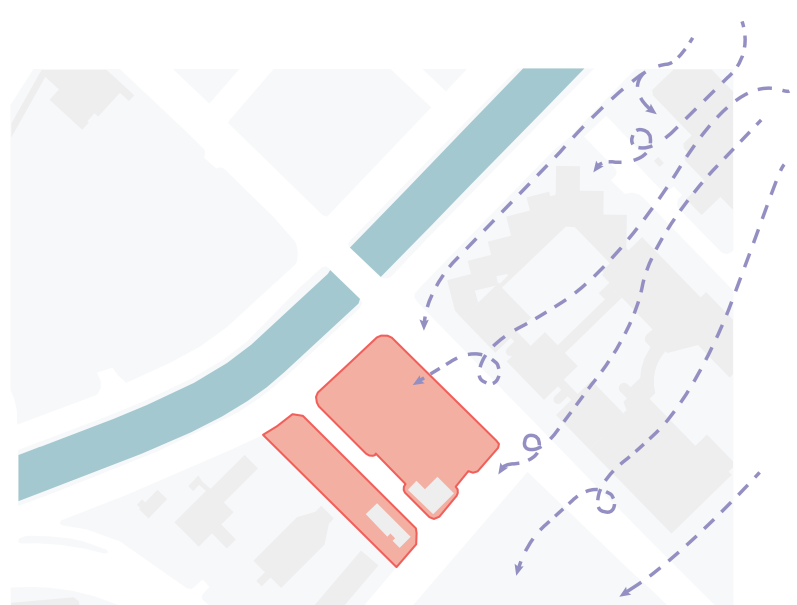

\section{Wind Path}

The neighbouring buildings are relatively low and narrow (fig. 47 ). This causes the row effect "where the wind tends to trip or fall over the row

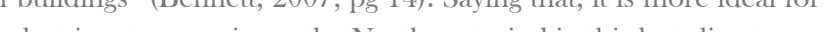

Fig. 45 (Far Top Leff): Singapore's Average Rainfall

g. 46 (For Bottiom Leff): Singapore's Average Wind Speed

fig. 47 (Opposite): Site's Wind Path Analyss

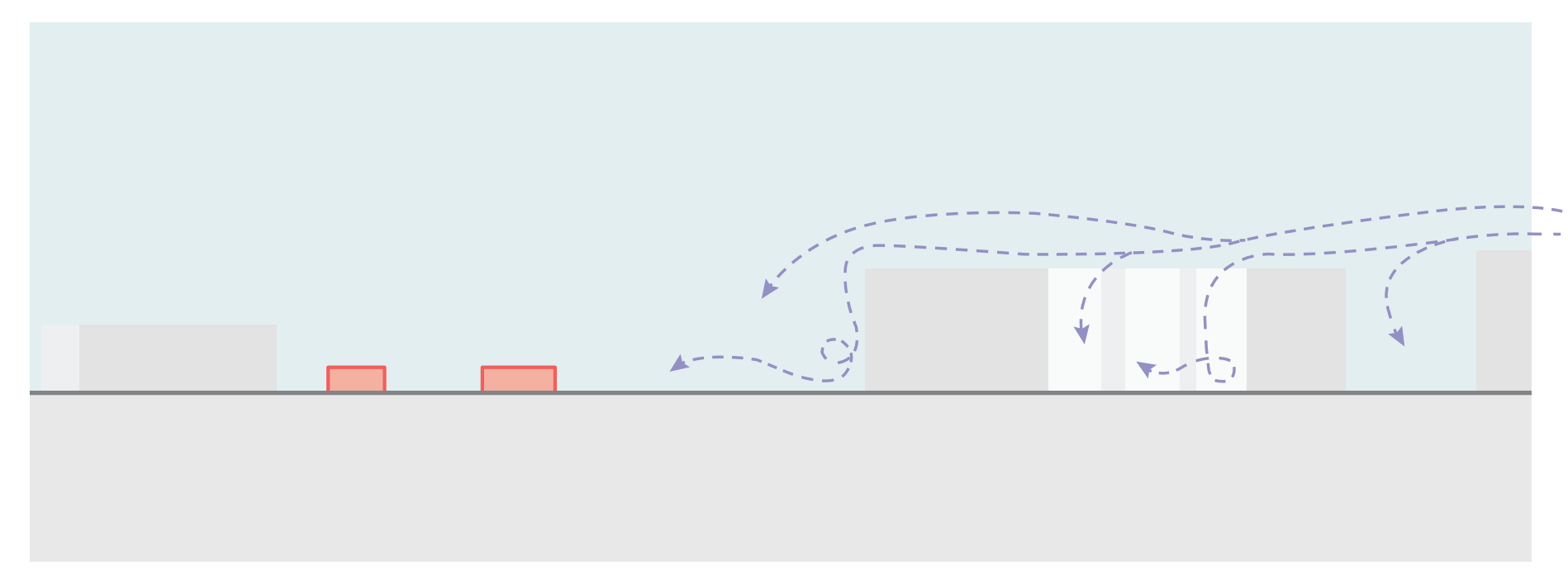




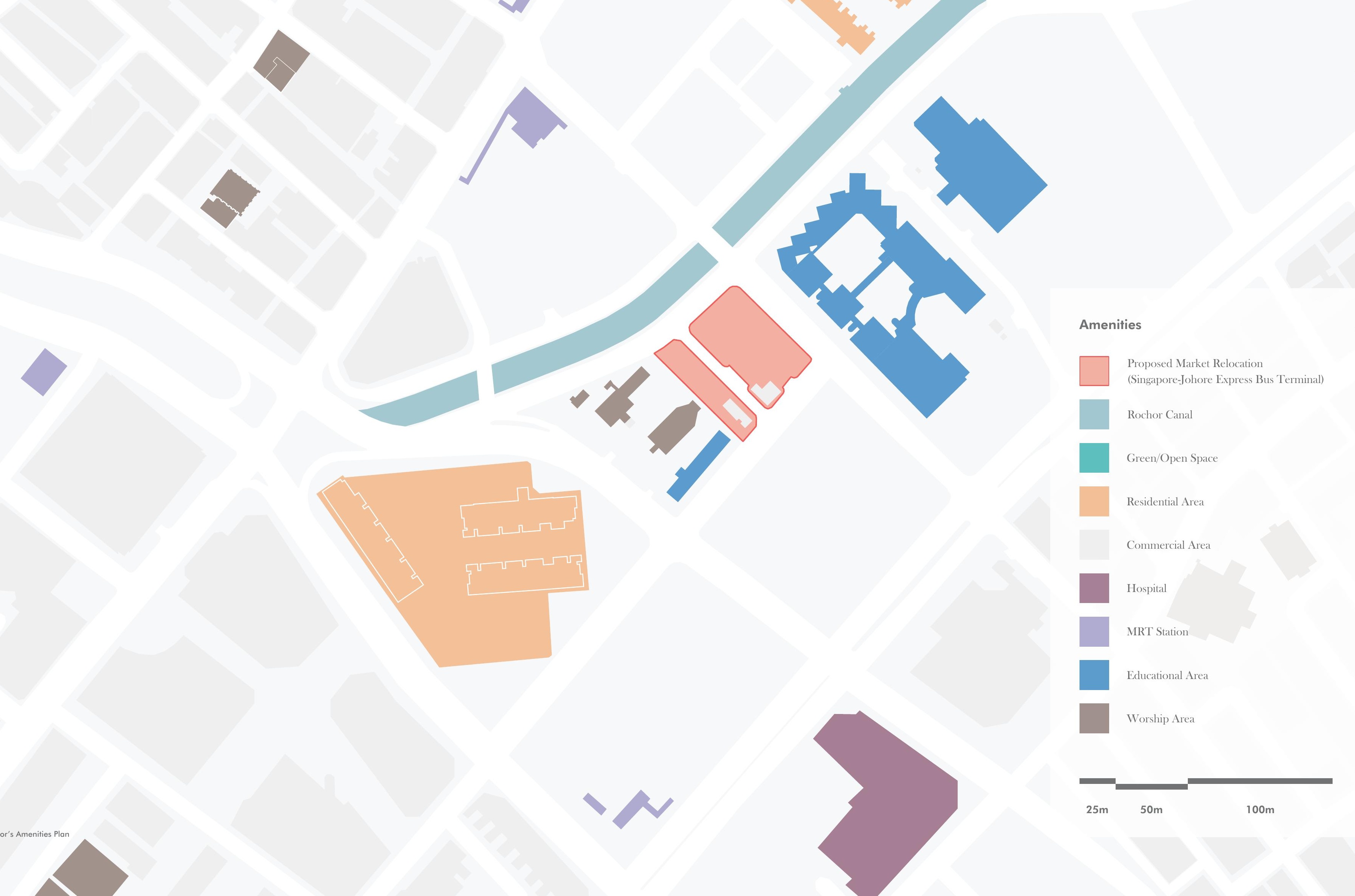




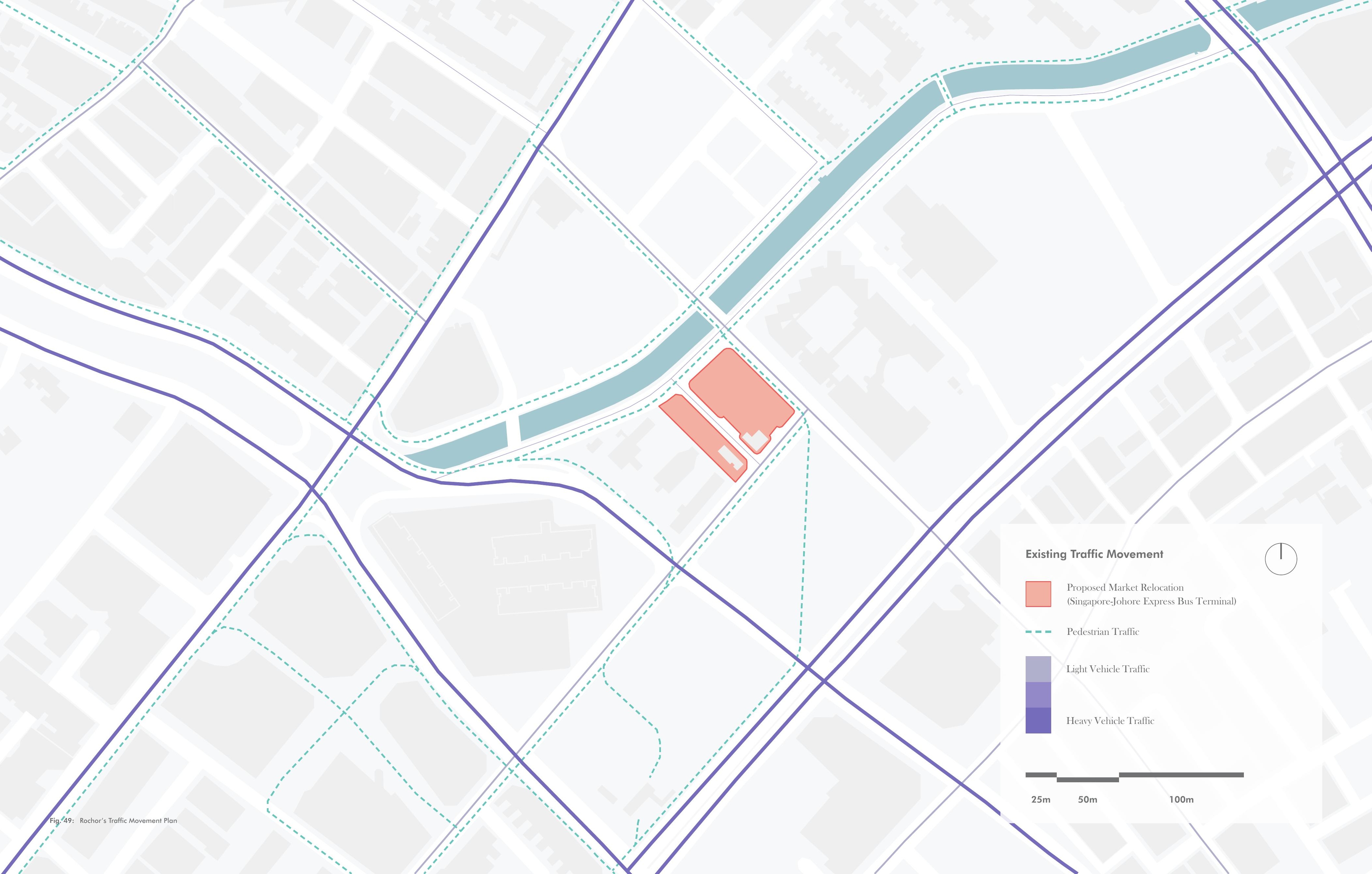


Singapore Field Research

22nd of May - 19th of June 2017

(Ethics Approval: 24468)

On the 22nd of May 2017, I conducted field research in Singapore for

a month. The main goal for this field research was to have a better

understanding of the site and the community that is associated with it. I
the duration of this experience, $\mathrm{Ihad}$ some questions that I wanted to be

the dwered, whether if's through observations, questionnaires or drawin

exercises. These questions include:

How does the construction affect the existing Sungei Road Market and traffic?

What other activities and events occur around site?

How does the vendors set up and take down their stalls?

What are the other existing markets and hawker centres like?

How does the community engage and interact?

What are people's thoughts of the Sungei Road Market?

What does the Rochor Community need? 
Throughout this field research, observations were made to gain more The observations were recorded through photographs to present owledge of Rochor and the Sungei Road Market. It provided greater visual understanding of the community's lifestvle, actions and Information on how an open-air market can influence locals to engage norms (Brown, 2014).

and interact with each other

Within Site

Fig. 51: People waiting for the Coach Bs

Fig. 52: People walking pass the Site

iig. 53: People walking through the Site

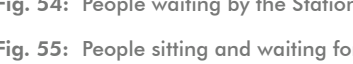

toxi

g. 56: Ticket Counter for the Coach
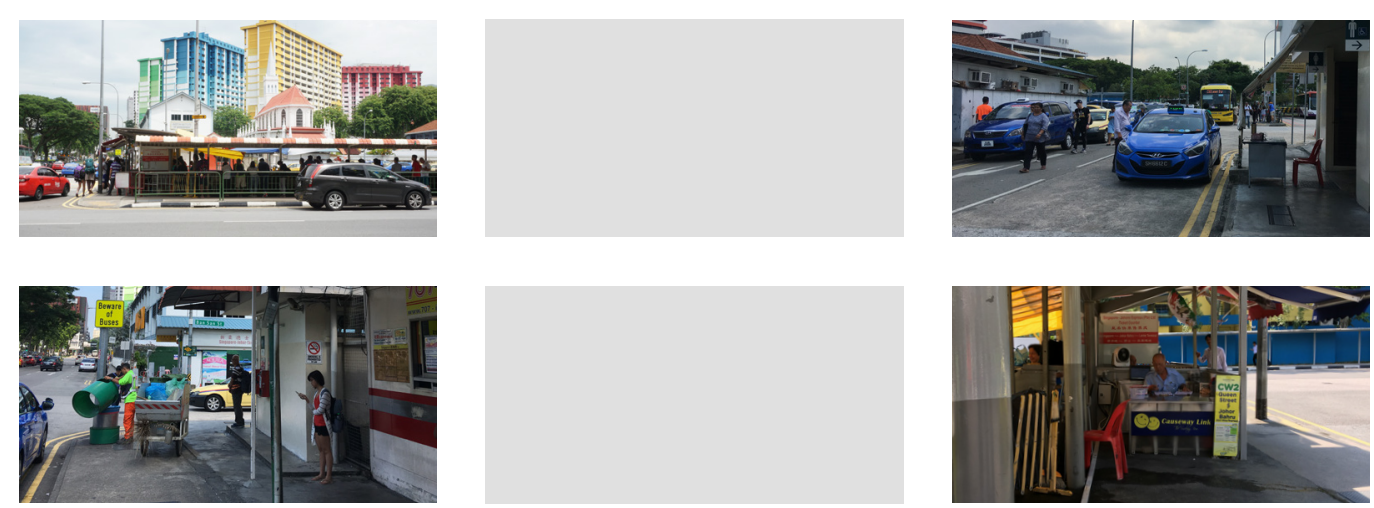

Around Site

Fig. 57: Construction
Station, Sungei Roo

Fig. 58: Eating in the Howker Centre,

Fig. 59: Shop

Fig. 60: Walking through the Bugis Street
Mall, Victoria street

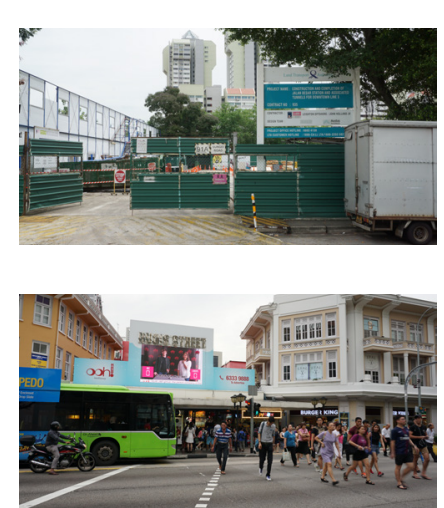

Around Rochor Canal

Fig. 61: Fishing and wo

fig. 62: Eating, Cycling and Walking

Fig. 63: Silting and Reloxing
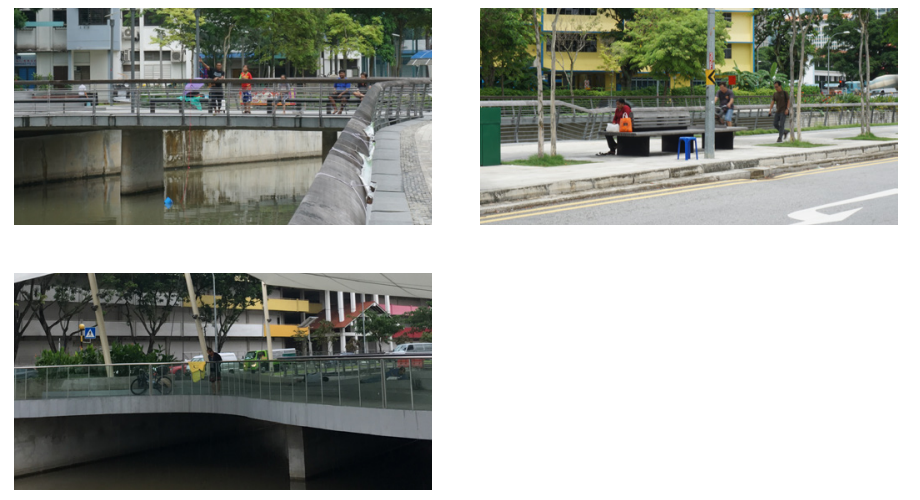

Within the Sungei Road Market

Fig. 65: Market Tour Group 1 .

Fig. 68: Market Tour Group 4.

Fig. 69: Lion Dance Performan

Fig. 70: Vendors Socialisis

Fig. 71: Bargaining

ig. 73: Shopper Squatting and Bargaining

Fig. 74: Squatting
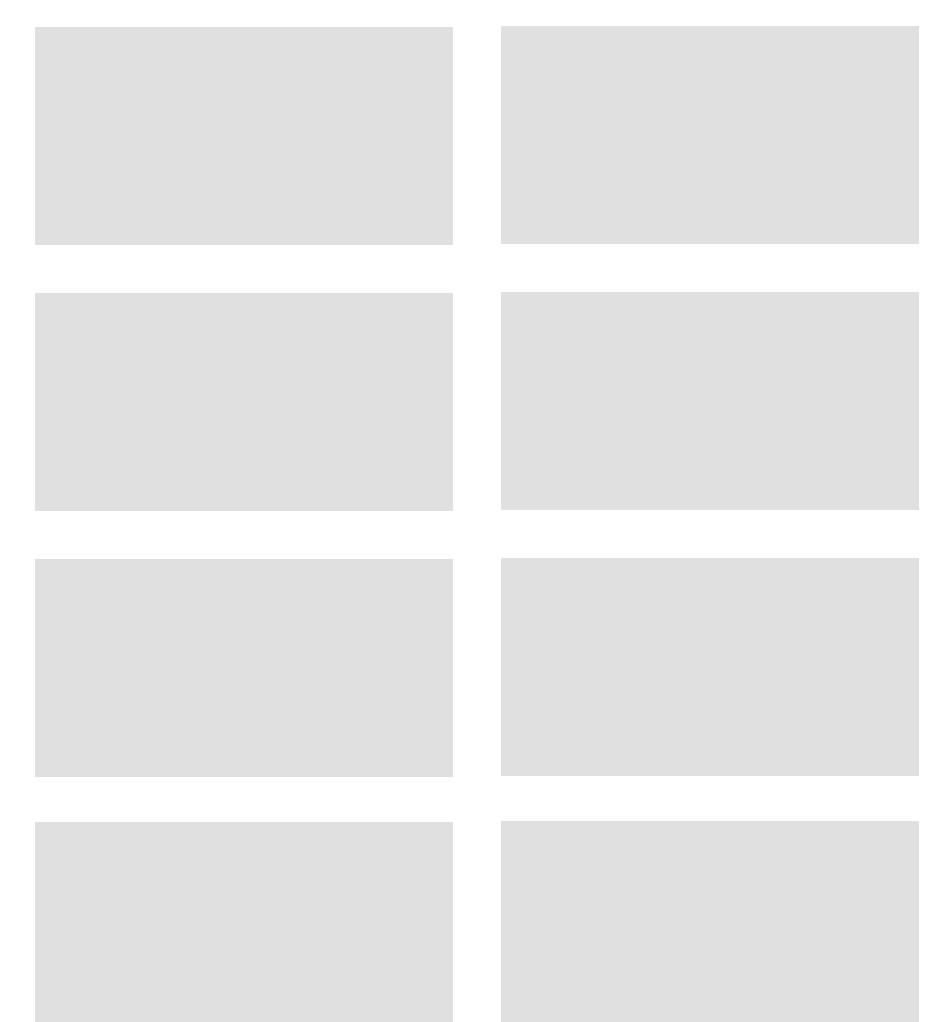

Shi. $1102 \times$

firsen 0

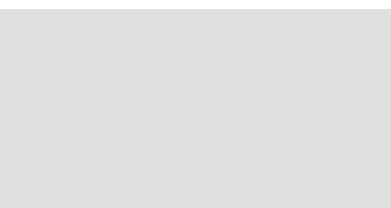


Market Stalls

Fig. 76: Tiger Umbrella, Bicycle and Chair

Fig. 77: Red Umbrellas and Fold up Tabos

Fig. 78: Blue Plastic Tarps and $M$

Fig. 79: Stools and Mat

Fig. 80: Umbrella, Stools and Mats

Fig. 81: Umbrella, Table and Chair

Fig. 82: Bench and Boxes

Fig. 83: Truck and Chair

Fig. 85: Umbrella and Hangers

Fig. 86. Blue Plastic Tors Bores and Cor

Fig. 87. Cort, Plastic Best toxes and

Fig. 88: Stool and Table

Fig. 89: Umbrellas and Canopy Tent Fig. 90: Umbrella, Carts, Newspaper
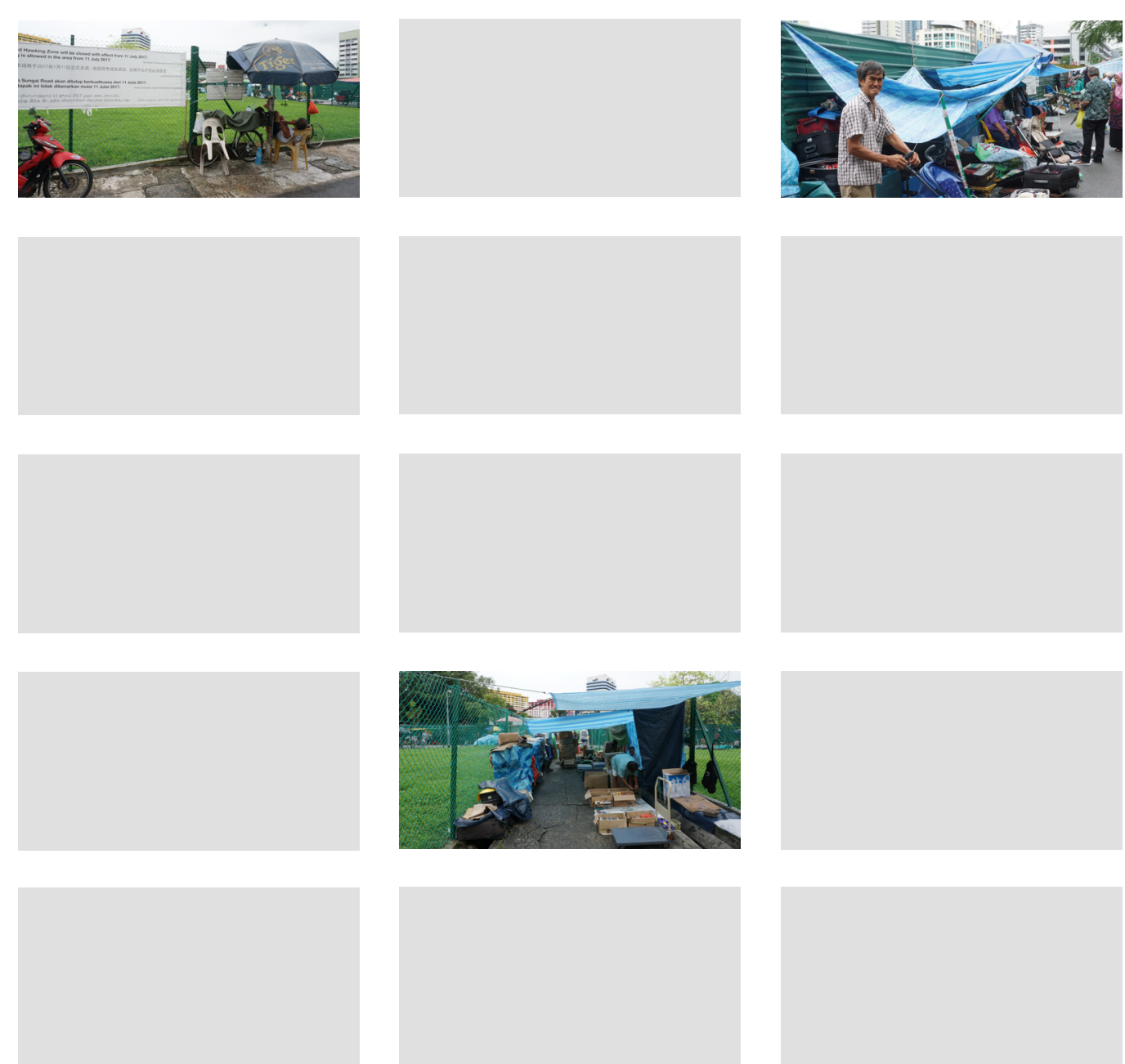

Transporting Goods

Fig. 91: Motorised Bicycle

Fig. 92: Small Truck

Fig. 93: Bicyle and Cart

Fig. 94: Shopping Trolley and Carrs

Fig. 95: Pushing and $C$ ard
Fig, 96: Leff on Site
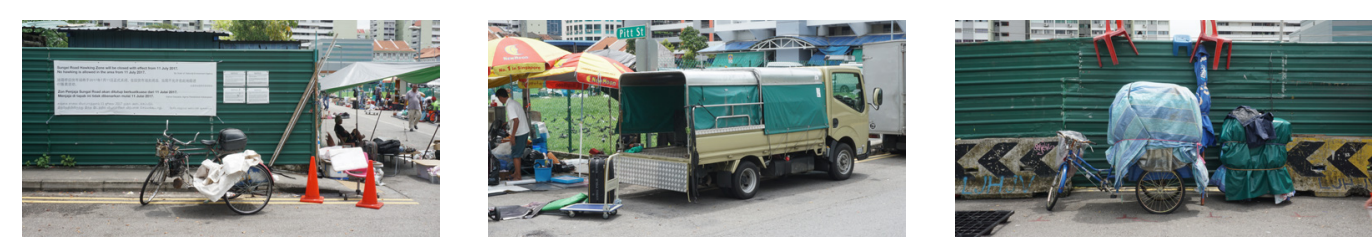

70.
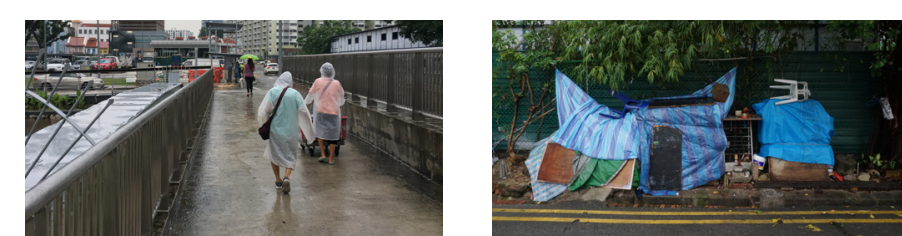

Setting up Stalls

Fig. 97: Hanging System that relies on the
Existing Corrugated Fence

Fig. 98: Cement Blocc

Fig. 99: Ties and Knots on to the Exisst

Fig. 100: Stuffed
Canopy's Weight

Fig. 101: Umbrella on Existing Wire Fenso

Fig. 102: Canopy Ten

Fig. 103: Vendor setting up his Stall 1.
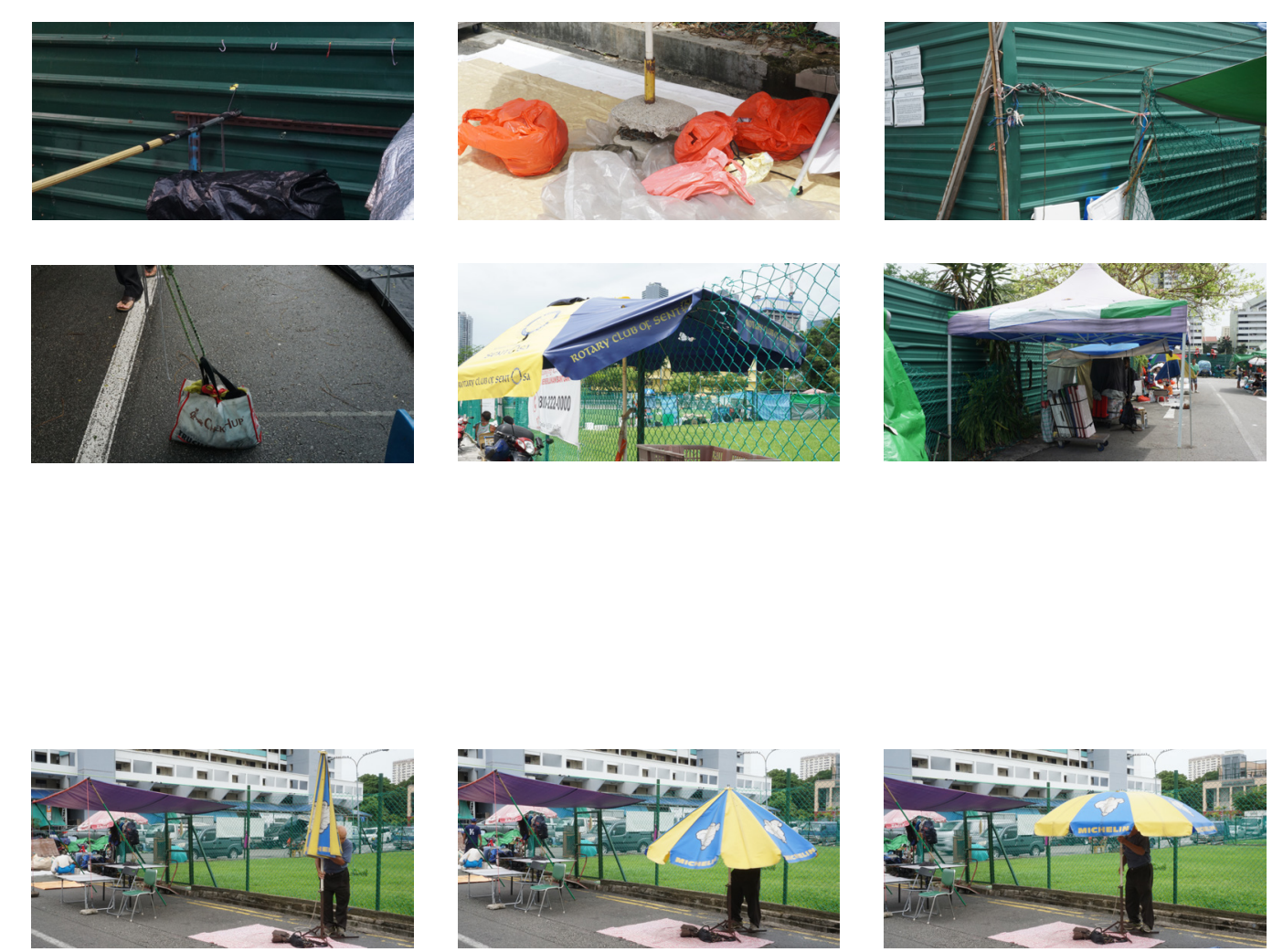

Dis-amenities

Fig. 106: Carts left on the side of the Rod
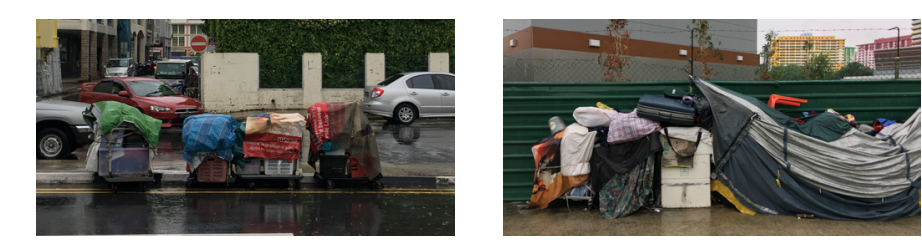

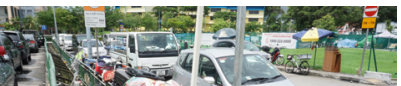

Fig. 107: Goods left on the side of the

Fig. 108.
Road 2.
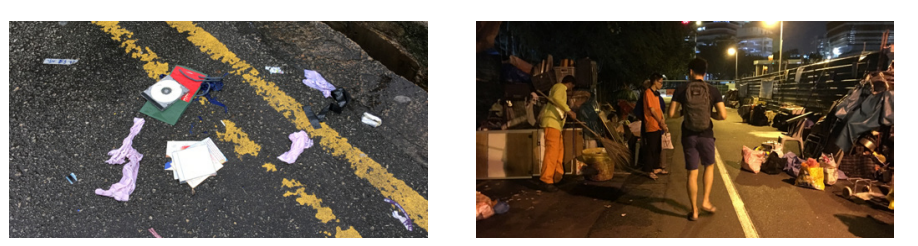

$4 \sqrt{2}=$

Fig. 110: Stalls leff behind.
Government Cleaners cleaning up and
local passing through the market

Fig. 111: Chairs and Government
cleaners claning up the rubbish that was
left behind सxifoking 


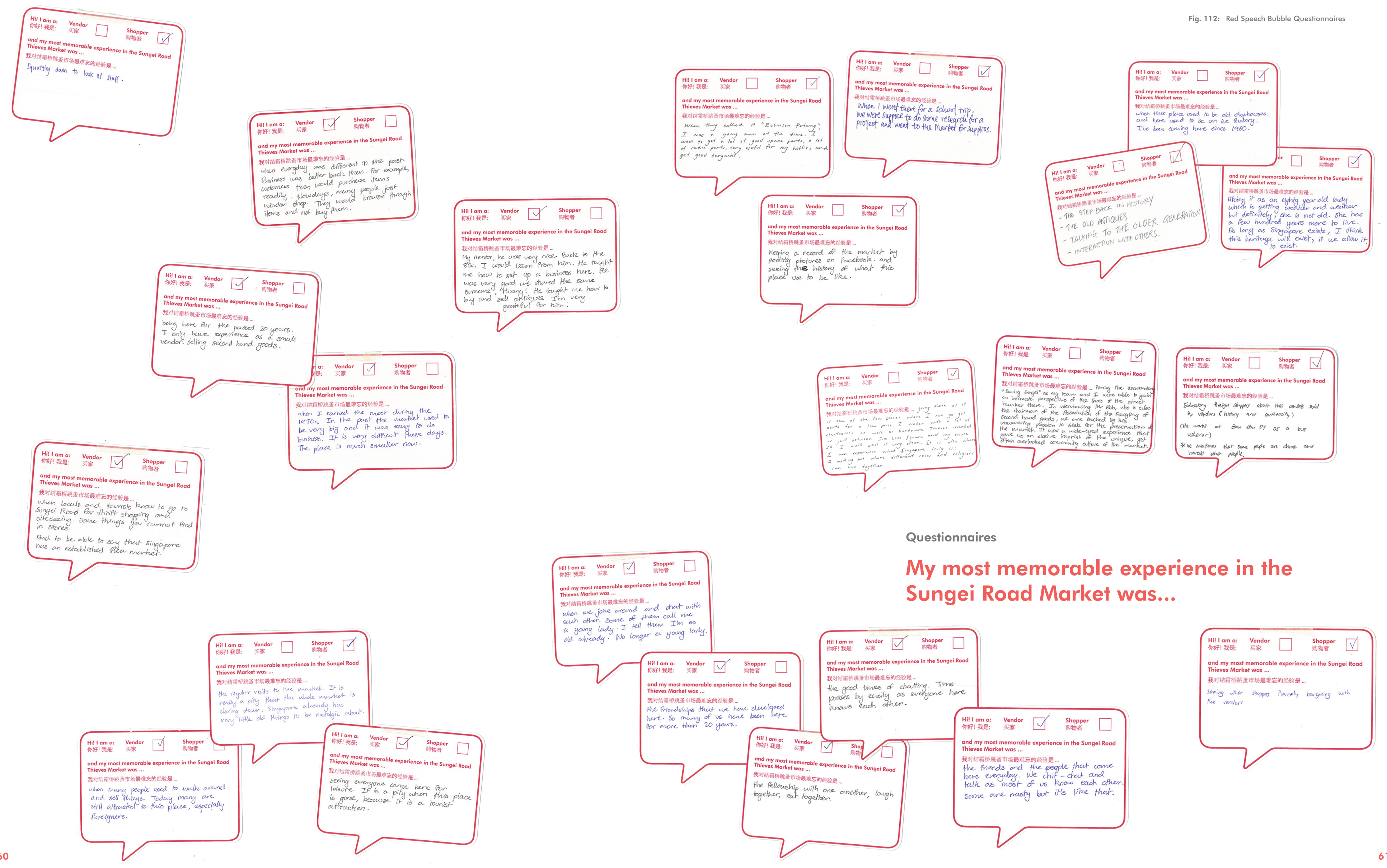



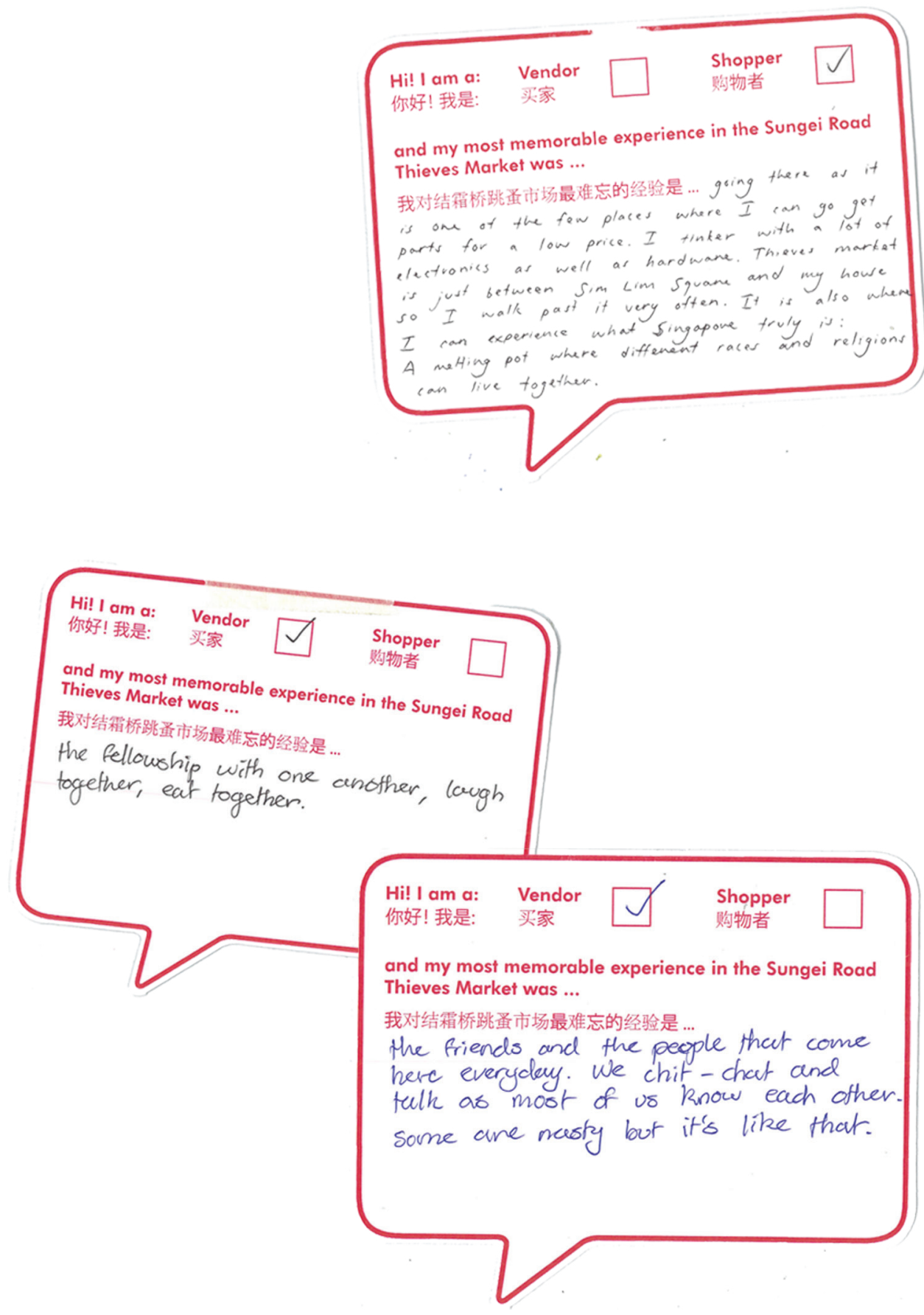

"Things worth saving need not necessarily be beautiful or historic as long as they are familiar or well loved" (Lowenthal, 1979, pg 555). This inspired the question of what are the vendors and shopper's most memorable experience in the Sungei Road Market. From asking his question, it provides an insight of the connections and memories associated with the market. According to Yuen, these experiences obtain a sense of belonging for the individual and the community (Yuen, 2005).

Sungei Road Market is a place "where I can experience what Singapore truly is: A melting pot where different races and religions can live together" (fig. 113

The most common answer for this question were associated with social engagement and cultural ties. Through observations, it was evident that the Rochor community used the Sungei Road Market as a social platform for various religions and ethnicities. Vendors gathered and appreciated "the fellowship with one another", while shoppers admired the intangible heritage that the market reflects. This encouraged more opportunities for the community to "laugh and eat together" (fig. 113) 


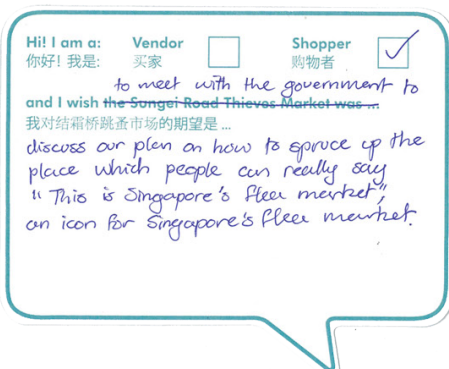

I wish the Sungei Road Market was...
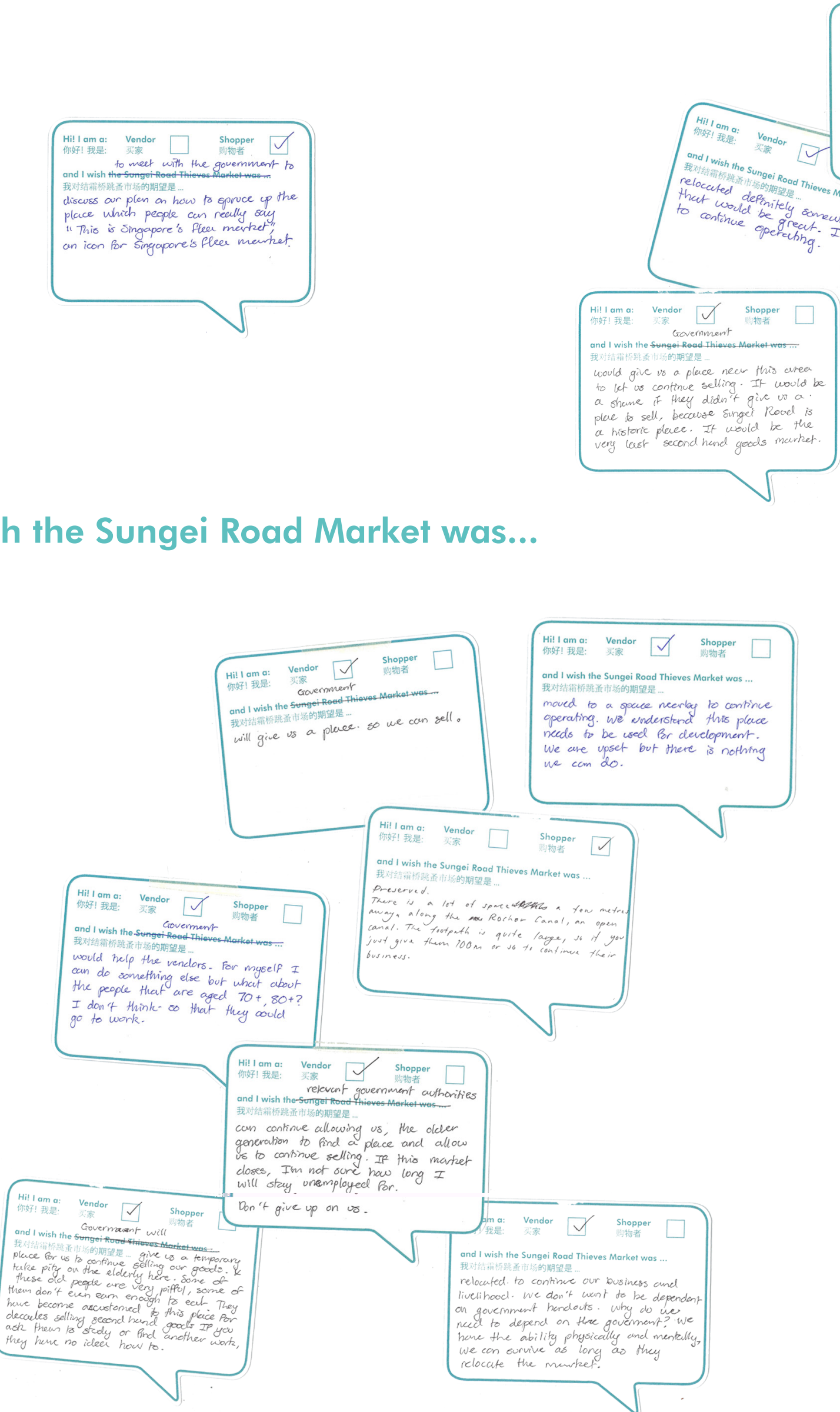
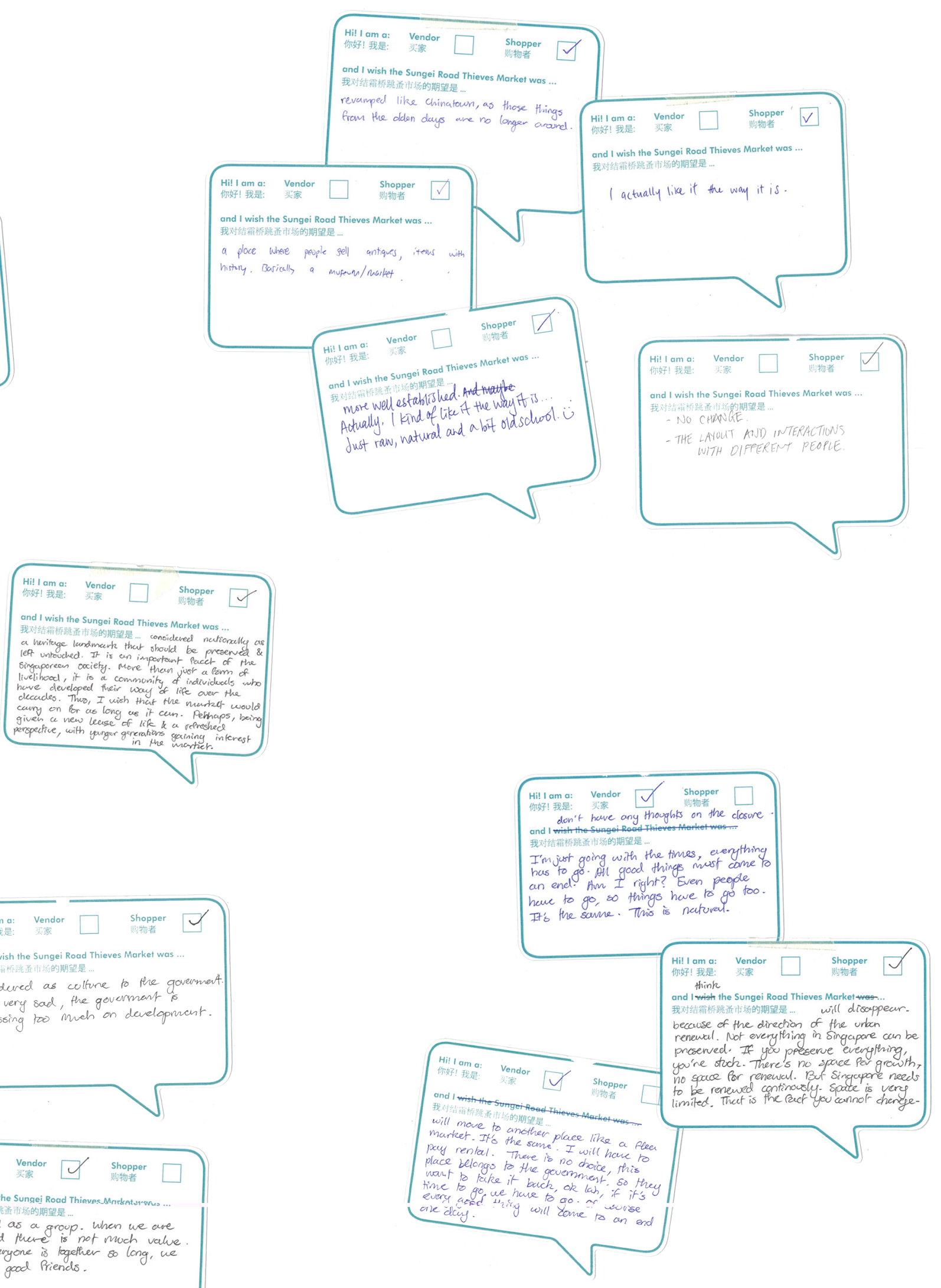

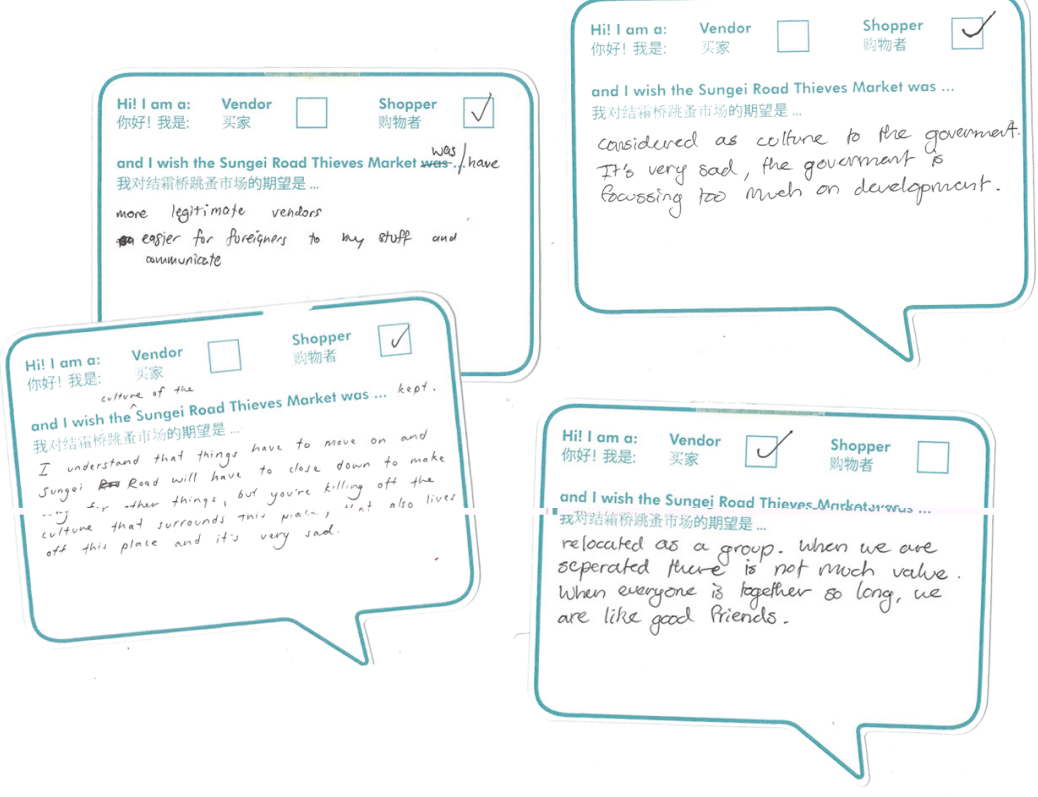




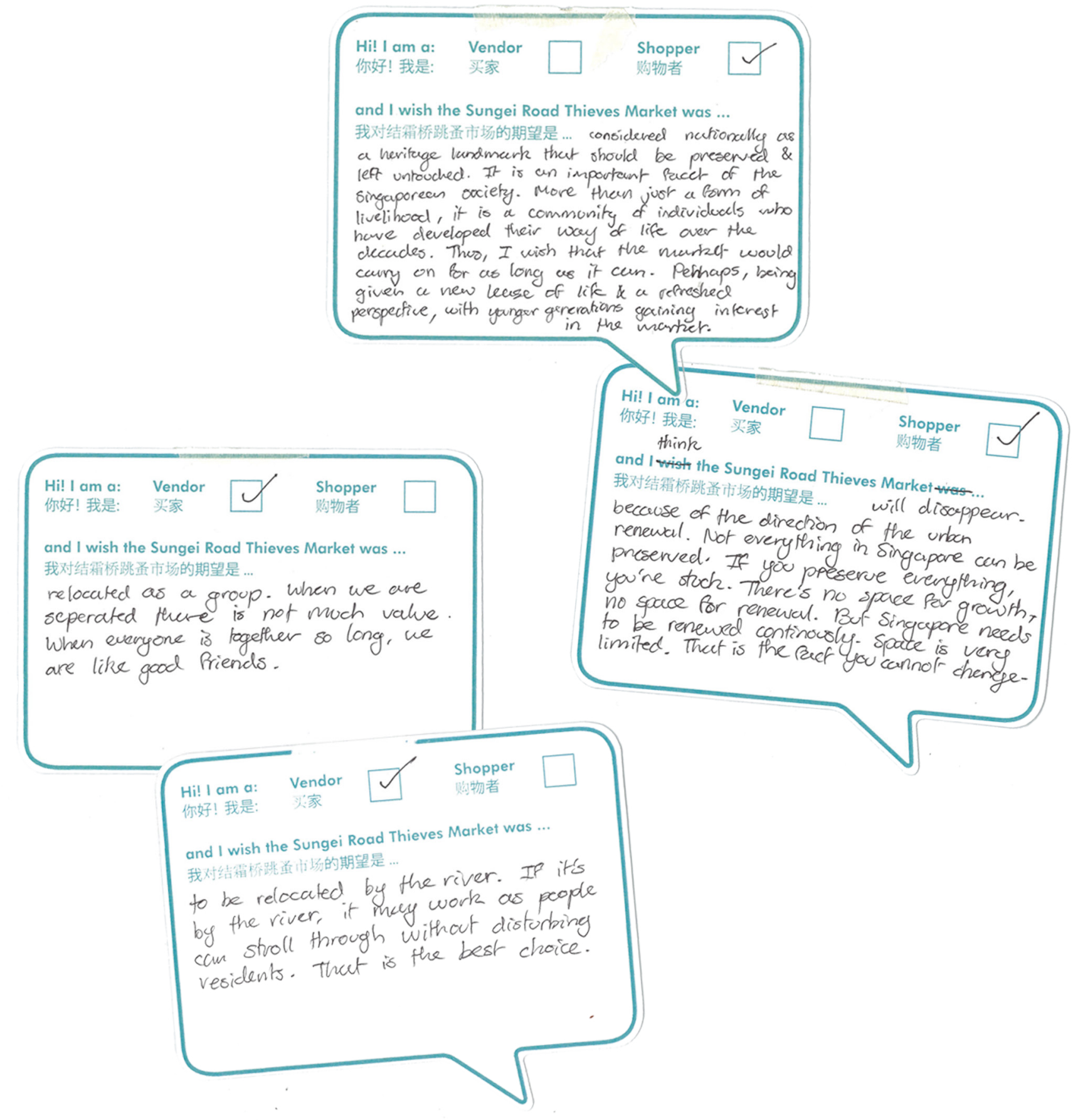

"Participation allows the images and meanings of places to develop from the bottom up. Inadequacies in the setting are far more tolerable and easily adjusted when one is not alienated from the place making process" (Rapoport, 1969). In the duration of these questionnaires and drawing exercise, social engagement was encouraged. This allowed the design process to be driven by the local community's assets, identity, character and needs (Melcher, Stiefel, \& Faurest, 2017).

"I wish the Sungei Road Market was relocated as a group. When we are separated there is not much value" (fig. 115)

The thoughts of what should happen to the Sungei Road Market varied between individuals. Some participants stated the market should be preserved as a "historic landmark", while others thought it was natural for the market to disappear over time (fig. 115). Nonetheless, the most common answer for this question involved relocating the market - to allow the vendors to carry on with their livelihoods. This emphasises the intangible heritage of the Sungei Road Market is more significant than the site itself, as the community reiterated the trades are "an important lact of the Singaporean society" (fig. 115). 

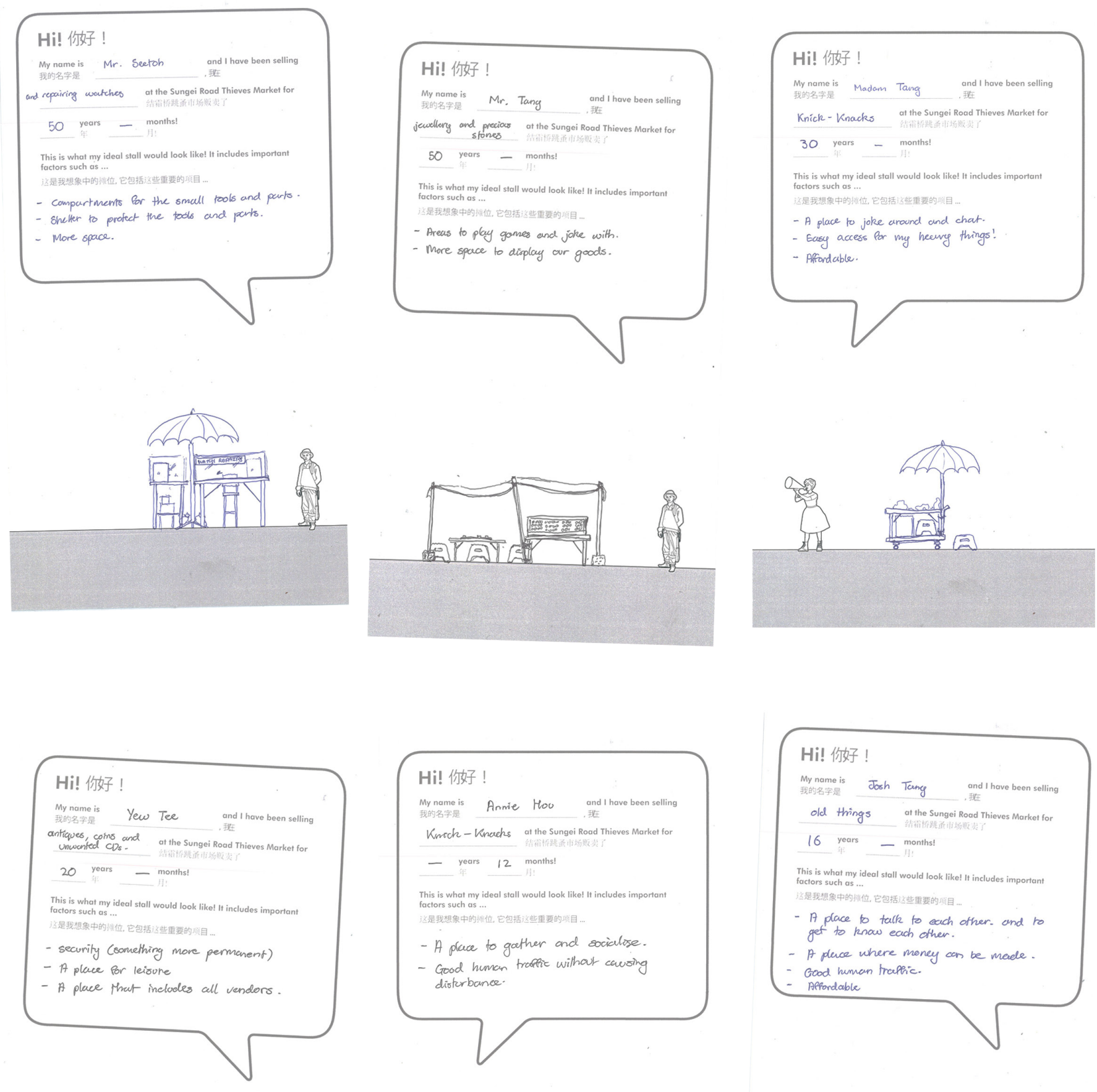

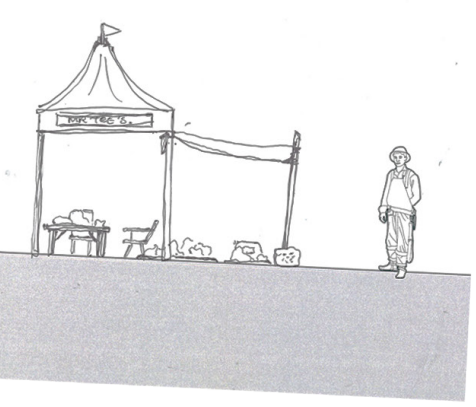

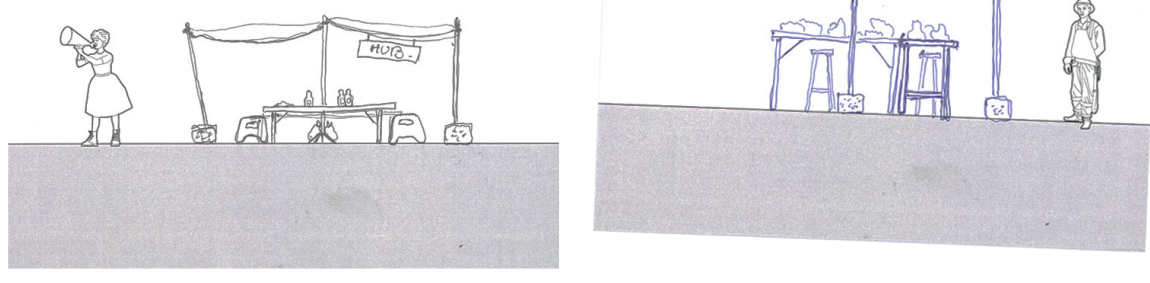

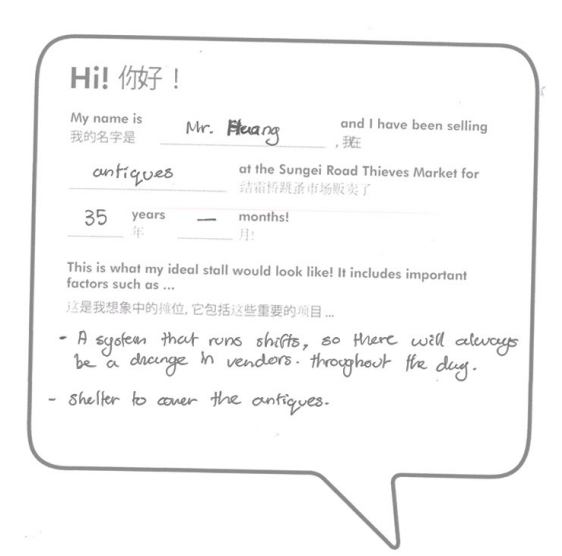
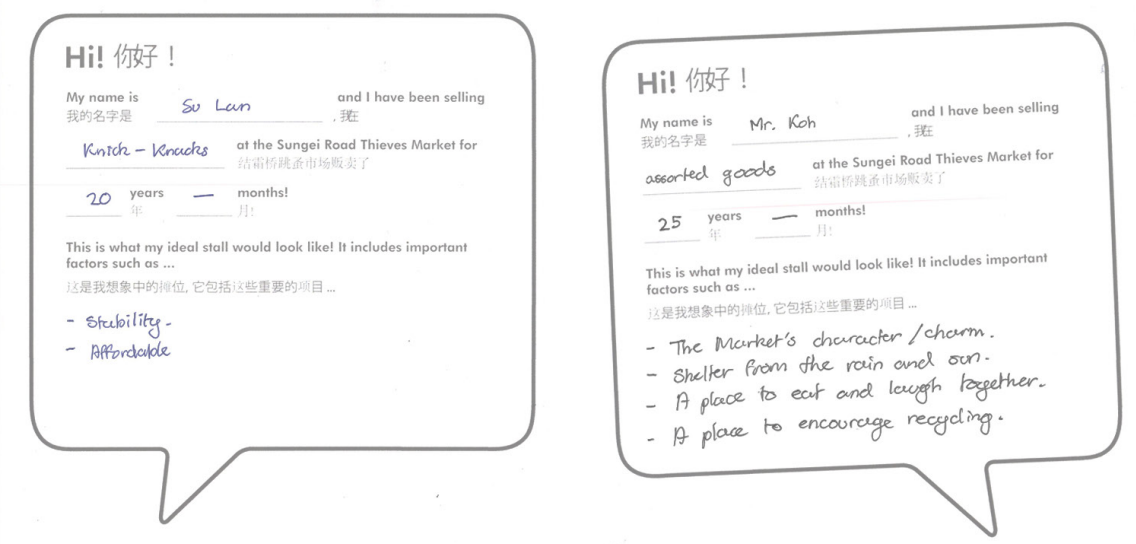

\section{Arina}

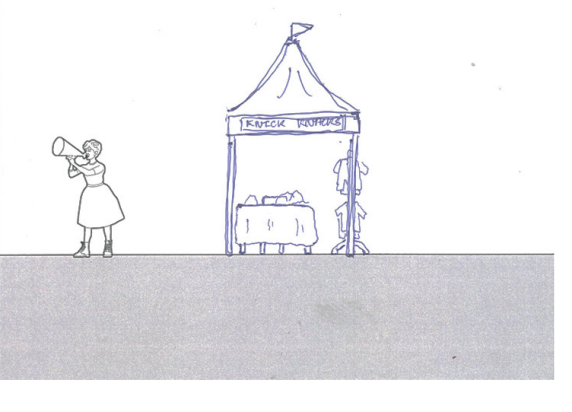

\section{Interpretations}

As a designer, it is important to interpret and convey what the Rochor community is trying to express. Through this drawing exercise, the vendor's ideal stalls were visualised and established. Majority are omplemented bv an area for vendors to relax and chit-chat (fir. 116).

"By being involved in the design process, participants can develop a sense of pride and an attachment to the place" (Melcher, Stiefel, \& Faurest,

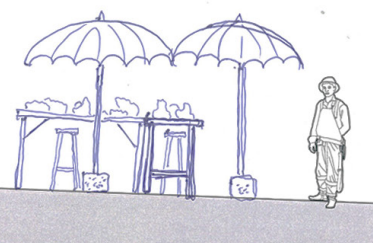


Vendors can not afford to lease retail space

Insufficient protection/shelter is provided for the public

Insufficient street amenities are provided for the public

The site is not a destination for the public (excluding passenger

the local trades of Singapore are vanishing

3.4 Design Guidelines

The outcome of this research investigation must:

Connect:

Fncourage more pedestrian movement through site

Integrate with its local and neighbouring context

\section{Activate:}

Reflect the characteristics of an open-air market

Protect the public from Singapore's climatic conditions

\section{Collectivise:}

Be adaptable to the fluctuation of the market and the community's daily pattern

Embrace the community found within the market and its local context

Promote the local trades by educating and engaging with the public

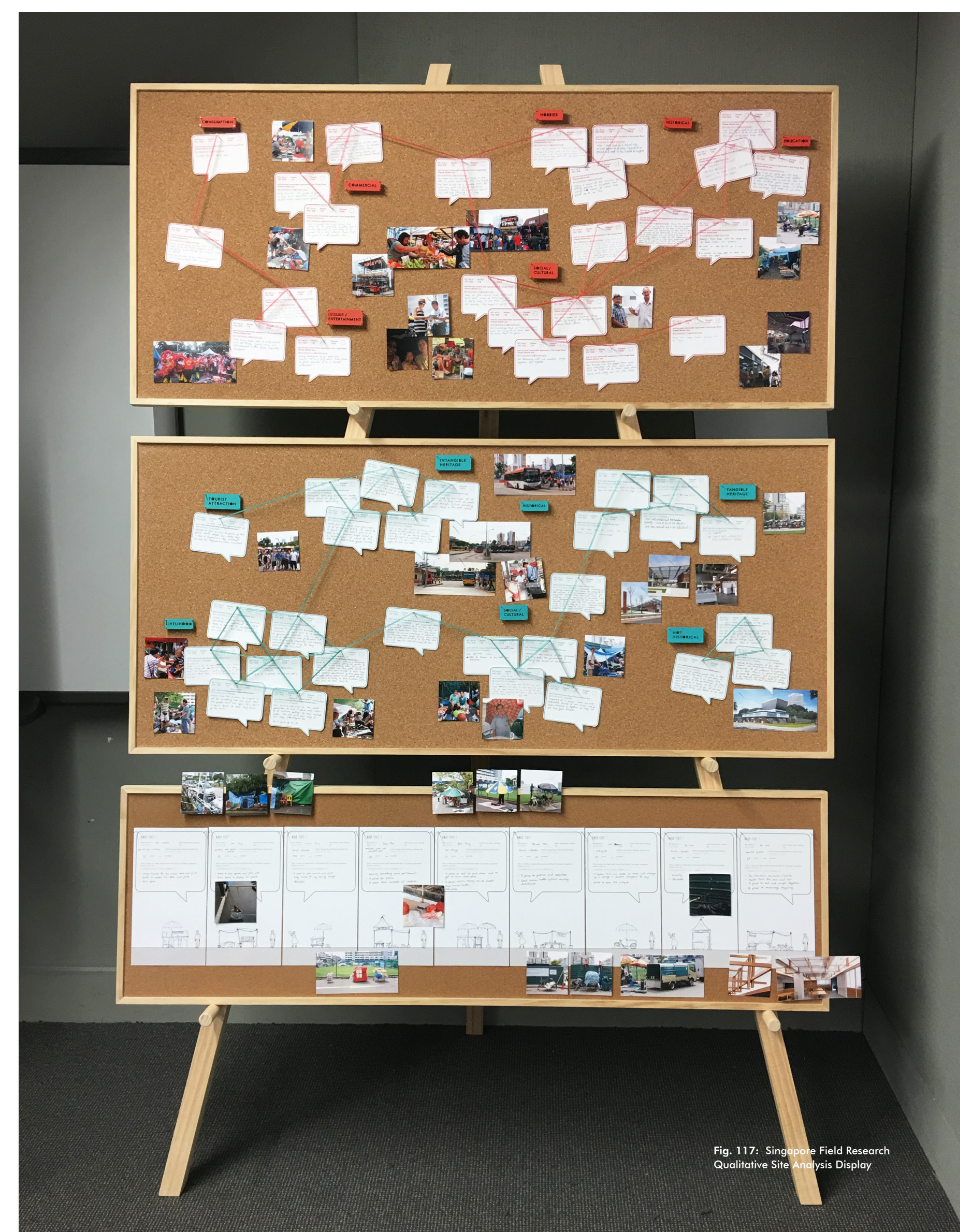


CHAPTER FOUR:

PRELIMINARY DESIGN
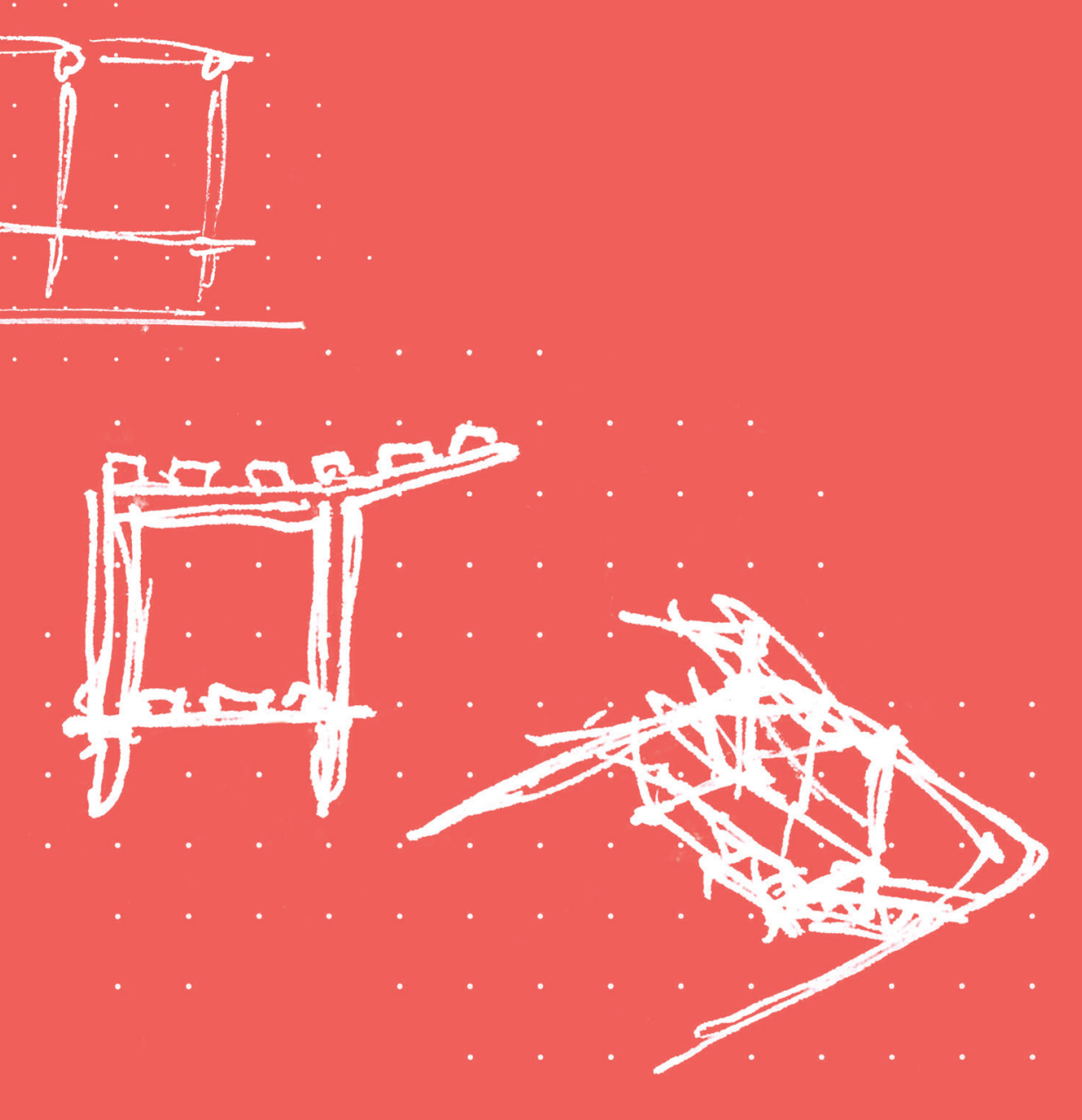

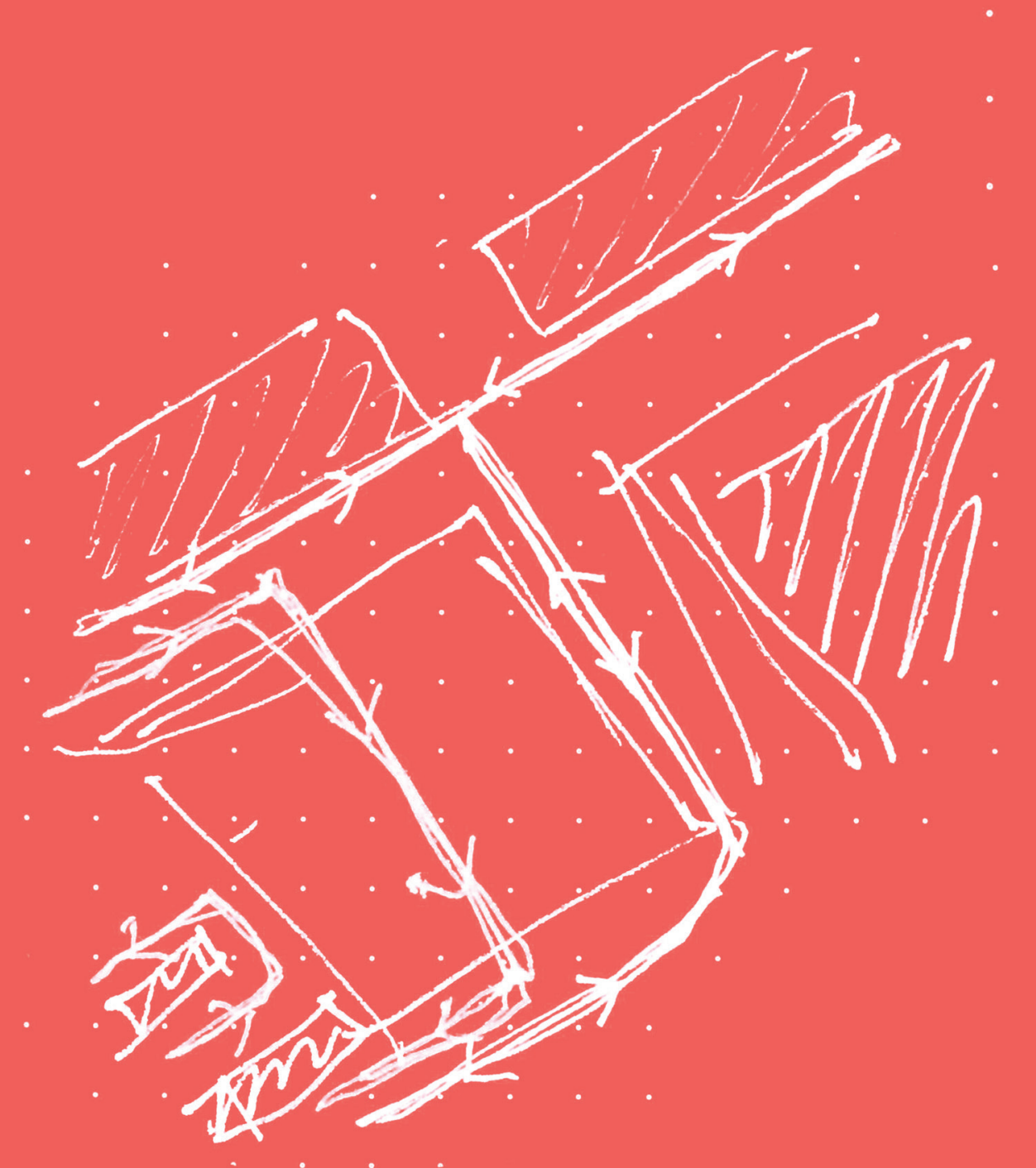

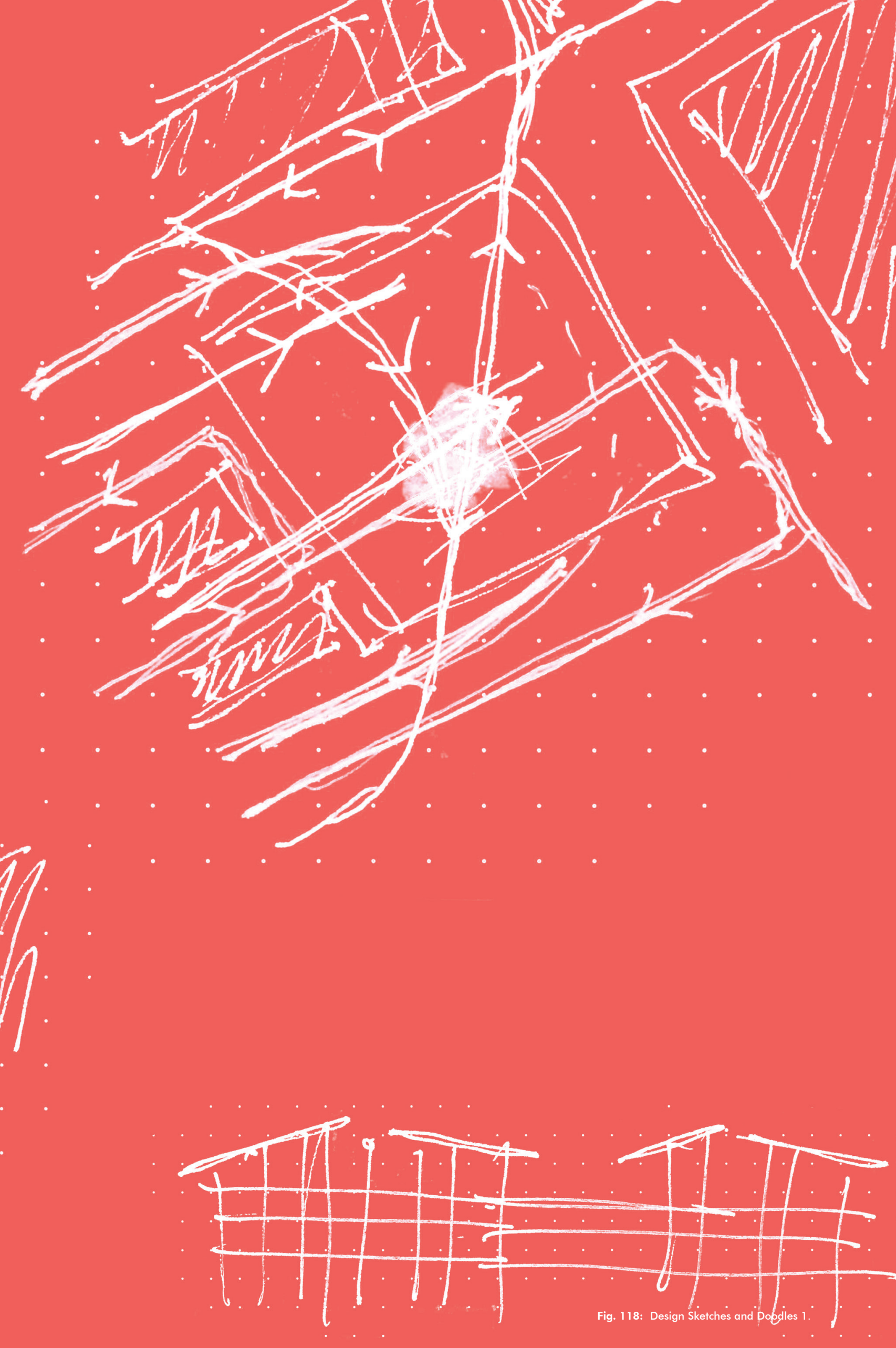


4.1 Design Intentions and Process

The intentions of the preliminary design are to:

- Investigate how the traffic movement can be revised to connect and benefit the proposed site

Fxperiment with various architectural forms to identify and activate the space

Propose architectural gestures that encourages socie engagement and inclusio

The experimentation of the preliminary design will begin through sketches to avoid constraints and limitations. Once an idea has take place, a transition to the digital realm will be made. This will solidify the preliminary design for the August 2017 design review.

An existing site plan was established to identify the immediate existins programmes and roads (fig. 119).

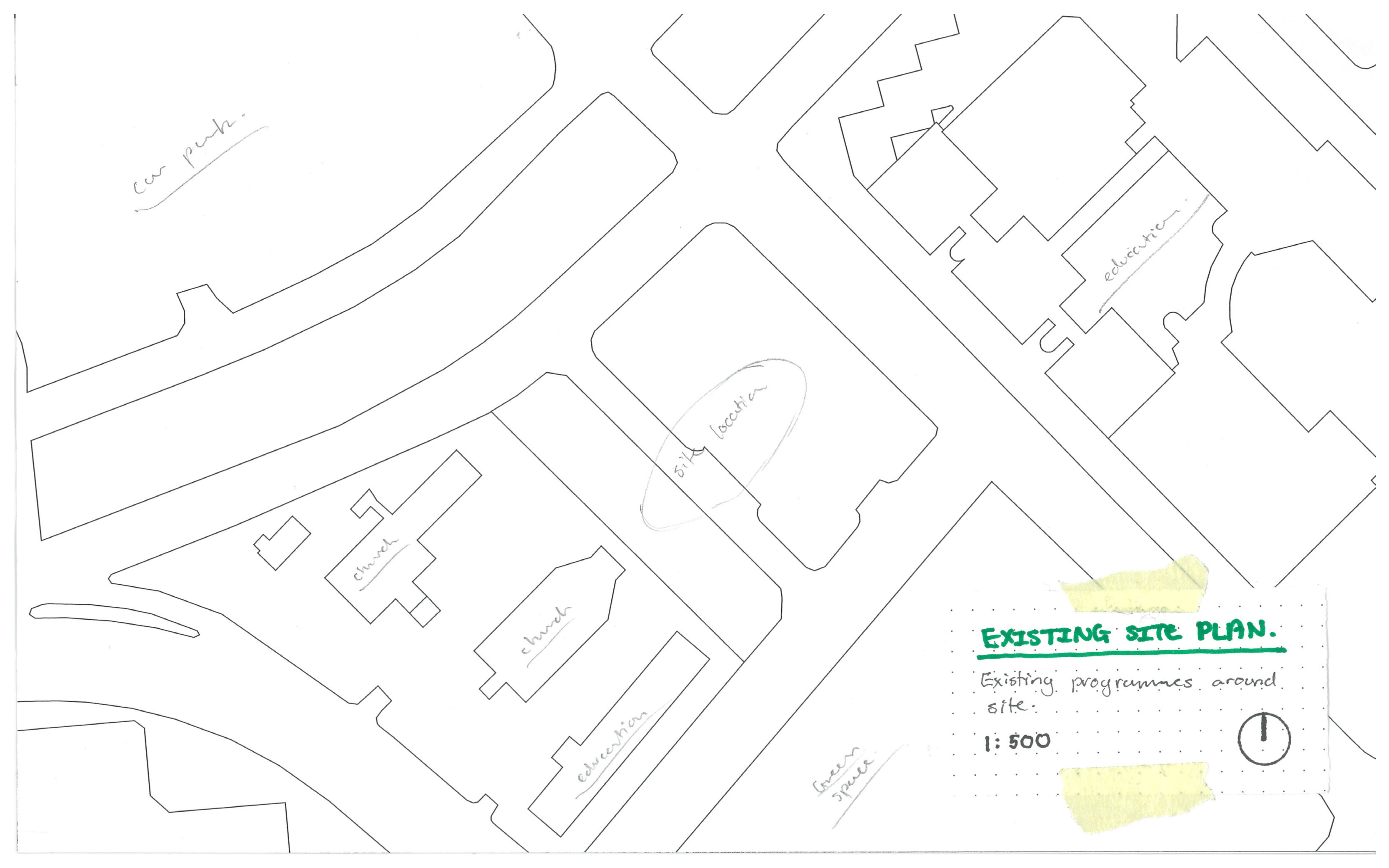


This influences the bus and car movement around site (fig. 120). From having a bus station, the site is heavily orientated around vehicles - with, cars and buses coming and going frequently. This makes the pedestrian

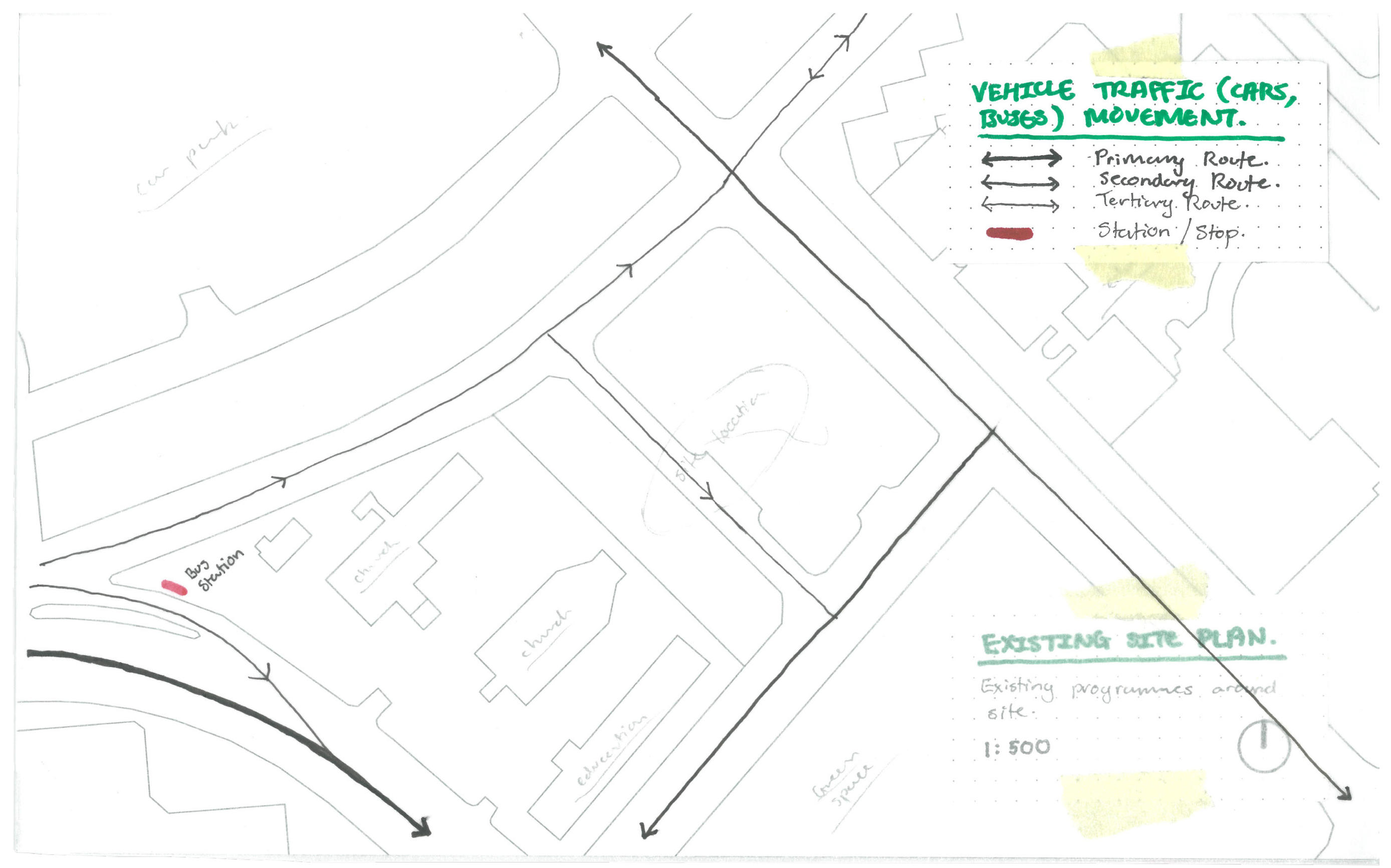


When pedestrians are passing the bus terminal, they walk along Queen and Arab Street to avoid the heavy traffic (fig. 121). Pedestrians also gravitate towards the covered walkways that runs around the which the bus terminal fails to do so. Therefore, the bus termin lacks in establishment, as well as pulling pedestrians into sise.

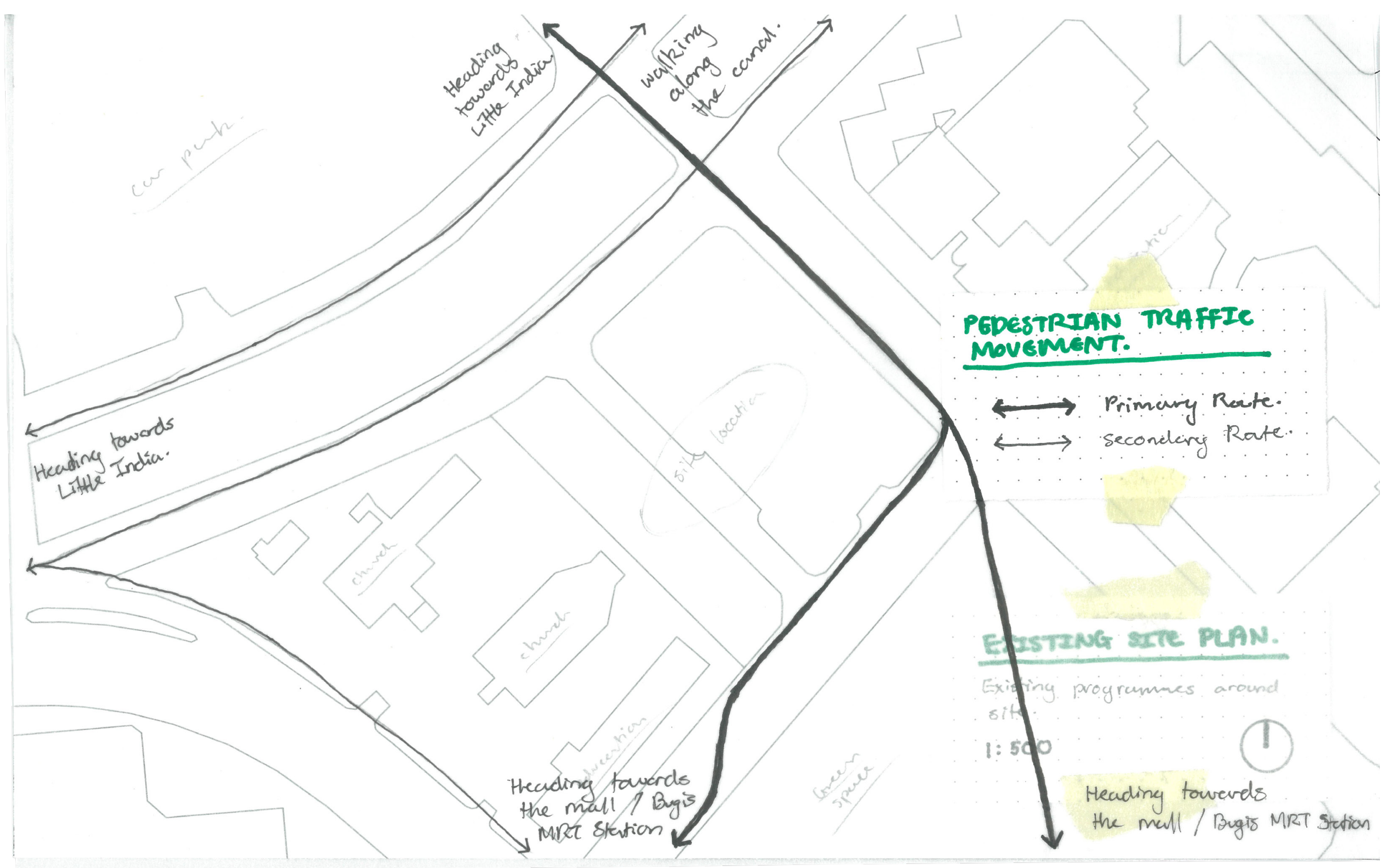


For the preliminary design, it will focus on connecting the space to its surrounding environment and programmes (fig. 122). The existing modified to allow the site to be ming and vehicle movement below ground.

The pedestrian movement was then modified to encourage people to cut

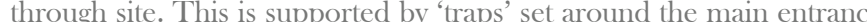
to pull pedestrians in. 'Traps' consist of programmes and architectum gestures that entices pedestrians to stop and deviate into the space. Therefore, turning the site into a destination for the community, as we as improving the relationship between the site and its contex

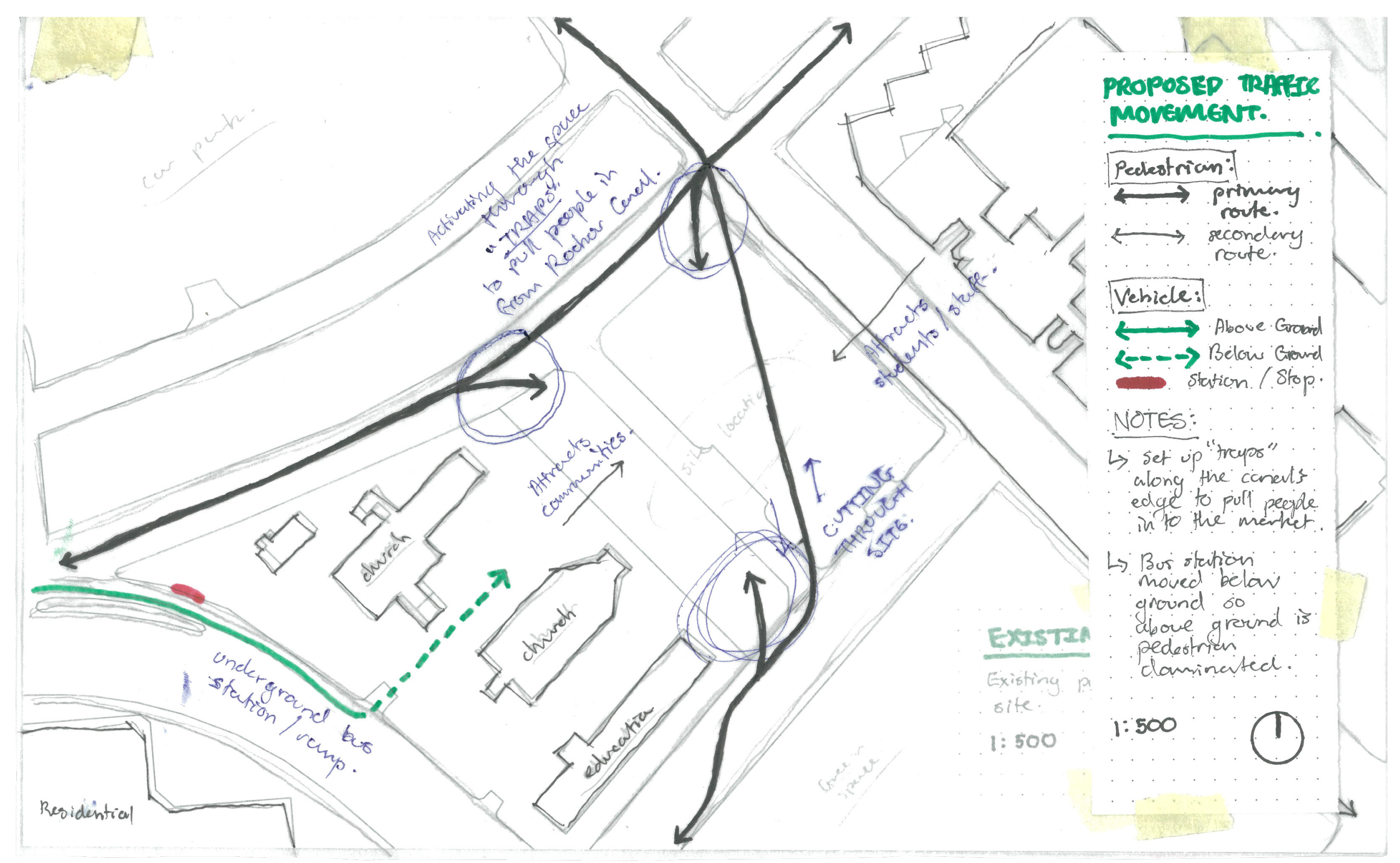


The beginning of the architectural form was explored through the experimentation of various levels (fig. 123) - by sketching bridges and ramps that casts over the site. This creates a sense of verticality where pedestrian and vehicle movements are separated. Pedestrians have an opportunity to look down on to the market stalls while using taking place.

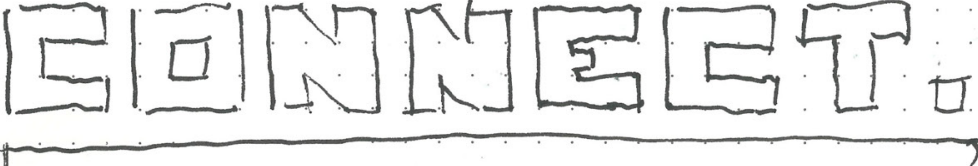

$\longrightarrow$ connect the space with its context - Provides more acecessibility
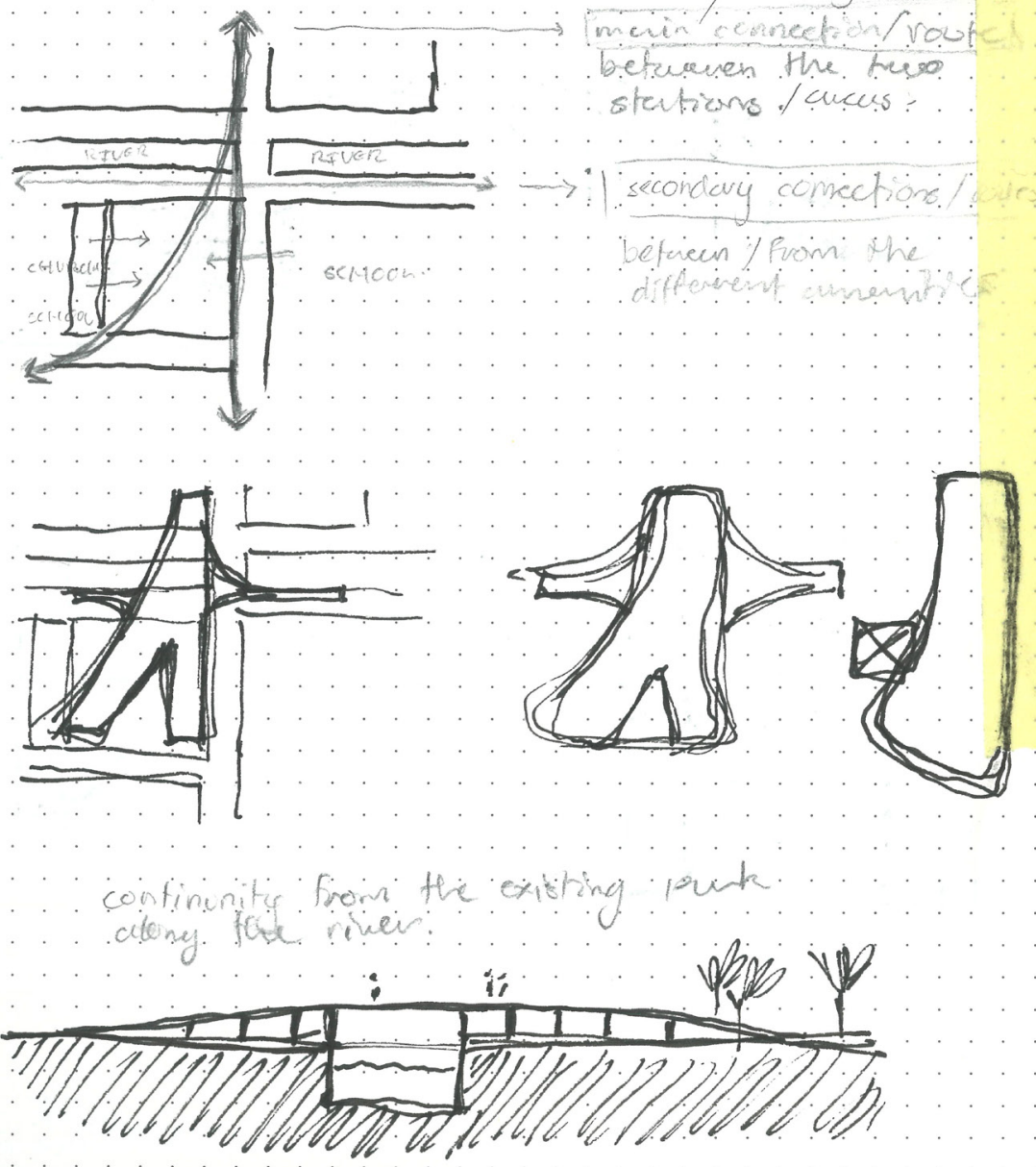

$\pi$
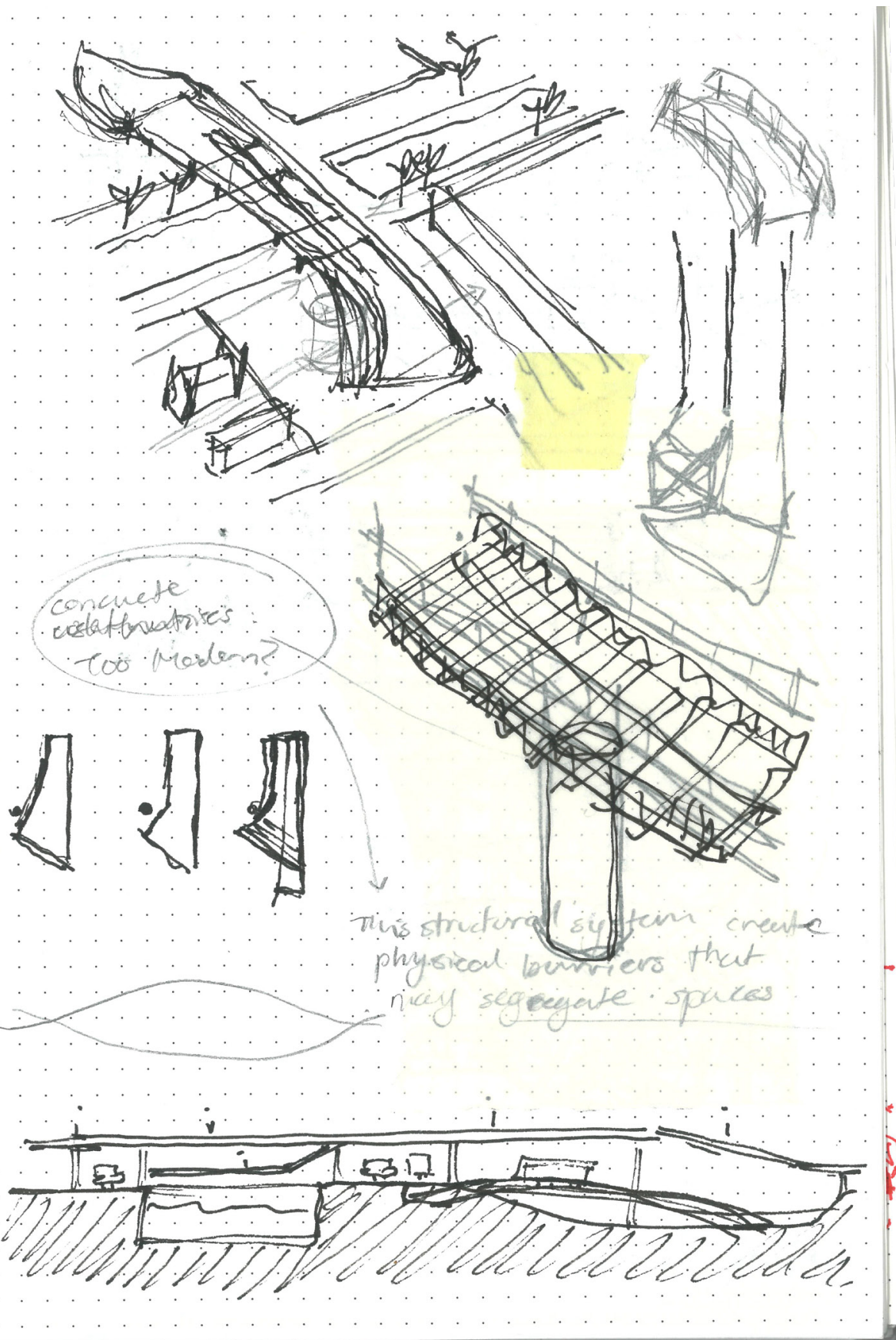
Precedent (right):

Seoullo 7017 Skygarden, Seoul, South Korea

MVRDV (2017)

The pedestrian walkway was inspired by the Seoullo 7017 Skvgarden in South Korea (fir. 124). What use to be an overpass for a highway, MVRDV transtormed ii into a newlv pedestrianised viaduct next seouls smain station (MVRDV, 2017). It was considered as the next ste introduced nature to the eit dwellers (MVRDV, 2017).

Saving that, when the architectural form and concept was implemented

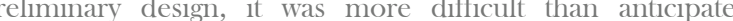
cyclists - hedad me (NZTA, n.d.). These ramps should be incorporated into the approad of the bridge to minger to to the limited size of the site, it made tie wathay inaccessible for pedestrians.

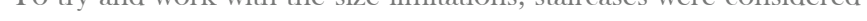

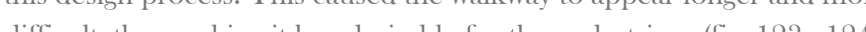

From having a pedestrian walkway, undesirable spots are created on the ground - directly under the bridge and staircases. With size limitations,

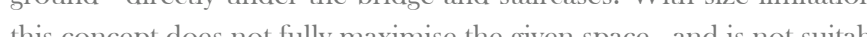
for this site.

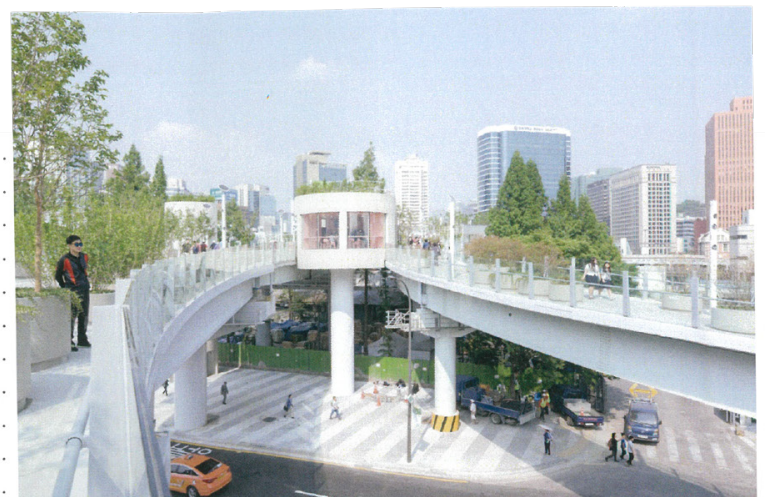

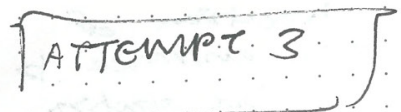

1

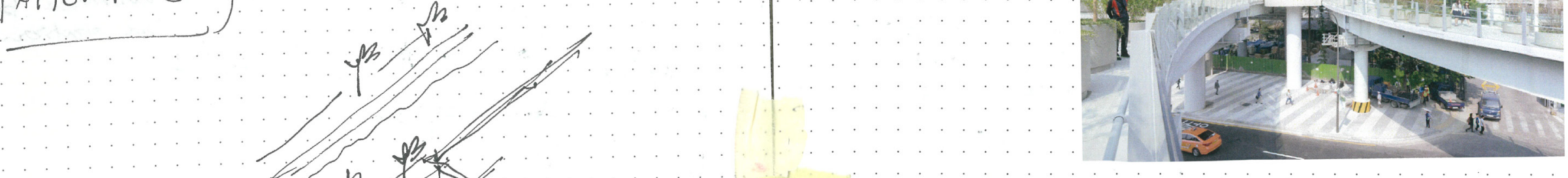$$
\text { 放里 }
$$

-1)
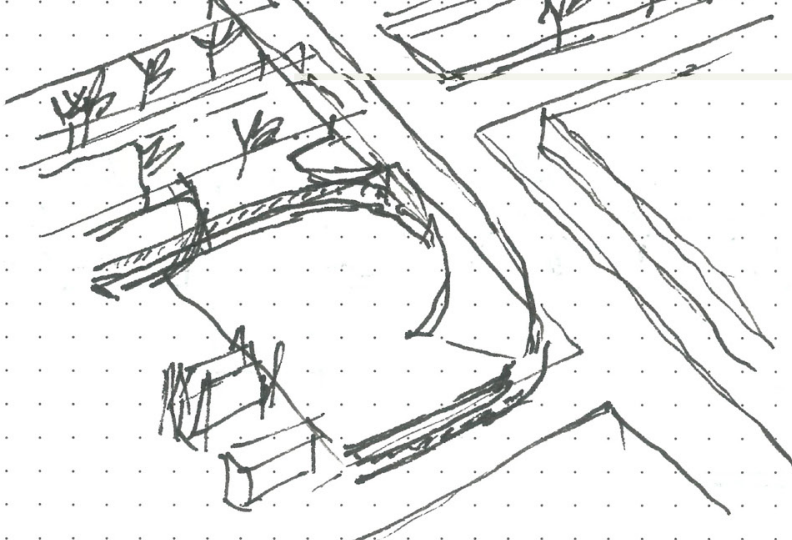

as

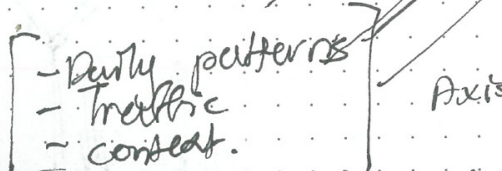

Itimeronit spots /Retart Thevry 


\section{Precedent (right):}

hosunoak The Oak, Seoul, South Korea

Seog Be Seog and MMOA (2017)

The second concept wis mspired by the Chosunoak the Oak in South Korea (tig. 12.5), where the architects wanted to contain time people urant (Seog Be Seog and MMOA, 2017). "W thimately wanted to contain the thought that this is a space where people reet and enjoy culture (Seog Be Seog and MMOA, 2017).

The ceiling detail of the restaurant stood out as a precedent for this etermined and defined spaces through the suspended gid - white stil pressening the restaurants history and characteristic his concept could be inplentented in the prefintinary design, as the amework appears to be flexible and open to change (fig. 125).

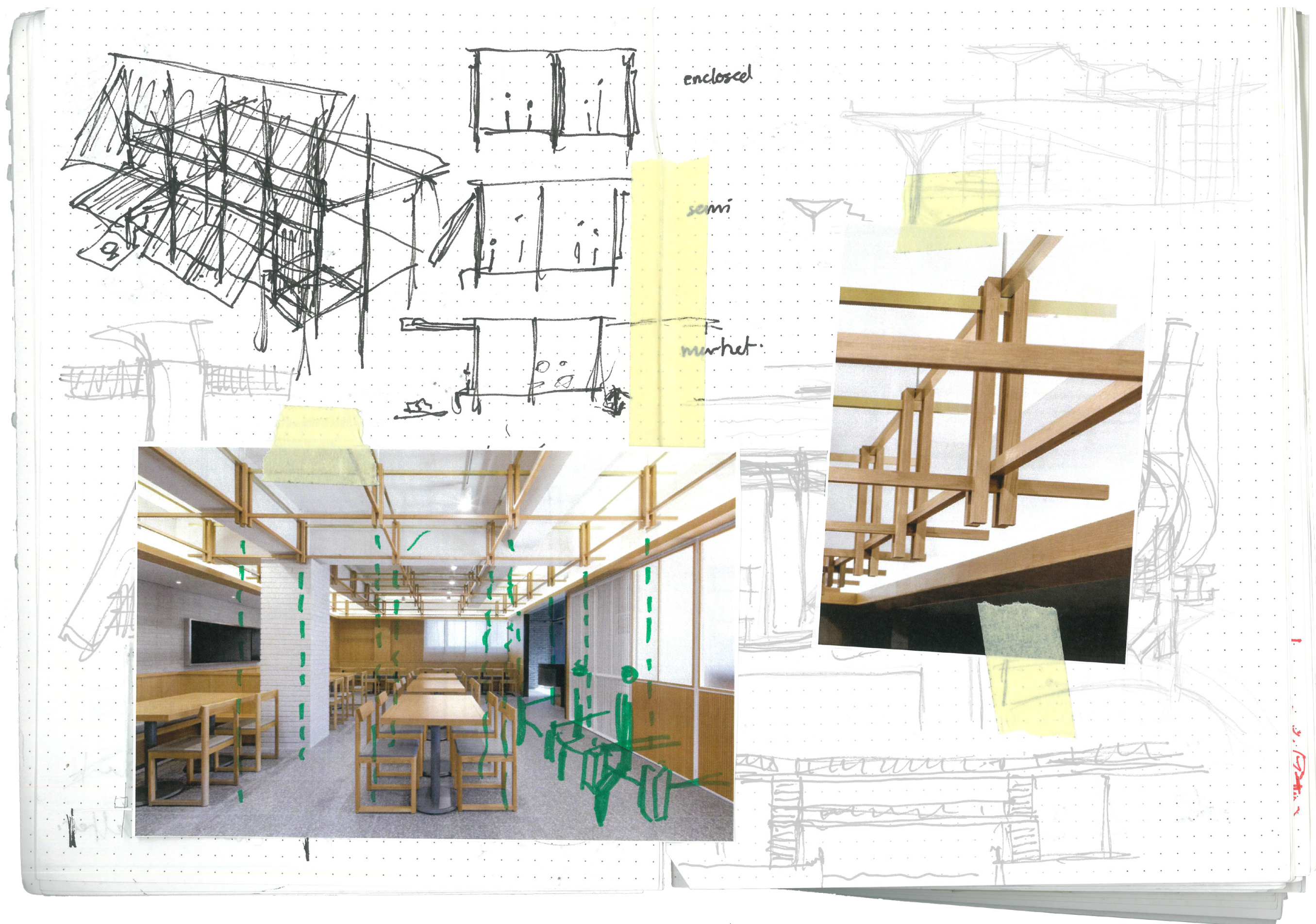


A framework was initiated in the preliminary design to accommodate for the market's fluctuation and Rochor community's daily pattern. the the (T) sabconsciously deffine spaces. The fant in tork on site can host between Do for

The bacic construction of the framework wasincired by the oberabos the in the fith made in the vendors used

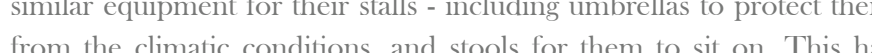

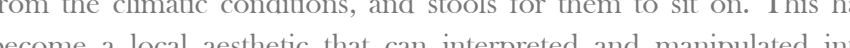
Cifferent for. The finided floor level of the proposed framework wo ised $400 \mathrm{~mm}$ to replicate the height of the stool. Whereas the screess a he used as an internal wall for semi-private spaces (fir 126), or as mbrella for the vendors (fig. 127).

Fig. 126 (Top Right): Enclosed Framework Sectional View Fig. 127 (Bottom Right): Open Framework Sectional View

Fig. 128 (Far Right): Framework's Dimensions

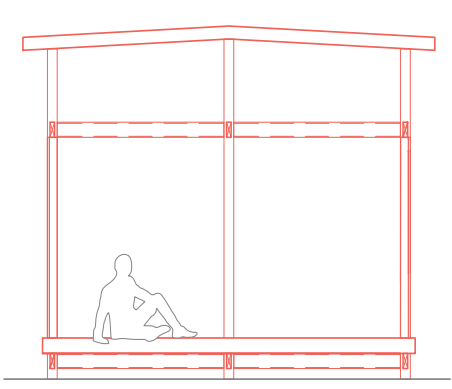

Enclosed Space

Generating semi-private rooms that can be used by the wider community

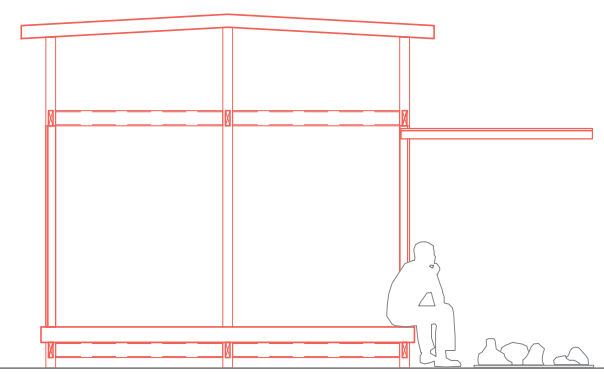

Open Space

Generating shelter that can be divided into individ market stalls

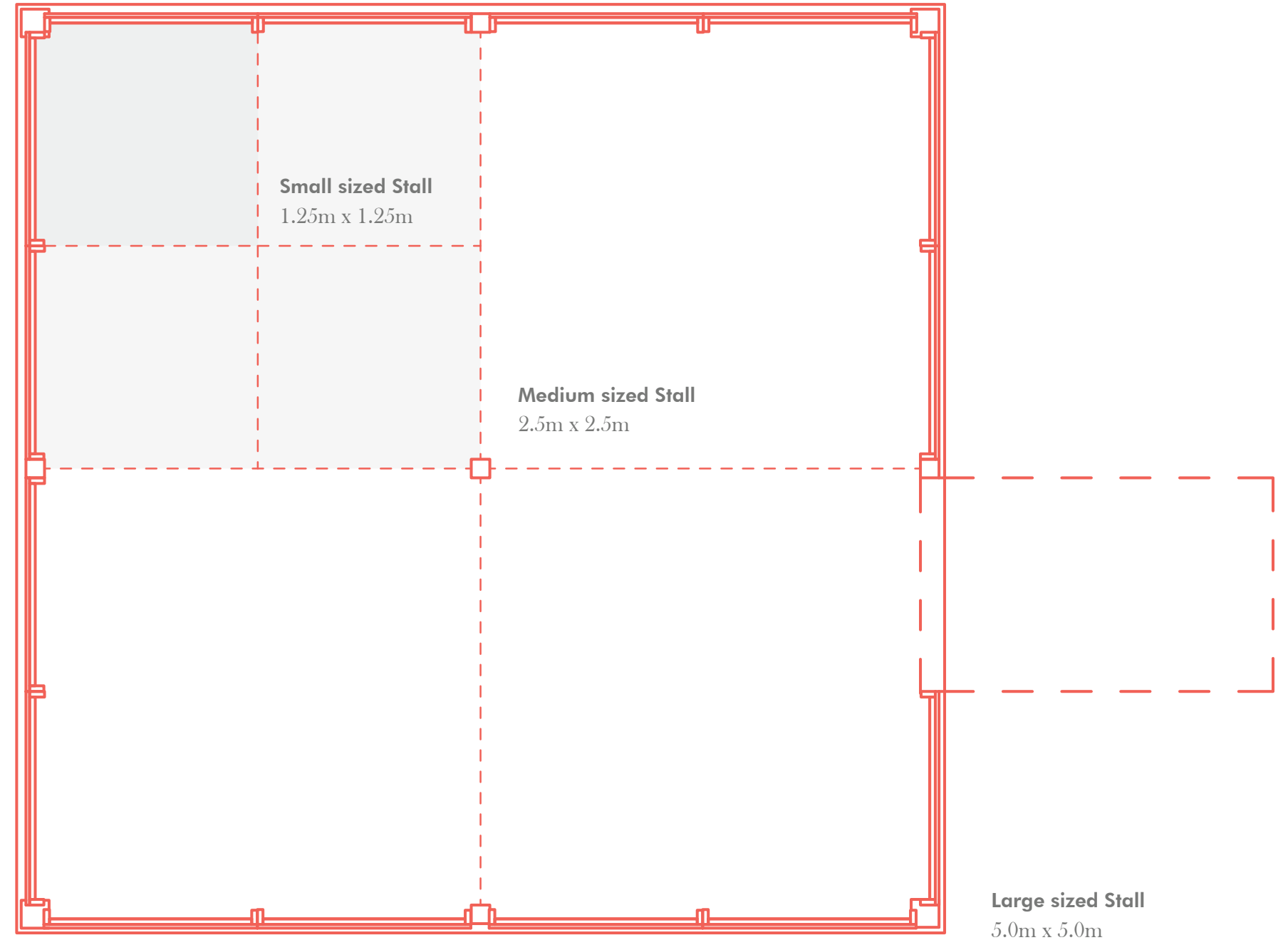




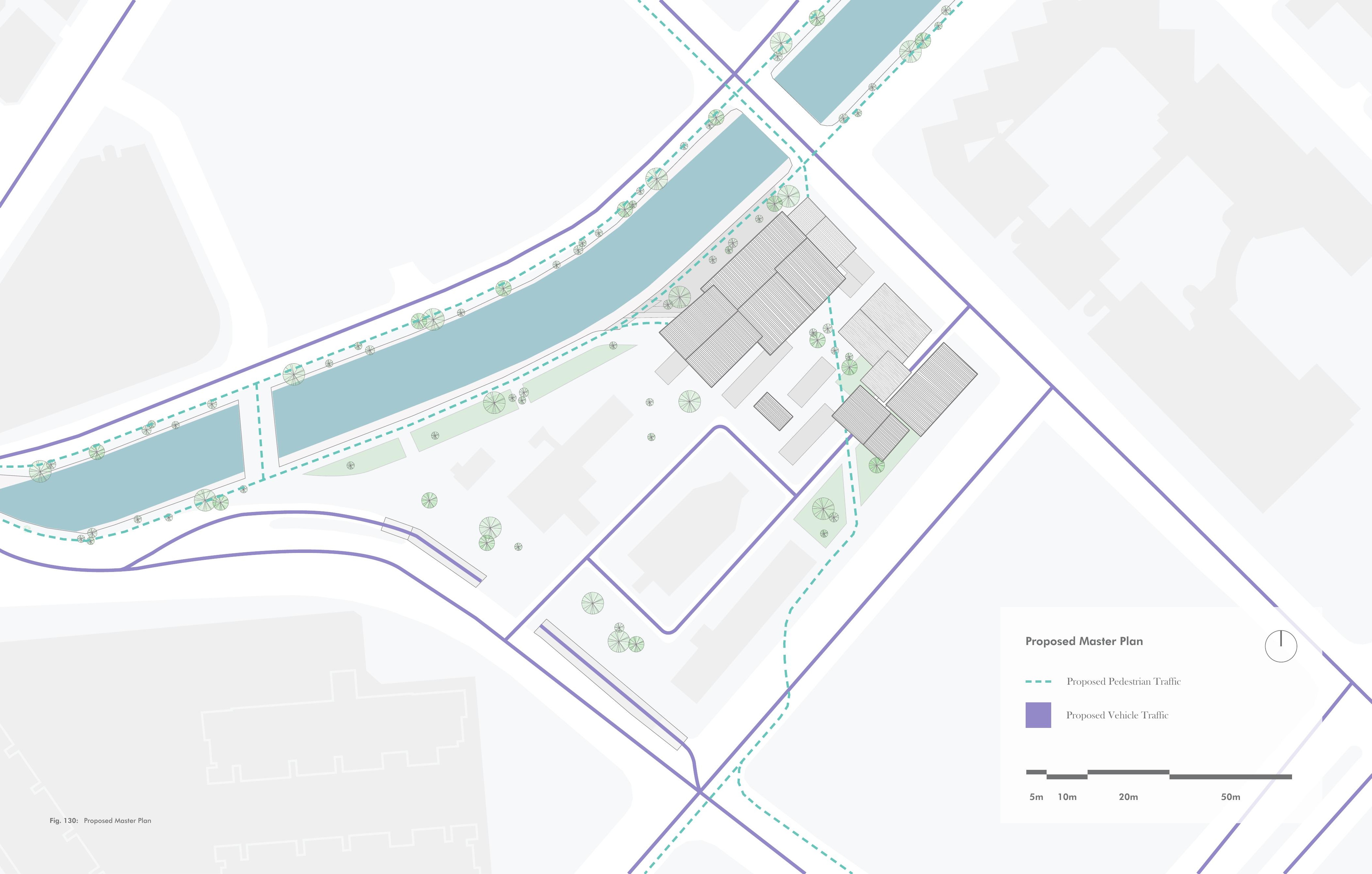




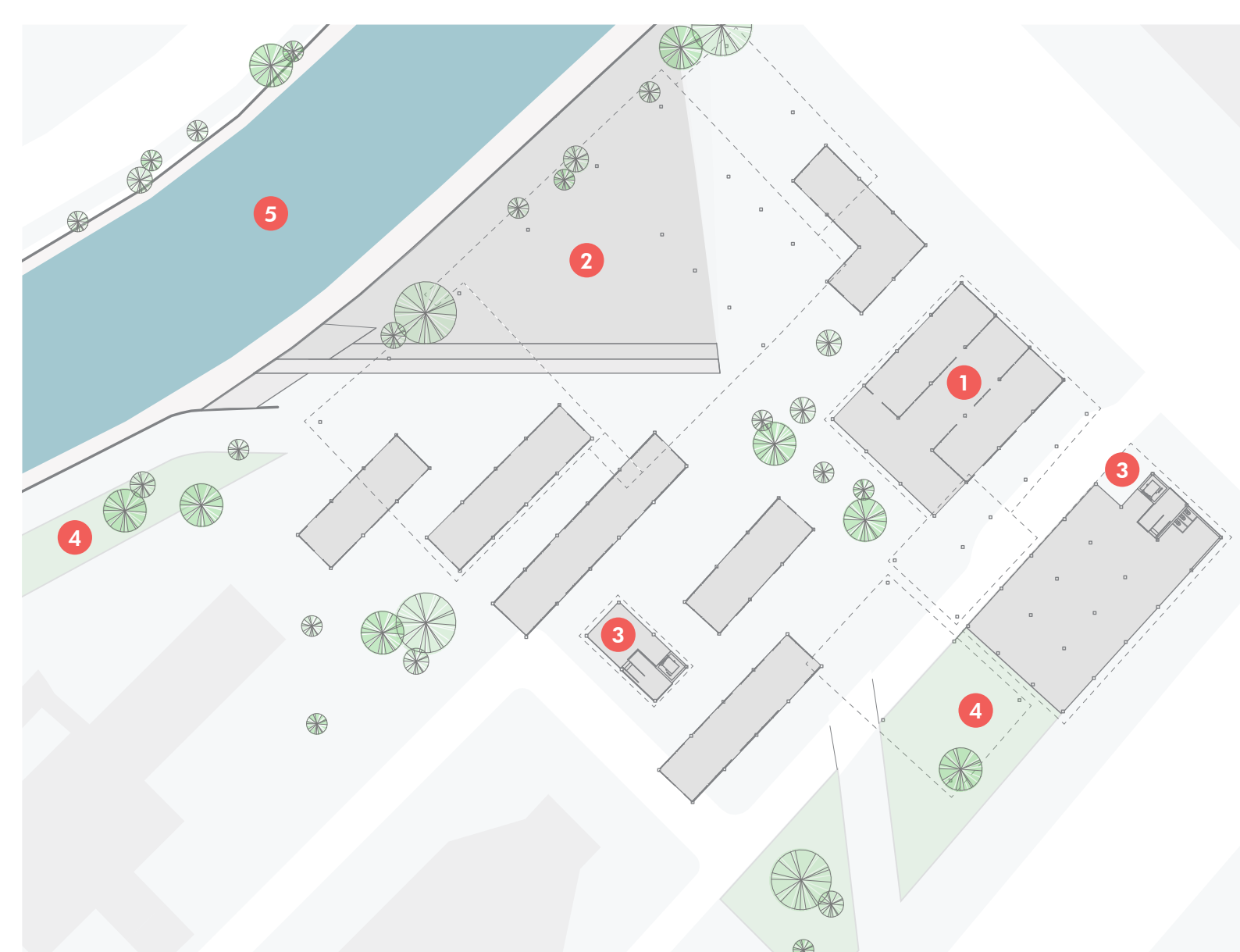

Proposed Above Ground Plan

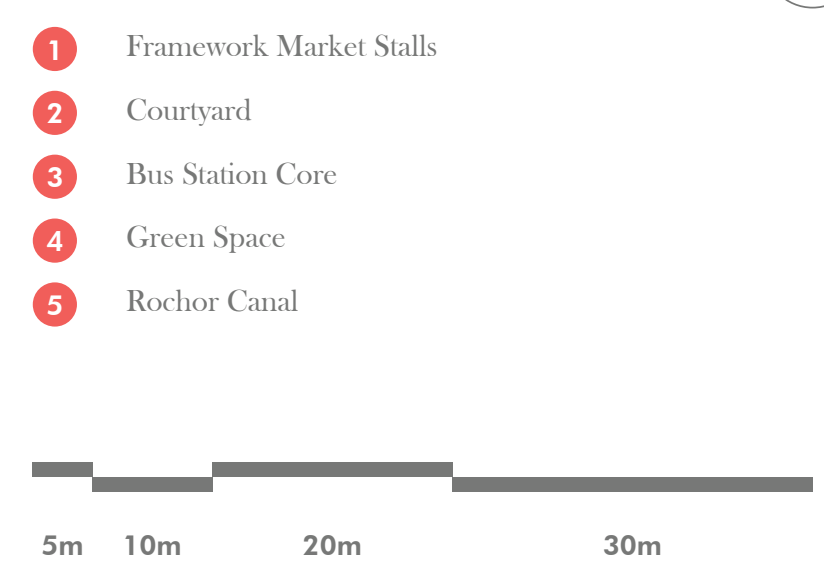

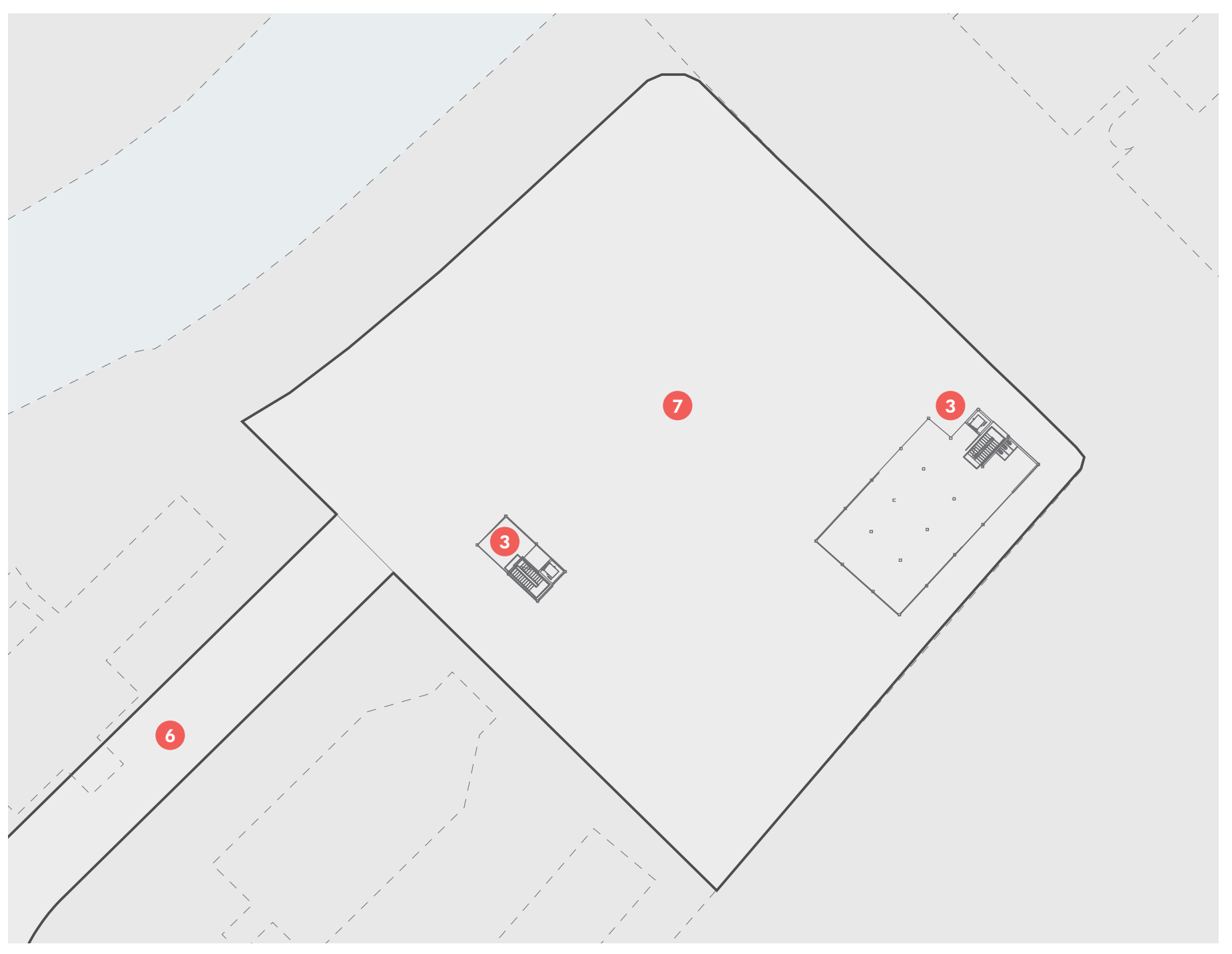

Proposed Below Ground Plan 


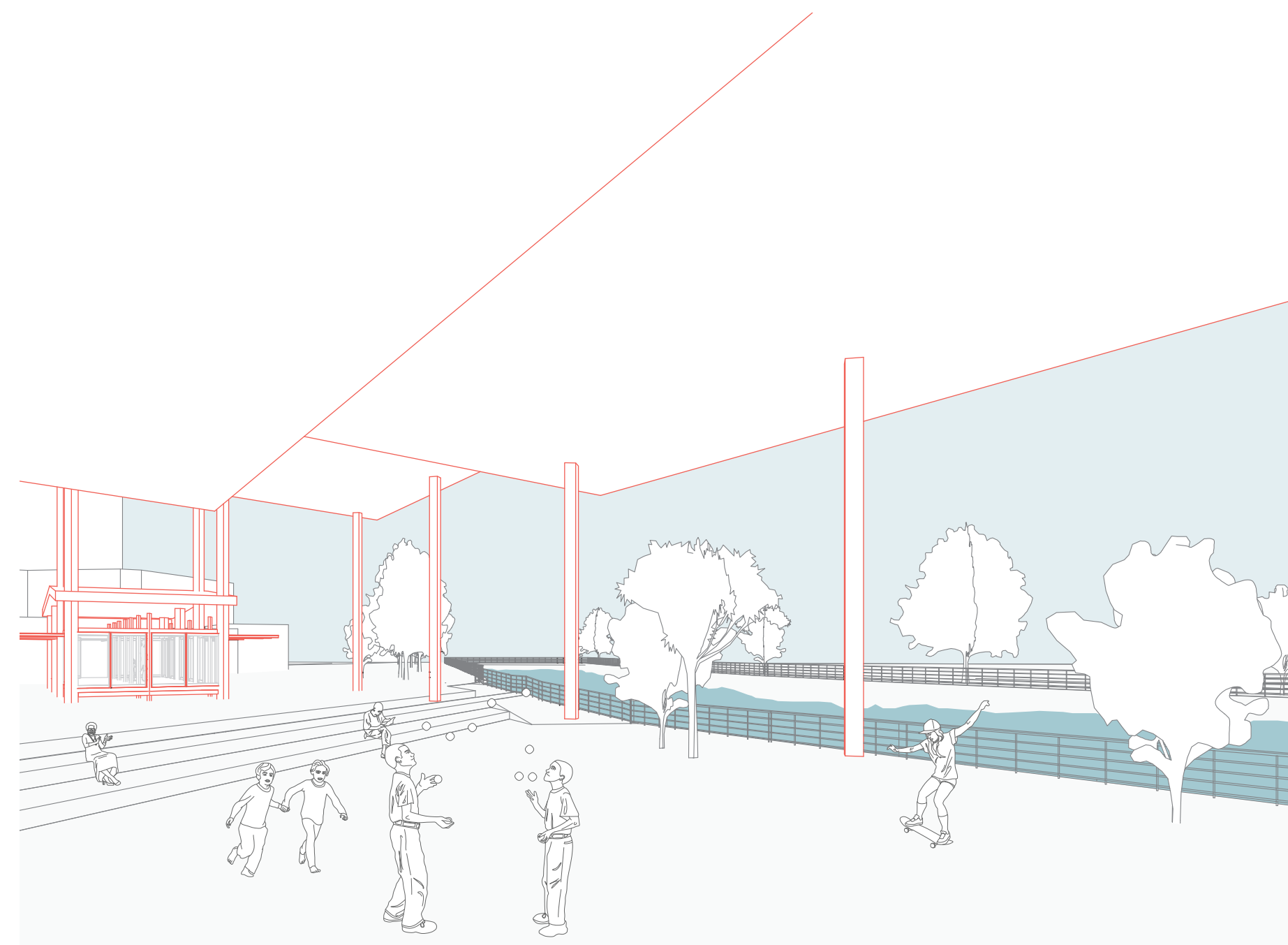

\section{The Courtyard}

The courtyard is considered as the main 'trap' for the preliminary design. Located by the Canal's edge, it pulls pedestrians in that are passing by the canal and market. It can function as a resting, play and performane

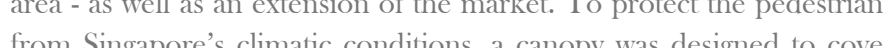

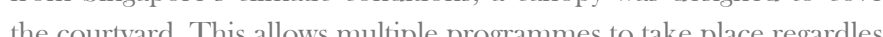

Fig. 133 (Above): Courtyard Perspective

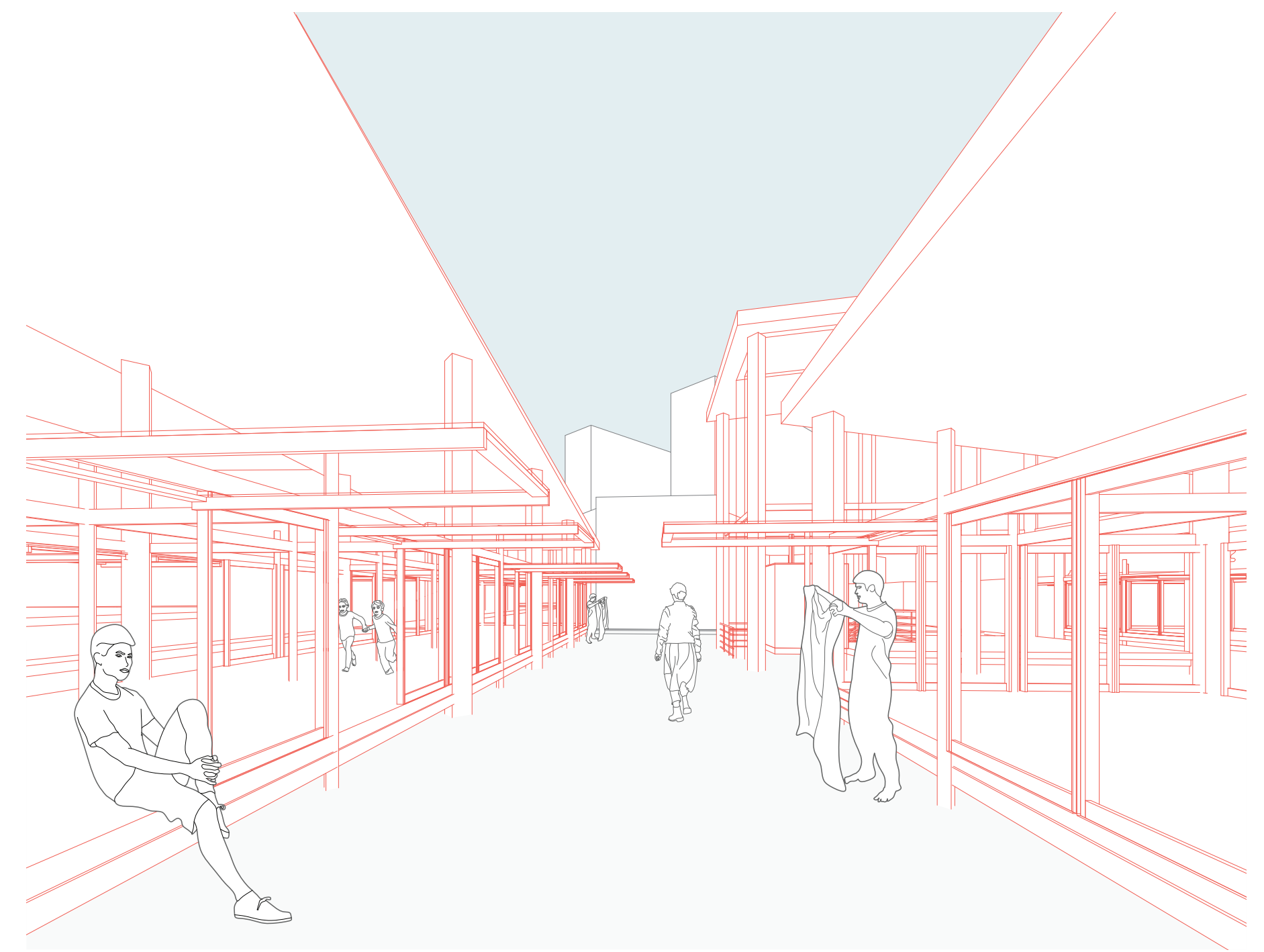

\section{The Framework}

The framework was established in the preliminary design to accommodate Fig, 134 (Above): Framework Proposal

for both the vendors and shoppers. It can function as semi-private meeting

and educational spaces - as well as individual market stals. This targets

Rocher

areas of the market. This provides an opportunity to be exposed to the

maious trades that take place. 


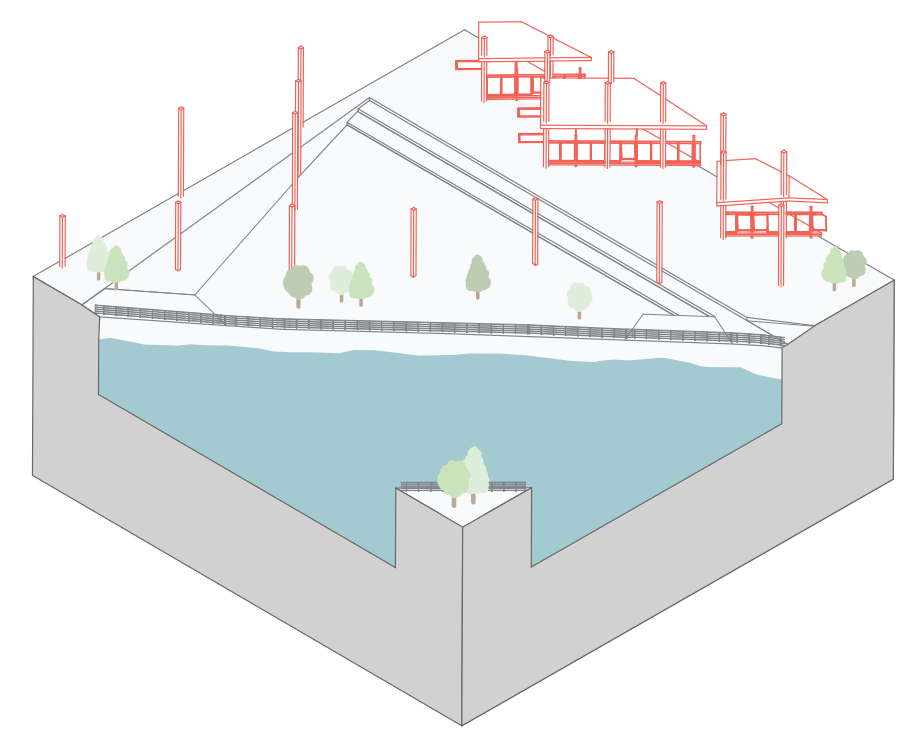

The preliminary design began to investigate how architecture can accommodate for the Rochor community. Different aspects were explored to experiment what was and was not successful. Based on the fect The canopy is underdeveloped in the preliminary design. It lacks in form exploration and fals to protect majority of the site from Singapore's climatic conditions. The bus station below ground was also spaces were absent. The scale of the urban context throughout the preliminary design was
minimal. This made it difficult for the reviewers to understand how and why the vehicles and pedestrians are moving the way that they do. The proposed pedestrian movement was peculiar and it was questioned whether it was well integrated with the rest of the urban scheme.

Due to the $5 \mathrm{~m}$ grid system, the above ground floor plan for the preliminary design was linear and monotonous. Further development of the programme layout is needed to break up the repetition. 
The intentions of the developed desion are to

- $\quad$ Revisit the proposed traffic movement so it is integrated wit the urban context and planning

Develop the initial canopy and bus terminal design so it is apparent in the overall scheme

Refine the proposed framework and programme lavout to reduce repetition

Like the preliminary design, this design process will begin throug sketches to avoid constraints and limitations. The digital realm will be used to develop and finalise the architectural form for the November 2017 design review. The existing site plan was revisited at larger scale to understand the wider
context around site. Notes were made to indicate areas that will be redeveloped in the future (fig. 137).

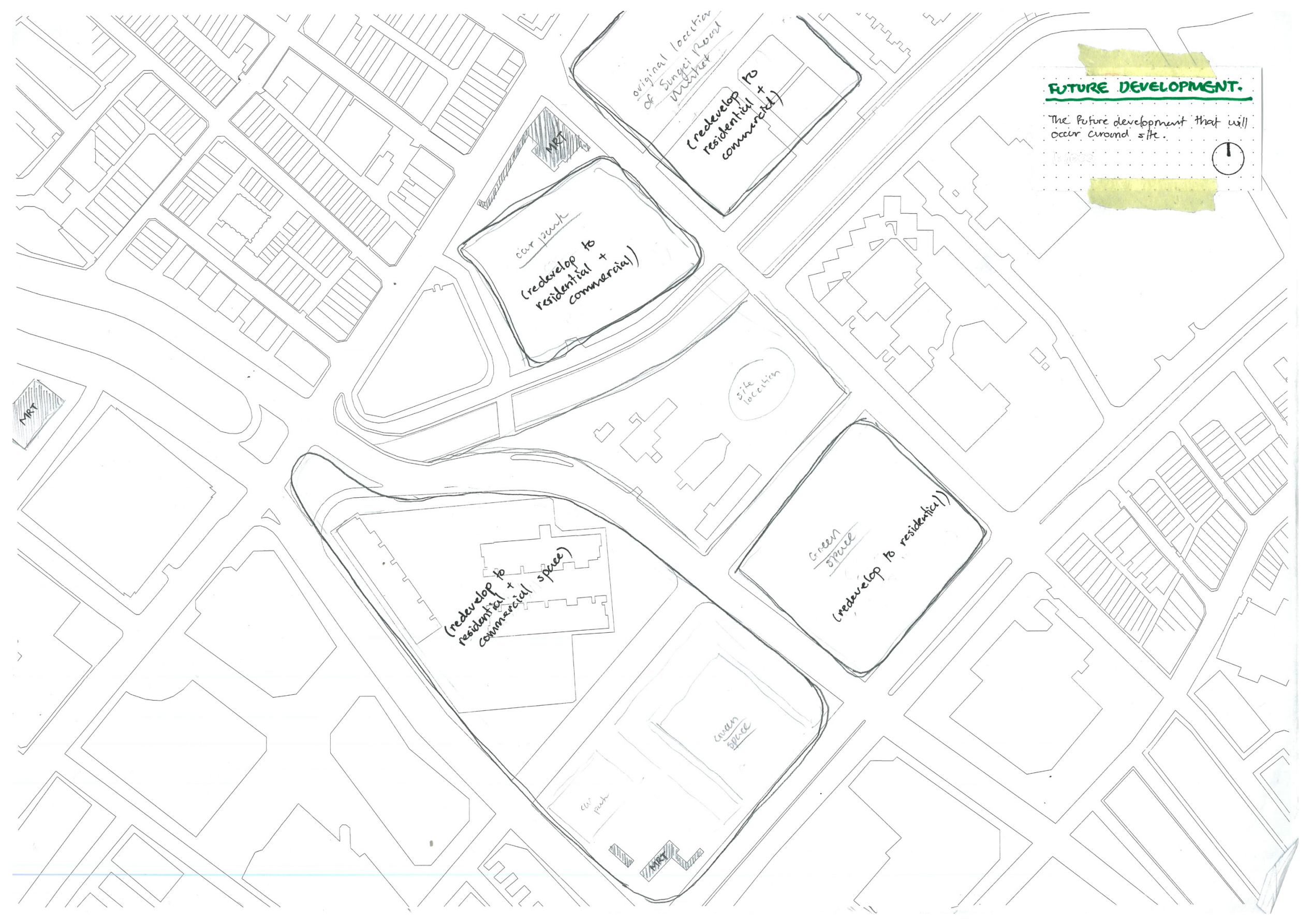


From looking at Singapore's future master plan and the development occurring around Rochor, it is evident that the existing traffic movemen (tig. 138). Queen Street will be halved to acco prodate

of the Suncei Roul Yaket will be remort This mates the init proposed traffic movement unusable for this research investigation, as

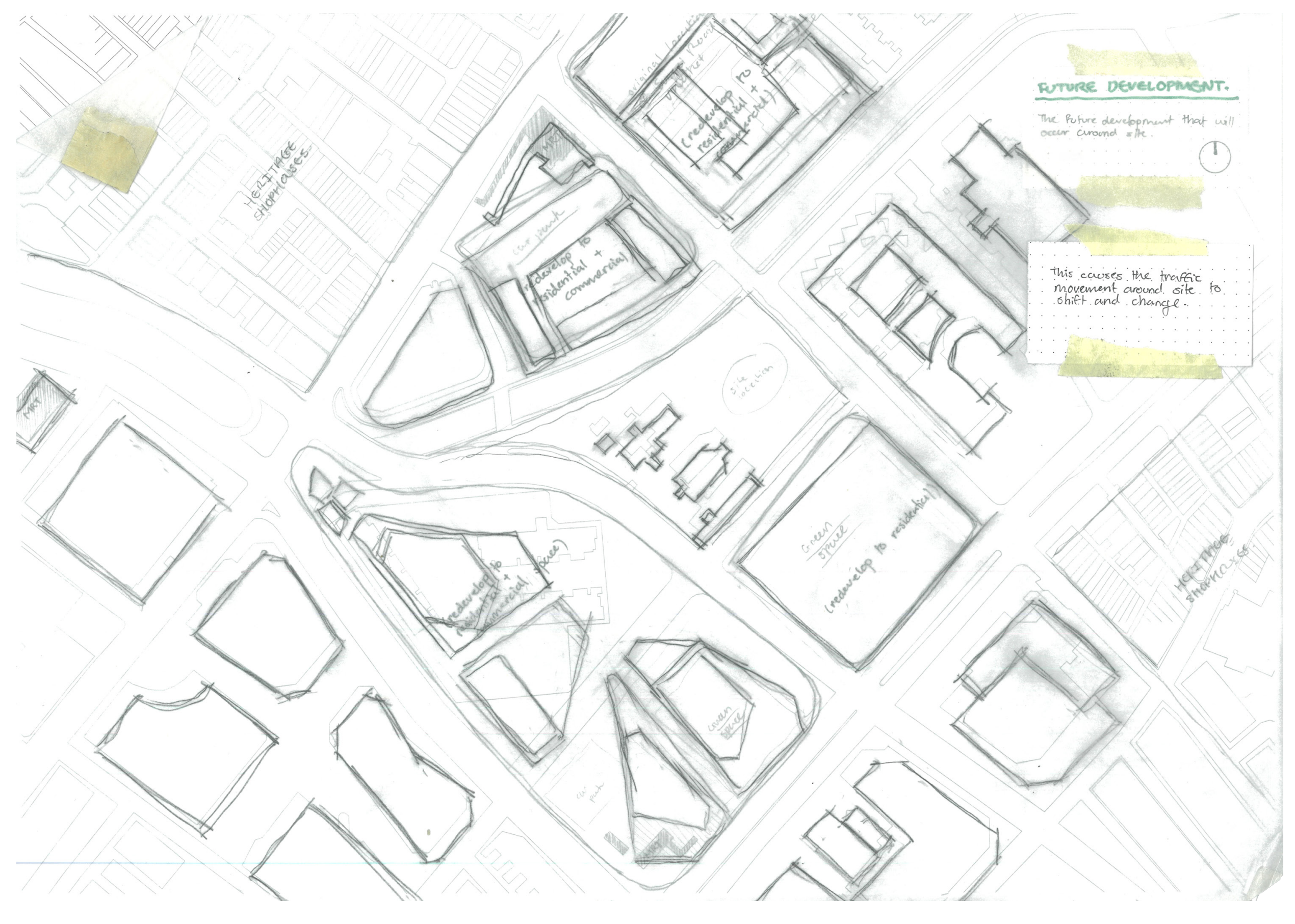


The new vehicle traffic movement will be less affected by future
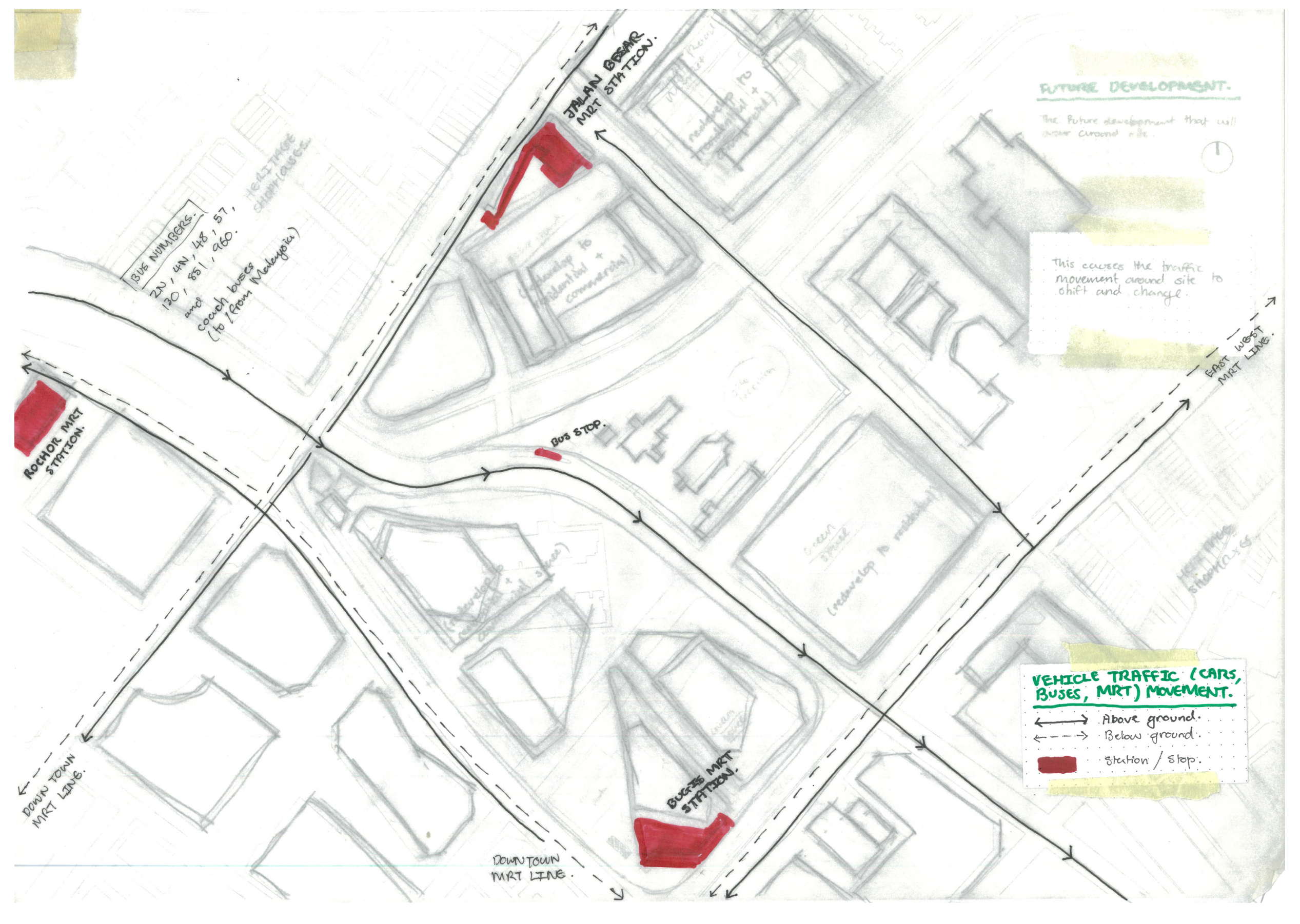
However, the pedestrian traffic movement will be heavily affected by

future developments, as Queen Street will be halved to accommodate

more residential and commercial spaces. This change will encourage

(fig. 140).

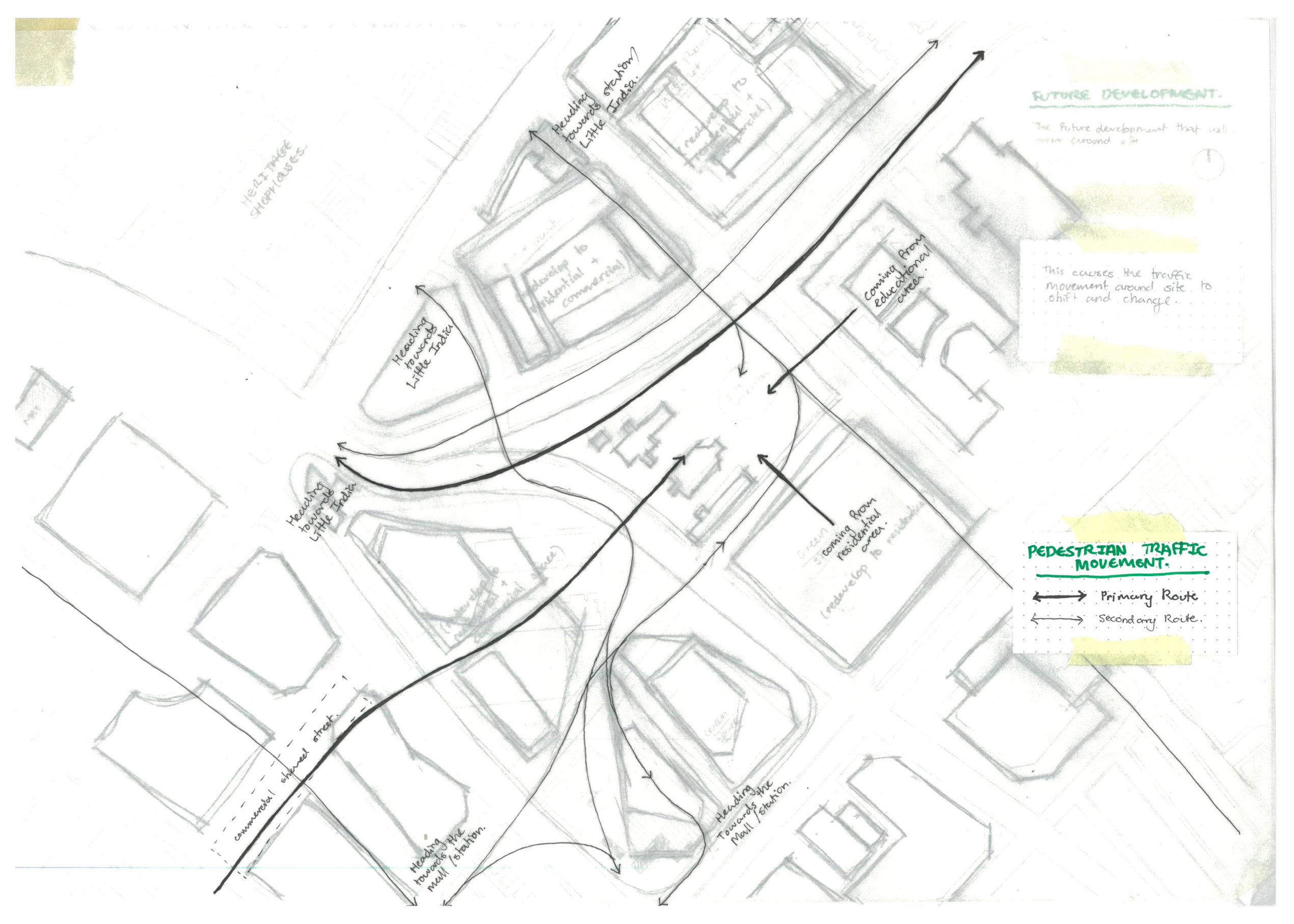


For the developed design, it is still focused on connecting the space to its surrounding environment and programmes. However, from the futur (fiv 141). The taffer new opportunities and situations are prare pedestrian orientated.

On the South-West of Rochor, there is an existing commercial share Mall and MRT Station. With the new residential and commercia development taking place, it will provide an opportunity to extend the

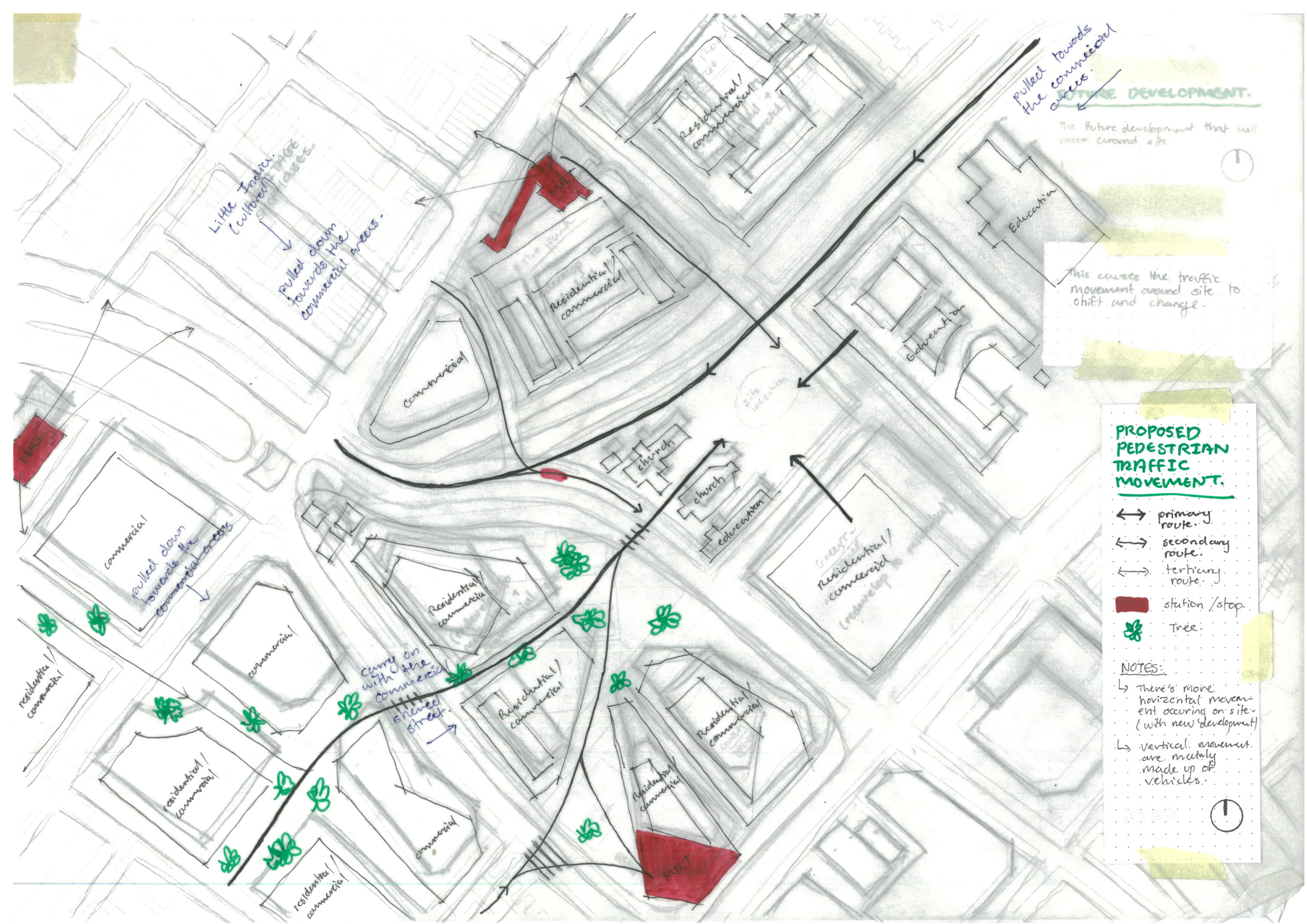


A revised programme layout was attempted to accommodate the

dominant horizontal movement occurring on site (fig. 142). Secondary

routes were also included to cater the vertical movement of pedestrita

with the primary the Canal. The framework was rearranged to wo

and monotonous layout which could be developed further.

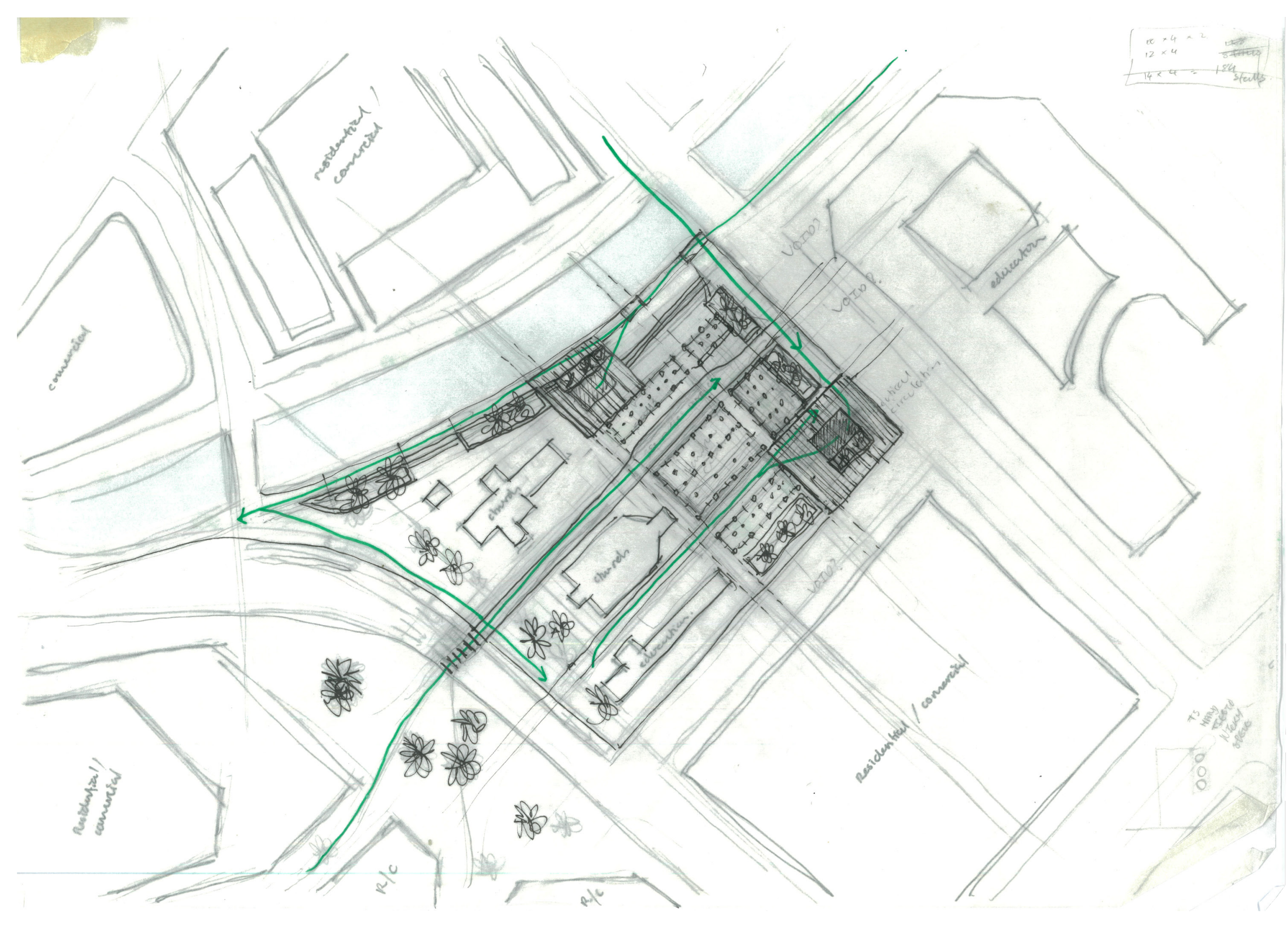


According to the existing bus timetable, there are 8 buses coming and going every hour. To cater for this, the bus terminal design will require a minimum of 3 bus stops.

An attempt was made to conceptualise the programme layout below ground, where buses can loop around to pick up and drop off passenge turning radius of $6.0 \mathrm{~m}$ (Land Transport Authority, 2011). With size constraints, this bus route would not maximise the use of space The also limits the bus terminal

From comparing the initial programme layout (fig. 131 - 132), it is evide that both floor plans lack in a cohesive architectural language. The above to be more fluid.

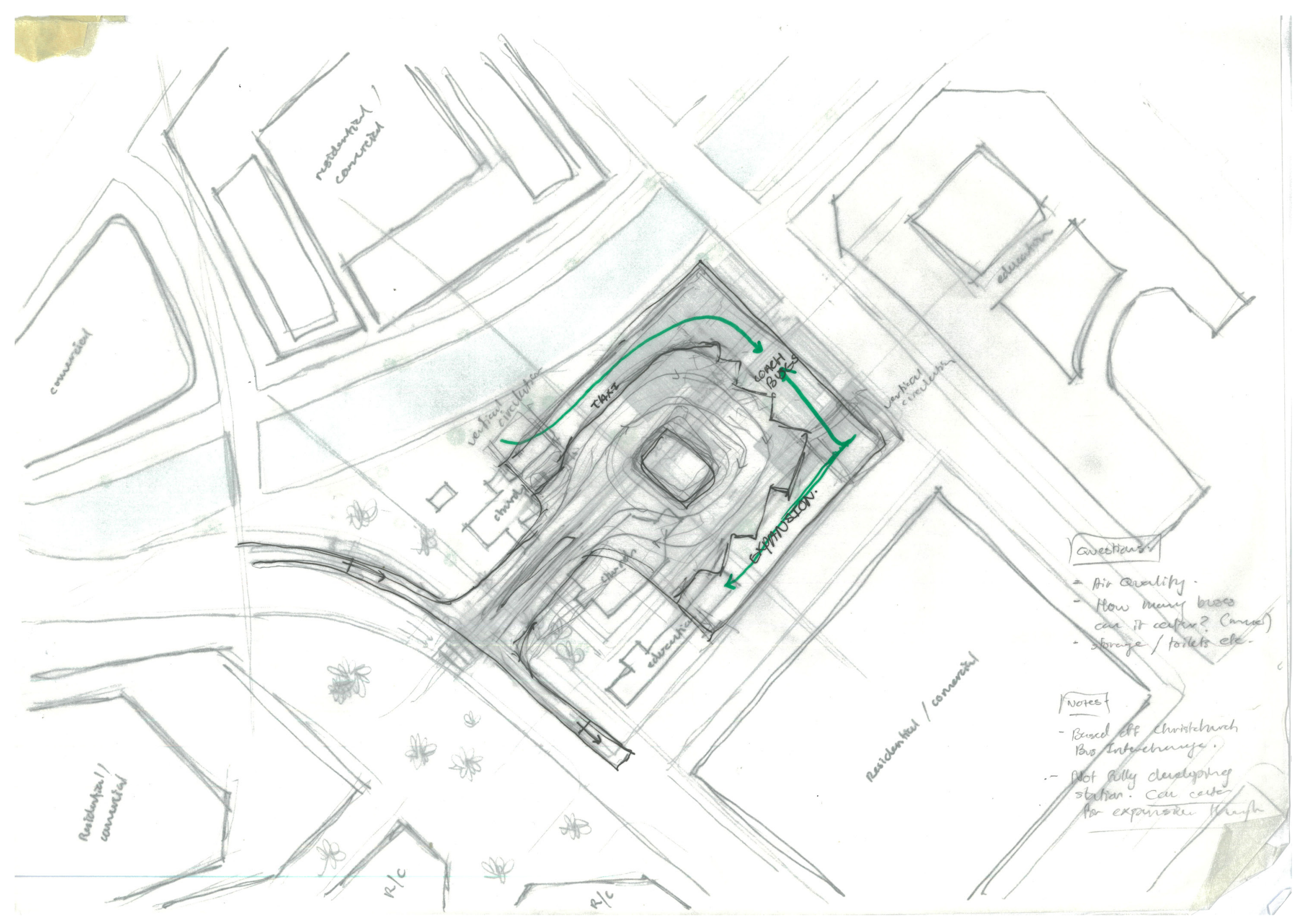


To develop a cohesive architectural language in both above and below

ground, the framework was revisited. Initially, the framework followed

this, $2.5 \mathrm{~m}$ grid was expotonous repetition (fig. 131). To reduce

of the framework can be offeet - breaking un the repetition while stains

true to a grid structure (fig. 144).

The developed framework will be implemented in both above and
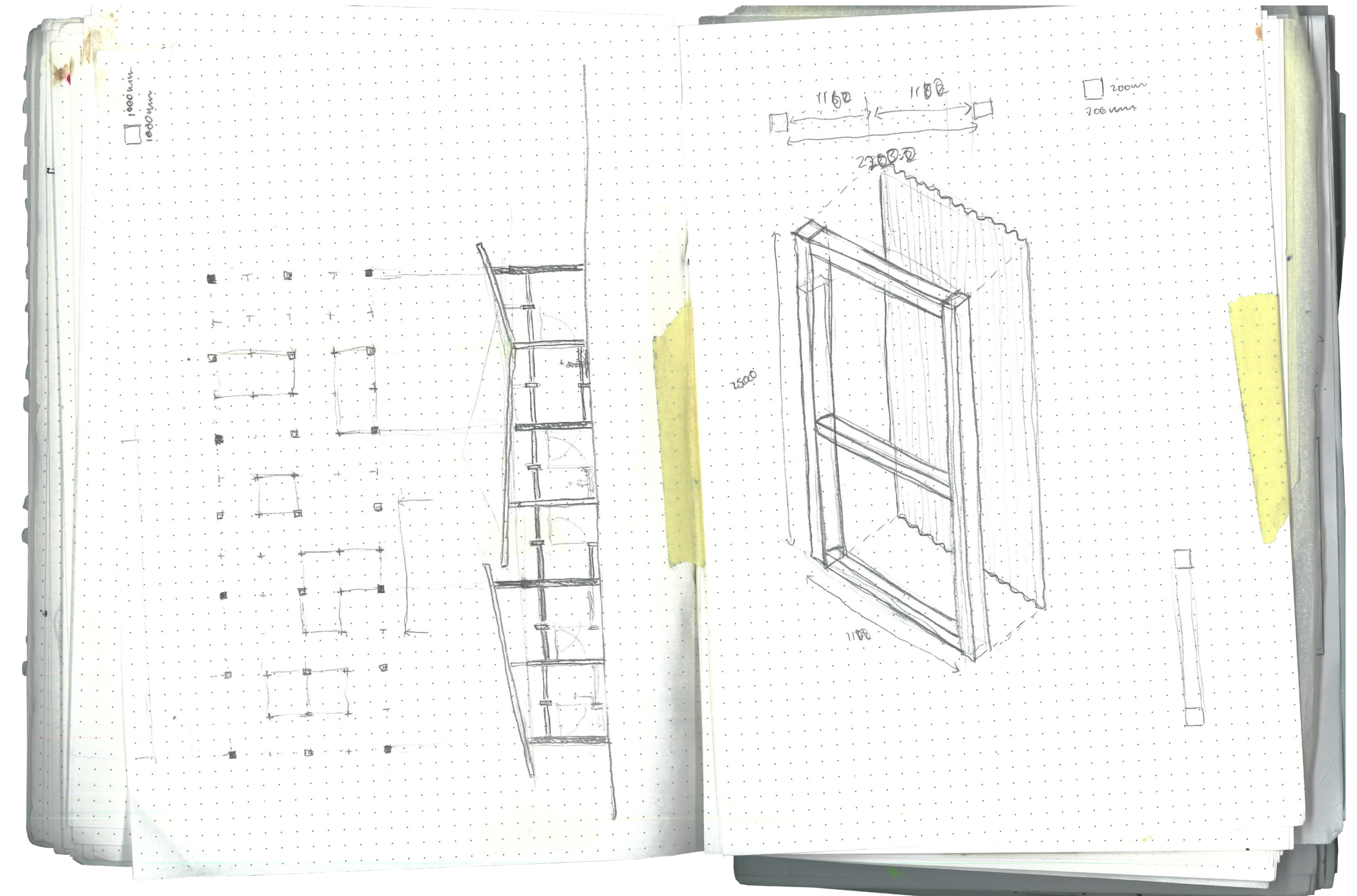

Th 


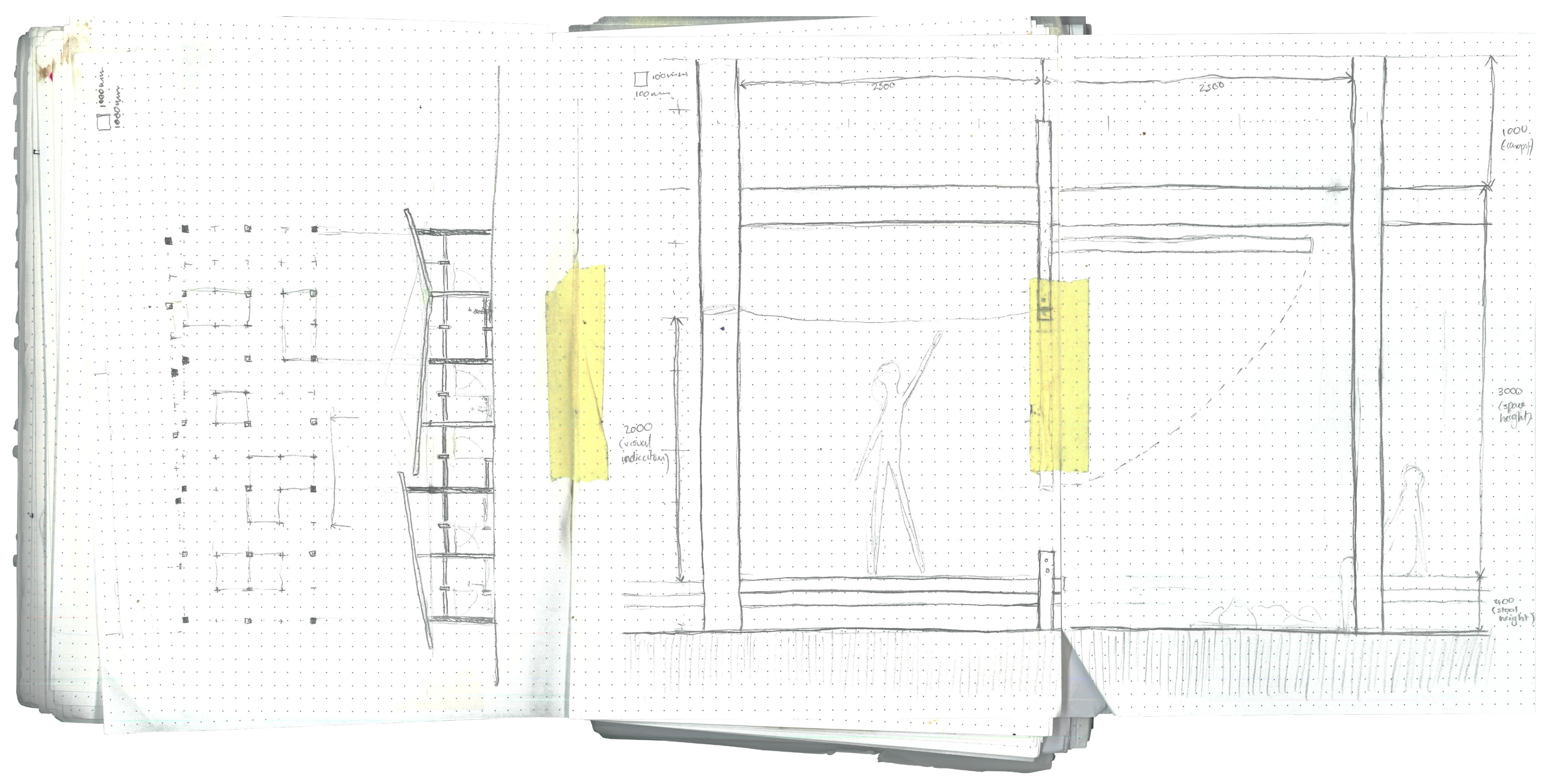


Based on the developed framework, the programme layout for above and below ground were revised (fig. 146 - 147). The commercial share street was extended to allow more pedestrian movement front the sou movement occurring in the middle of the site.

The horizontal movement is supported by secondary routes that accommodate for the vertical flow The fir specific areas to avoid obstructing these pathways. From doing this, the secondary routes perform as view shafts to the canal - pulling pedestrian into the marke

One of the pedestrian access to the bus terminal was relocated, as it was initially placed in the middle of site (fig. 131). With the new proposed pedestian movement, it is more ideal to have the entrances III areas that have easy access and large horizontal movement. The pedestriar access now lies where both horizontal and vertical movements intersect (fig. 146); thu accommodating a larger pedestrian surface area.

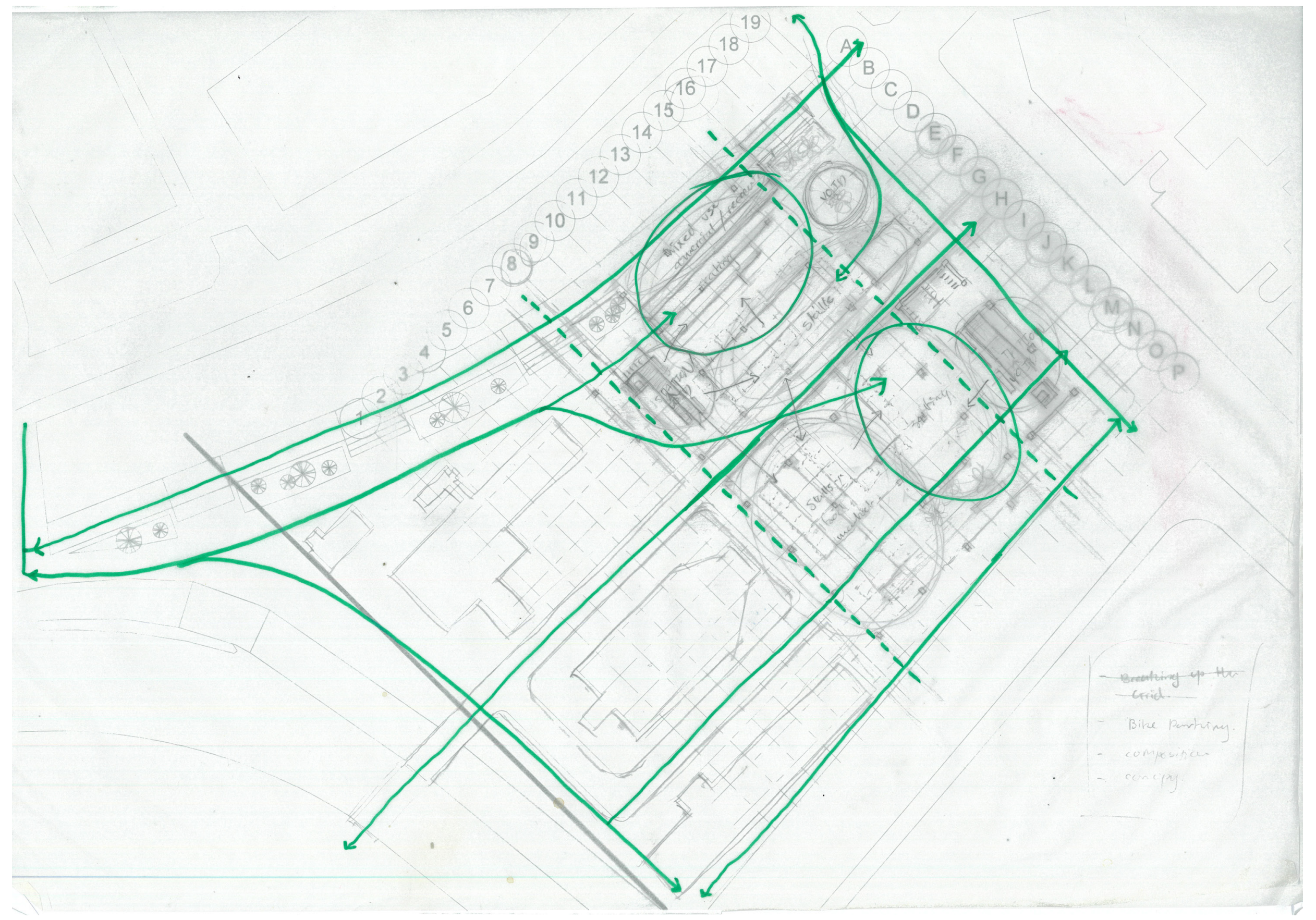


When pedestrians enter the bus terminal, they are guided towards the middle, where the information desk and ticket centre are located. This is supported by the developed framework which is also implemente Gatherins spots for ventors and the wider community fis 147).

Initially, there was a limited quantity of bus stops in the conceptual design, which would constrain the terminal from future development and expansions. When the below ground layout was revised, this was bus terminal to host public transport buses in the future.

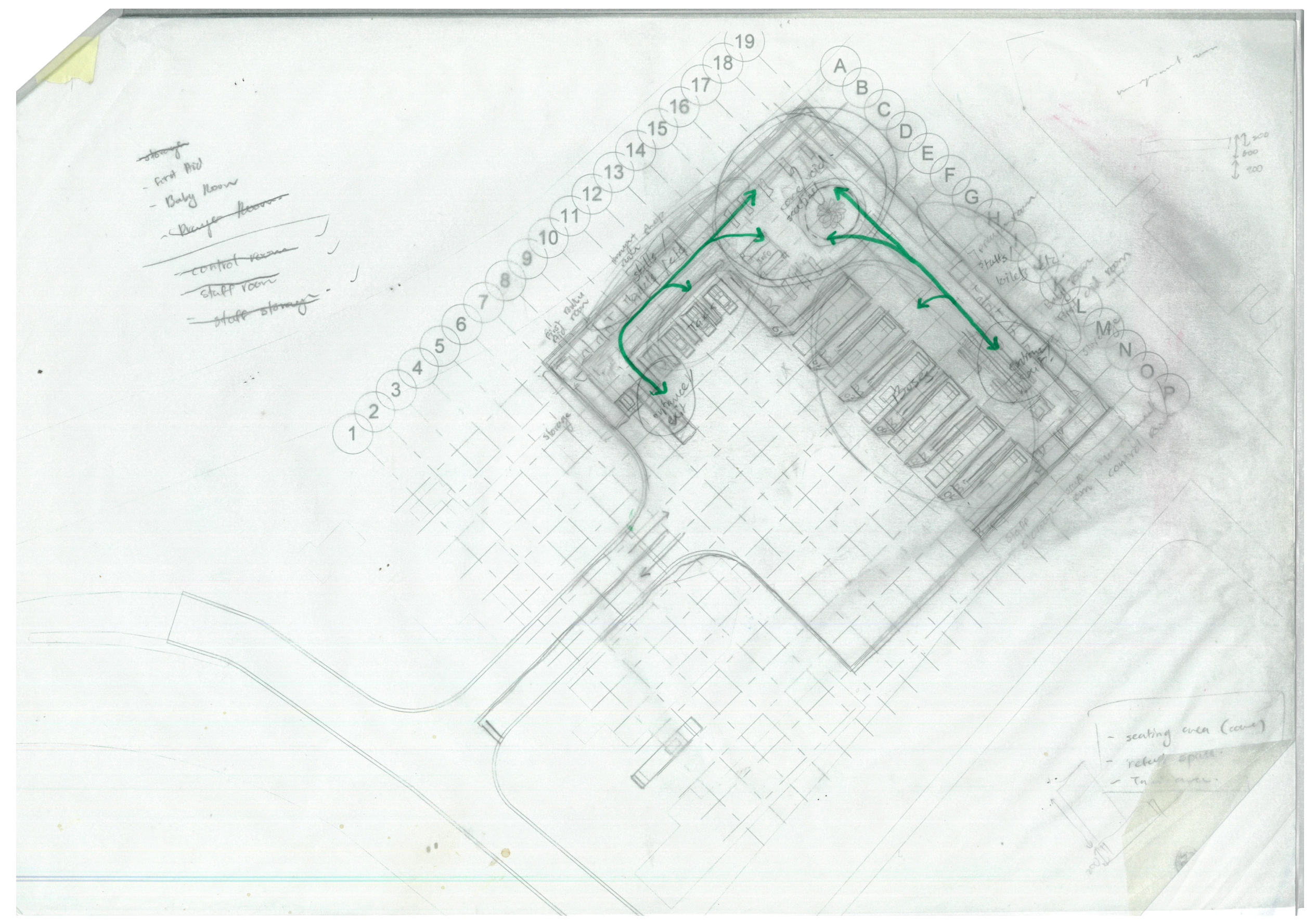


In the conceptual design, the courtyard was originally triangular to work (19) hes not flow with its surom with Rochor Canal the courtyard was revisited. Gradual steps we co dded to allow pedestrians to look down to the canal, as well as up to the market - creating a visual connection between the two (fir. 148). The teps could a loo be used as a seating and resting area, which encourages the community to gather.

The original screens of the framework finished at floor level, whic aised the issue of pedestrians overheating. To mitigate this, the screen and roots of the framework were raised and angled - facilitating cros entilation throughout the site.
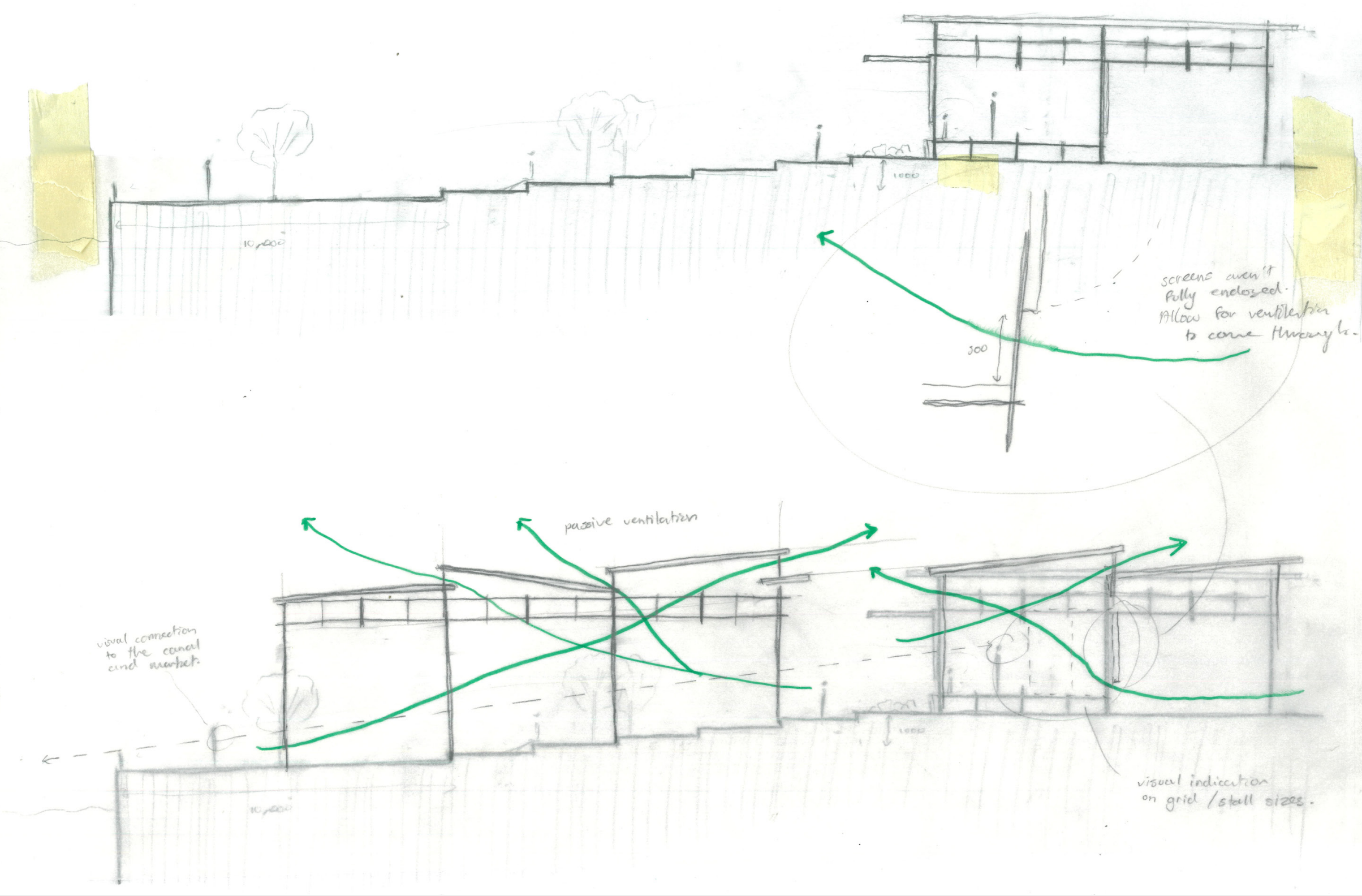
Rochor is surrounded by various historic shophouses that once hosted the majority of Singapore's local trades. Due to the rapid economic growth, this was slowly phased out. For this research investigation, the canop pitch can be manipulated, to reflect the trading history in a contem manner (fir 149). This experimentation began in the preliminary desion phase - where it failed to protect majority of the site from Singapore's climatic conditions (fig. 40 - 47). For this phase, the form will be furthe developed and explored to improve these conditions.

Iteration One:

Large roof panels were pushed and pulled to create various levels. Voids were added to let more natural hight in.

Iteration Two:

The roof panels were sliced to imitate the size of the shophouses. The eamopies above the bus termintal were kept the sarre to reflect the different programmes underneath. More voids were added to let natur light in. This canopy appears to be overwhelming and disordered.

Iteration Three:

(7) Vaious rod differences between the shophouses

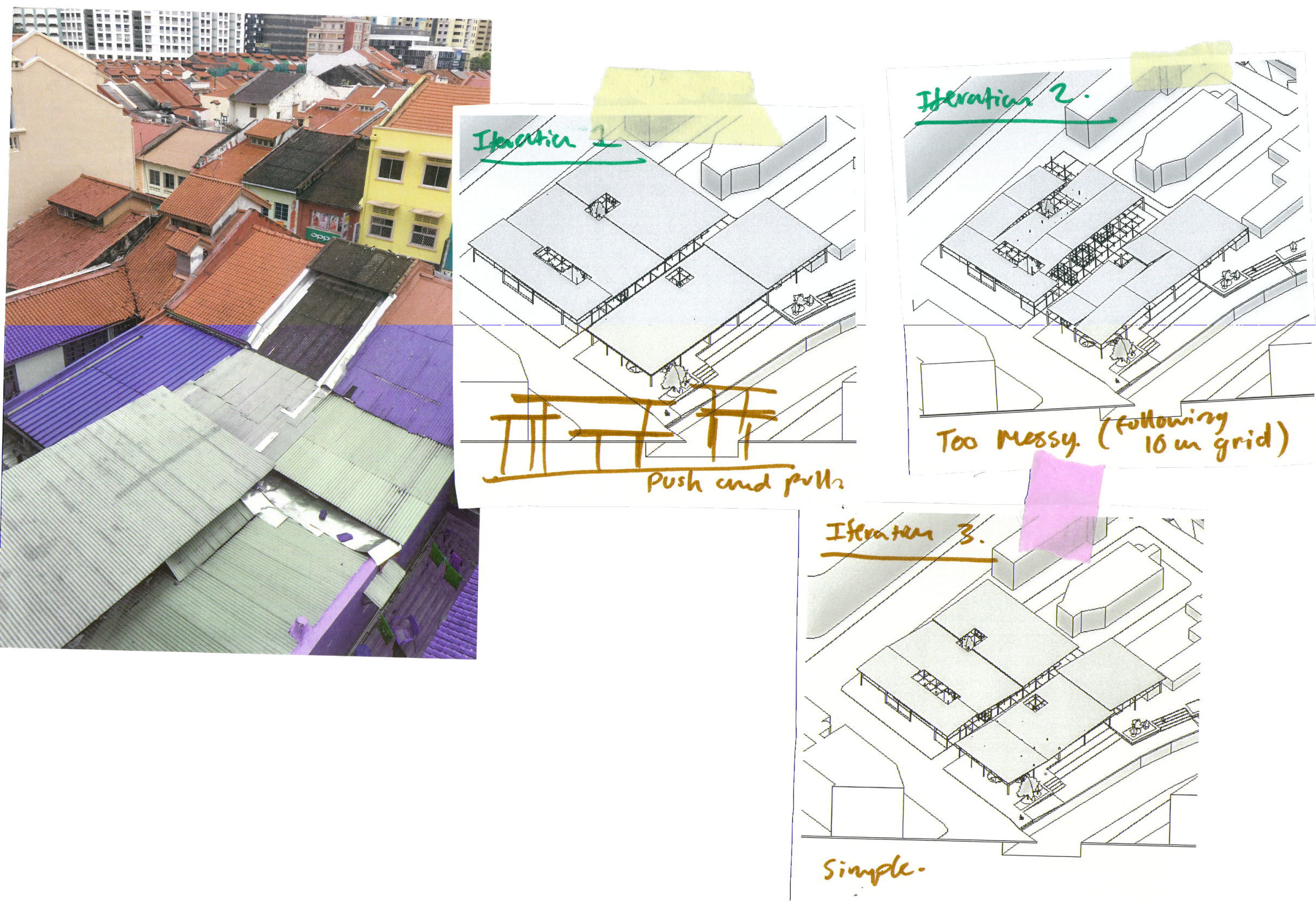


Iteration Four:

Were introduced back to the canopy in a simplified manner (fig. 150)

Iteration Five:

政 and placements However the canony still appeared disorganised and place - clashing with the framework underneat

Iteration Six: were altered to allow each roof panel to be the same as the one adjacen This creates a more coliesive canopy design that does not clash with the framework and its surroundings.

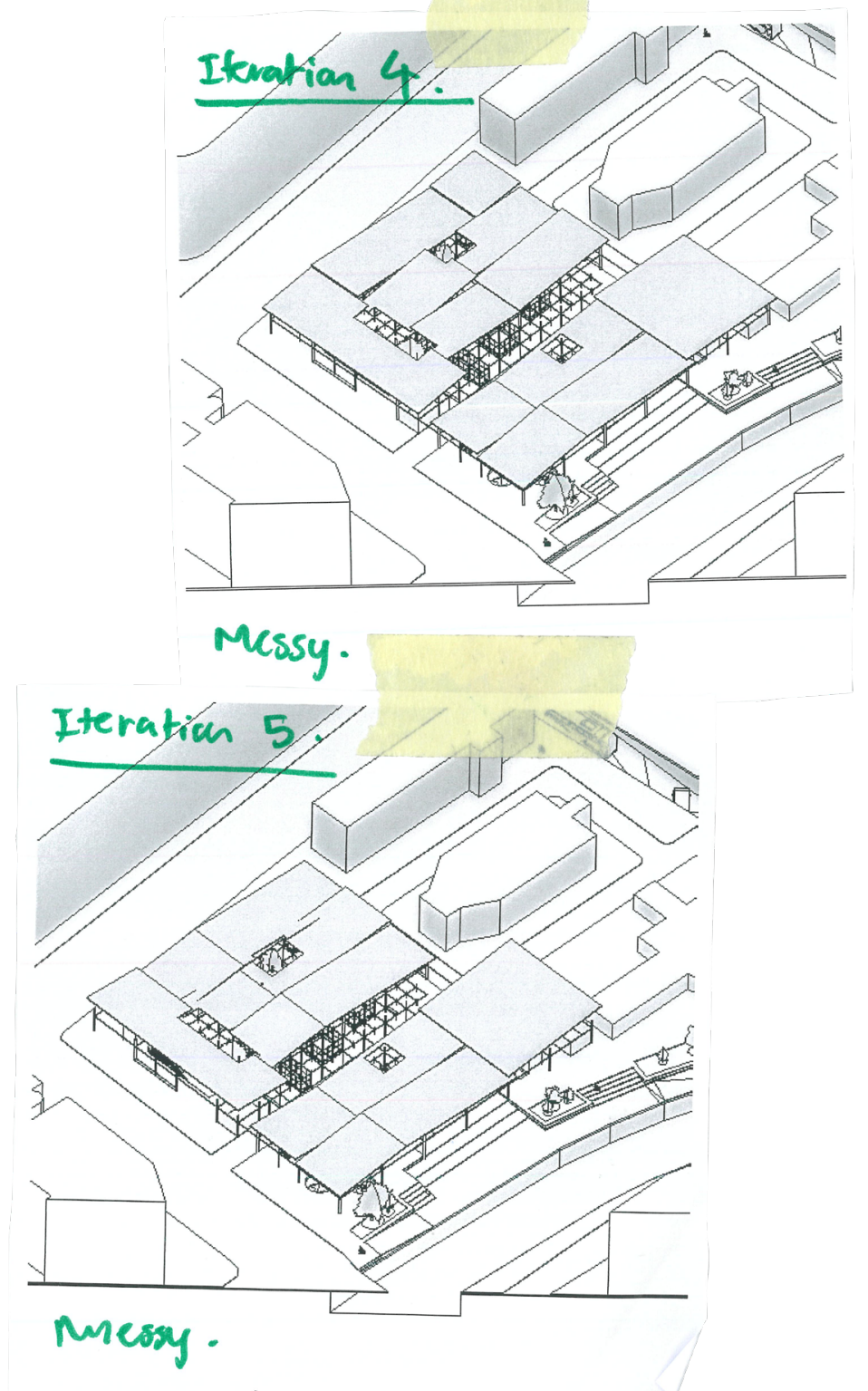

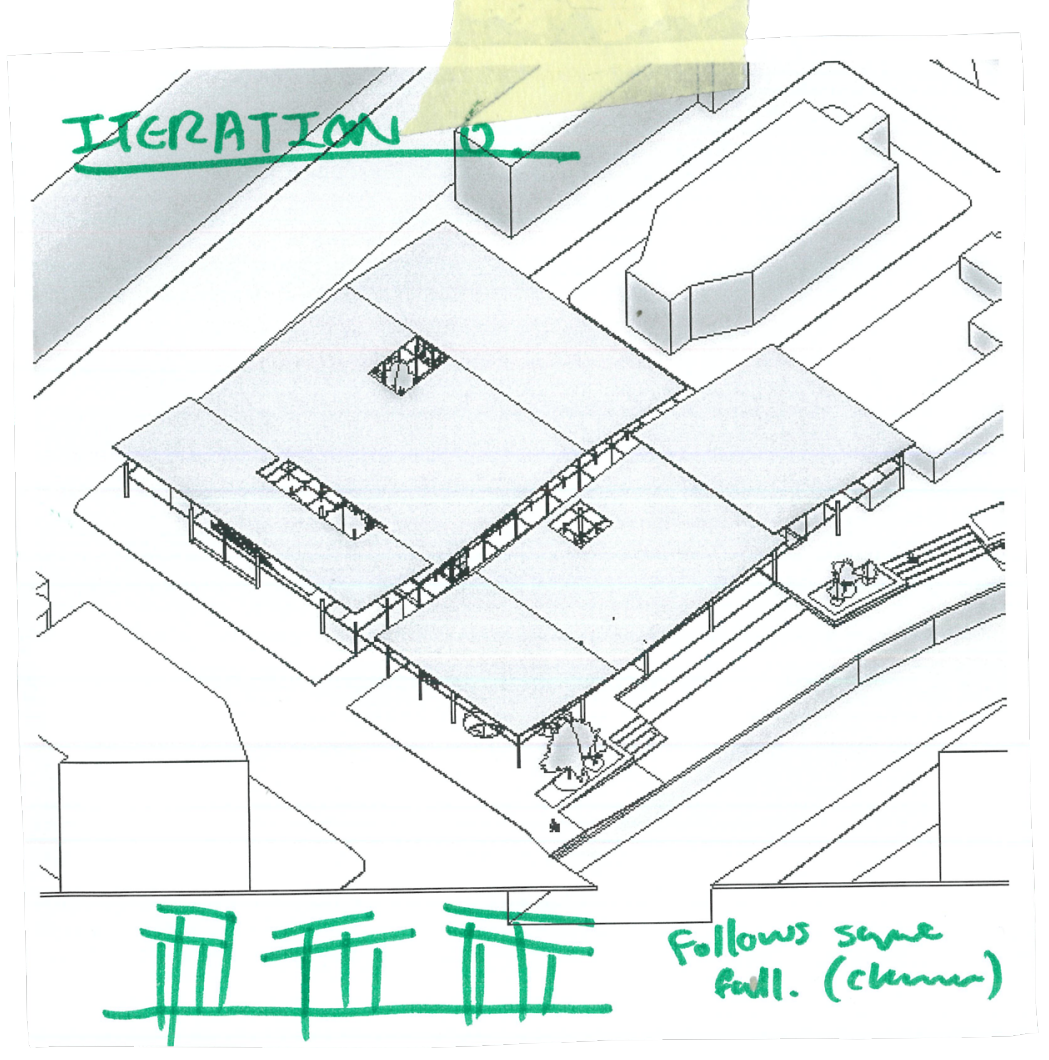




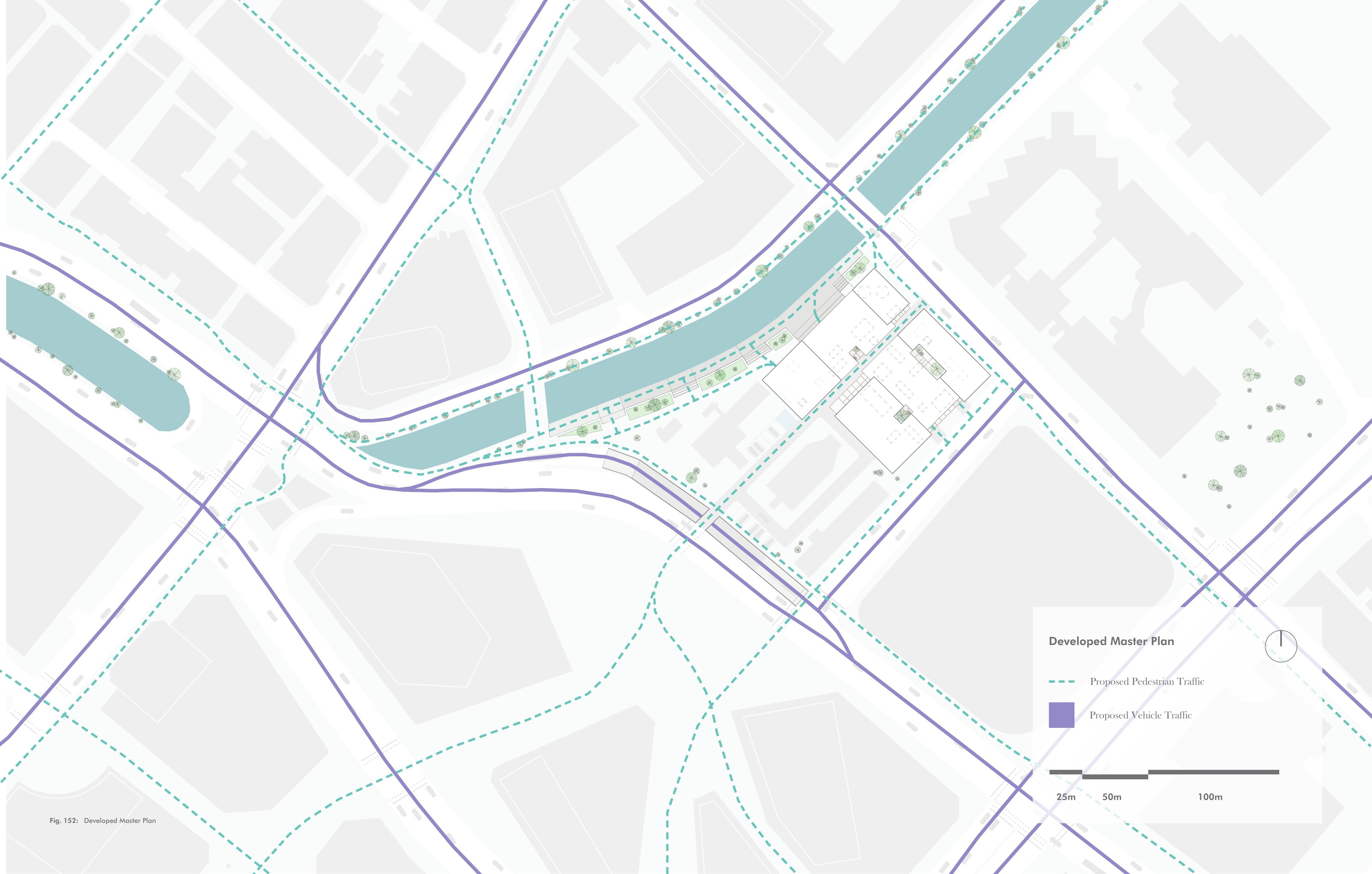





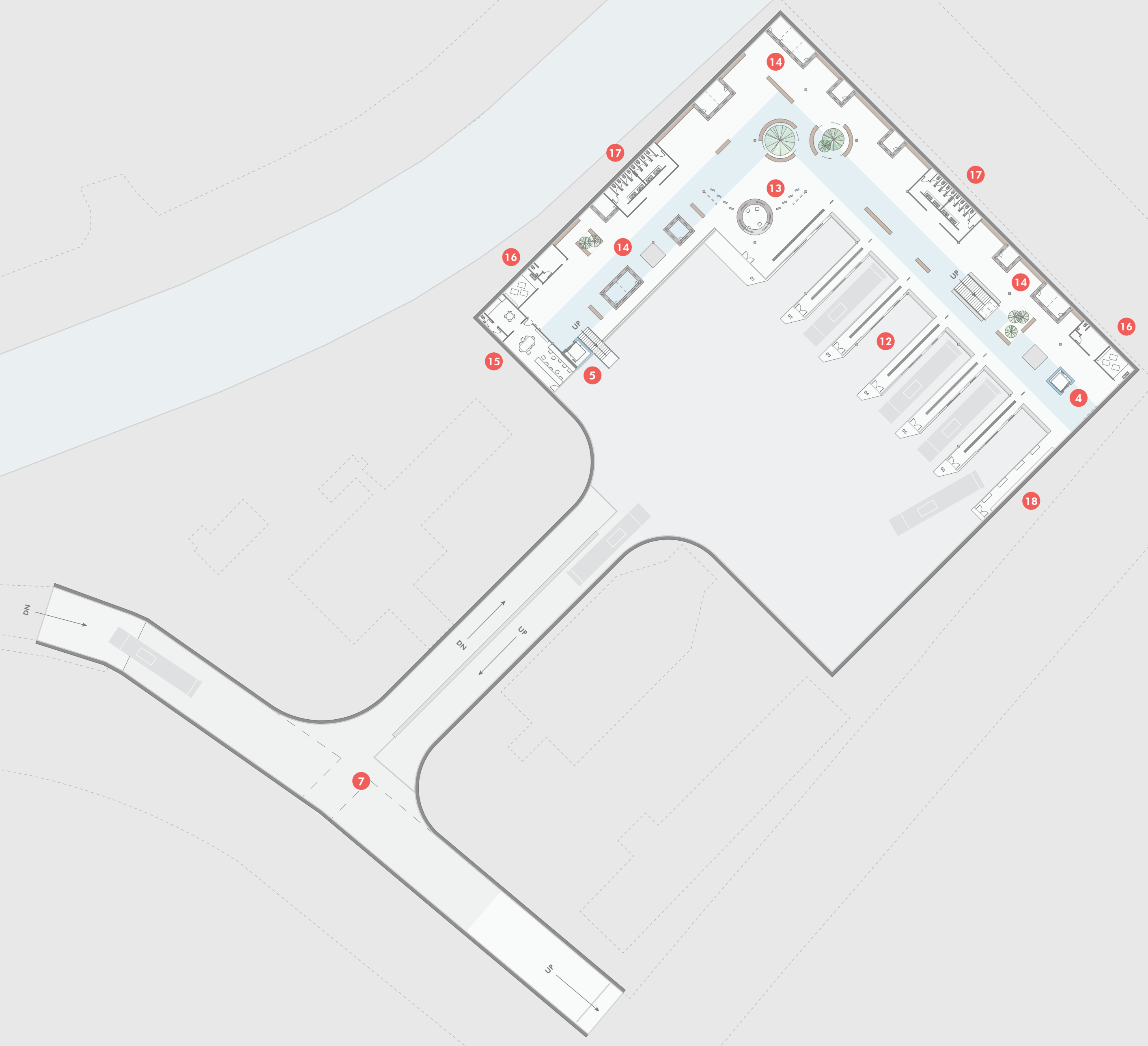

Developed Below Ground Plan

(4) East Bus Station Entrance

5 West Bus Station Entrance

(7) Vehicle Ramp

(12) Bus Stops

(13) Information Desk \& Ticket Centre

(14) Kiosk

(15) Management Office \& Staff Room

16 Prayer Room \& First Aid Room

(1) Toilets

18 Lockers / Storage Area

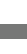


(1) Flexible Framewor

5 West Bus Station Entrance

(6) Taxi Parking Area

(7) Vehicle Ramp

8 Our Lady of Lourdes Churcl

(12) Bus Stops

(14) Kiosk

(15) Management Office \& Staff Room

(17) Toilets

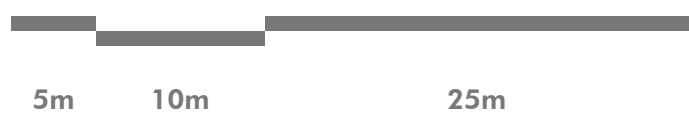


(1) Flexible Framework

2 Courtyard

(4) East Bus Station Entrance

(11) Rochor Canal

(12) Bus Stops

13 Information Desk \& Ticket Centre

(14) Kiosk

(18) Lockers / Storage Area

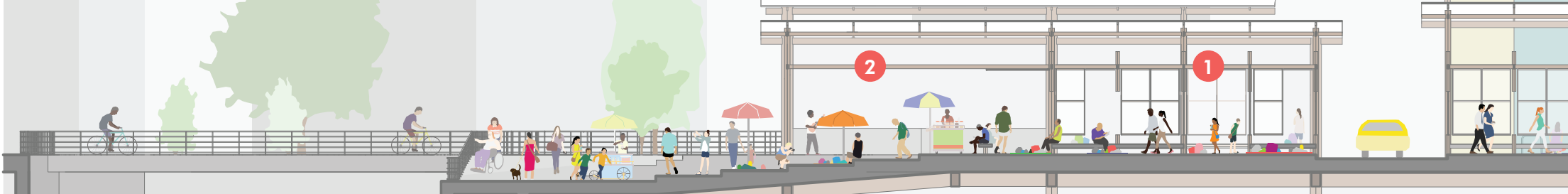
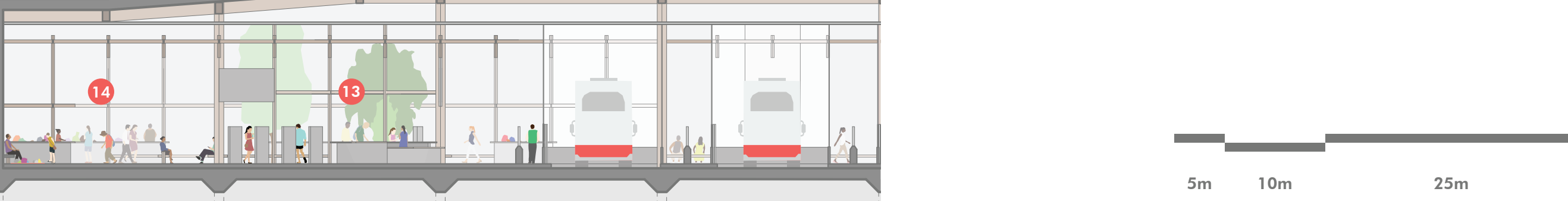

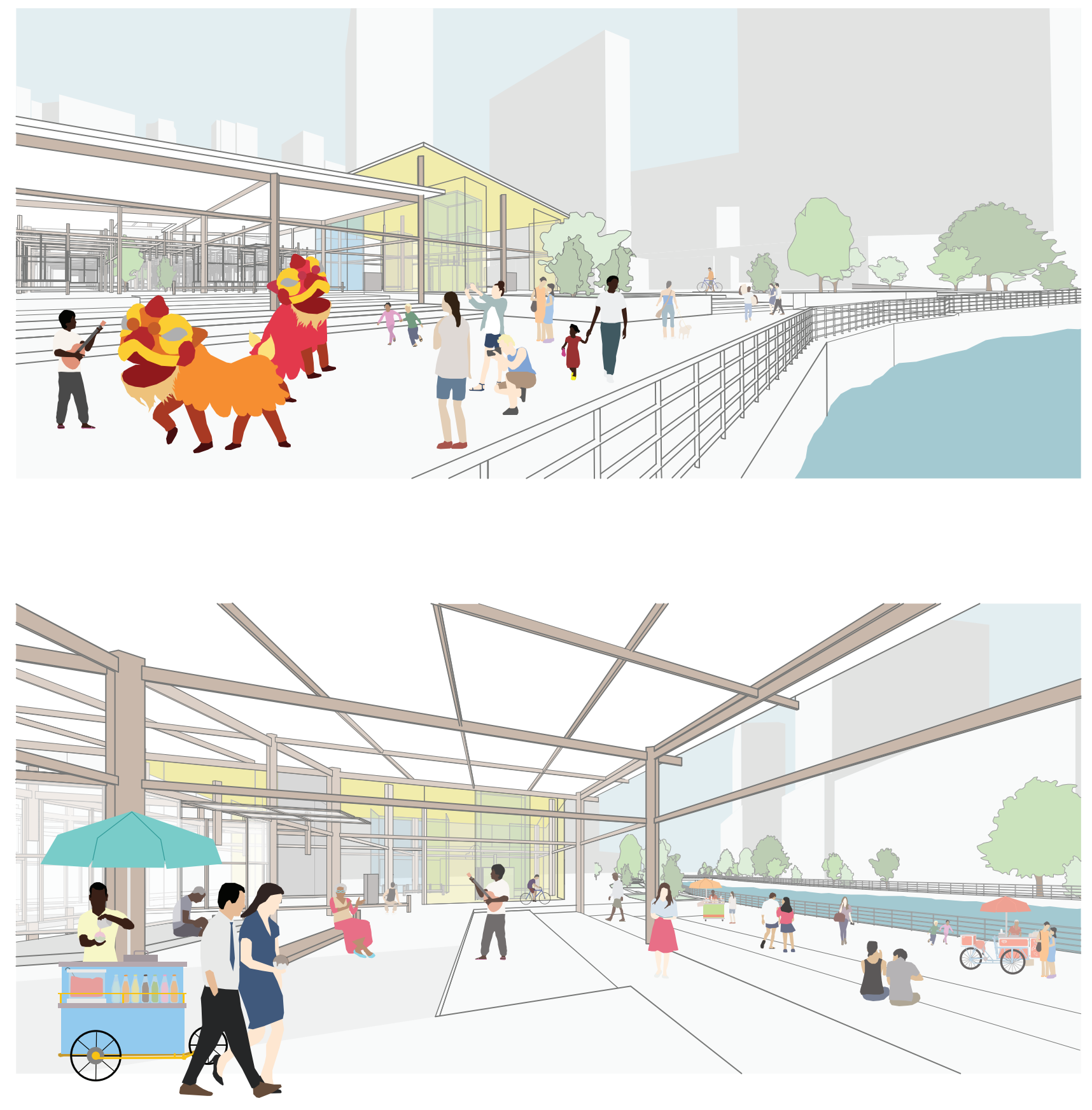

\author{
The Courtyard \\ Like the preliminary design, the courtyard is considered as the main \\ "trap" for this marketplace. It was developed to allow pedestrians to look \\ into the market from the canal - pulling in passers-by. Gradual steps \\ canal, encouraging pedestrians to use the space as a pit-stop and resting \\ The courtyard was further developed to make it more accessible for stall \\ cers athen \\ extend the marketplace beyond the architectural framework.
}



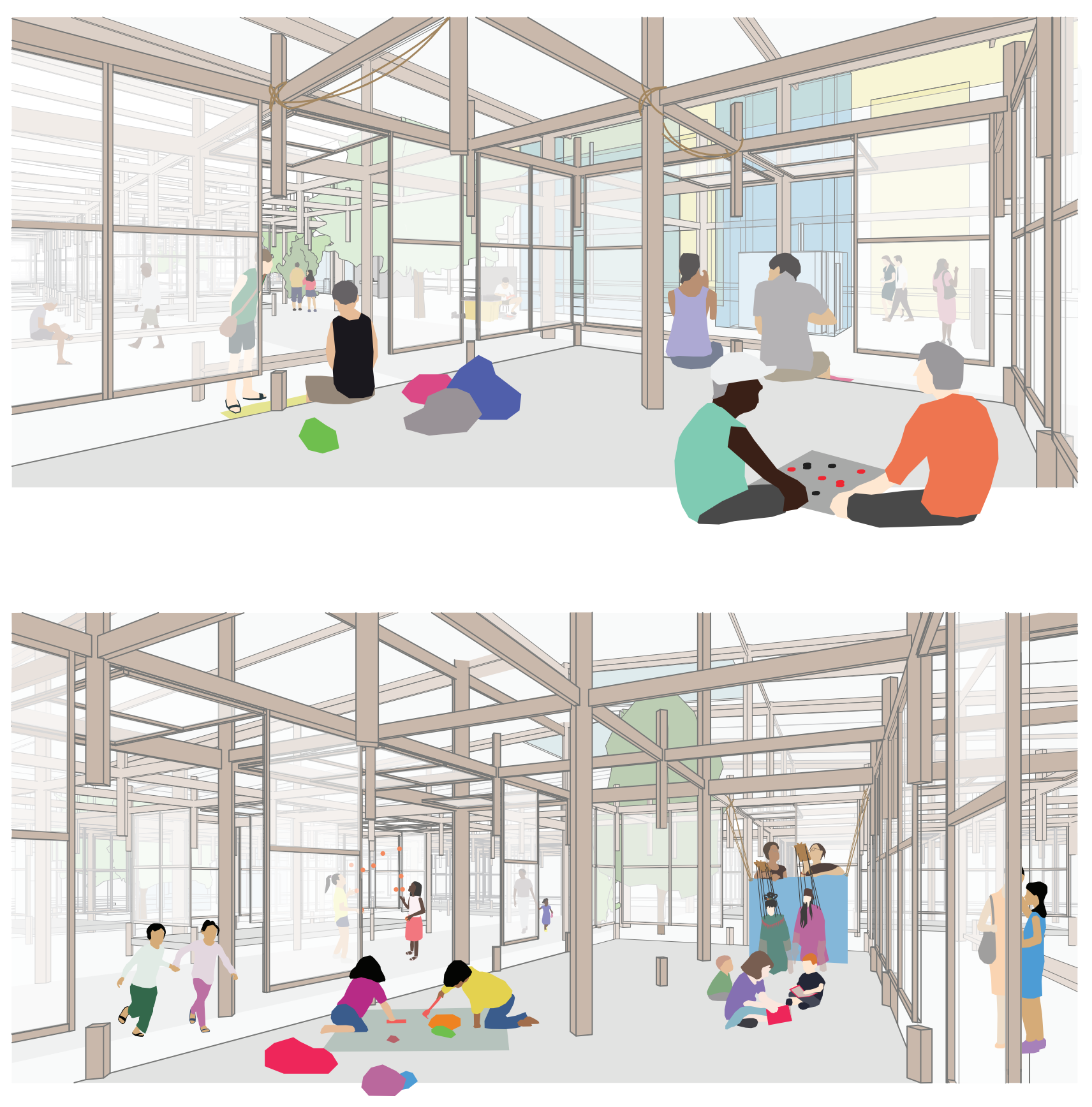

\section{The Framework}

The framework can be used for multiple public and semi-private programmes to accommodate both the vendors and the wider community. These programmes includes educational spaces as well as individual market stalls (fir. 159 - 160). It was developed to address the isue of pedestrians overheating - by shortening the screens and adding of fils to the canopy. From doing this, it encouraes more cress entilation to take place above ground (fig. 148).

The framework is made up of steel beams and columns that are concealed with timber She This and lohtweicht ther fin This creates a lighter and more open atmosphere for pedestrians to walk hrough and use.

\section{The Bus Station}

Two access-ways on the East and West side of site allows pedestrians to enter the bus terminal below ground. As they enter, they pass by the bus stops, seating areas and kiosks (fig. 161 - 162). The blue concrete paving and ticket centre are bount

The framework was implemented below ground as a means to maintain the same architectural language as the above ground marketplace. This as well as a gathering area for the wider community to sit, relax, wait and socialise (fig. 164). 

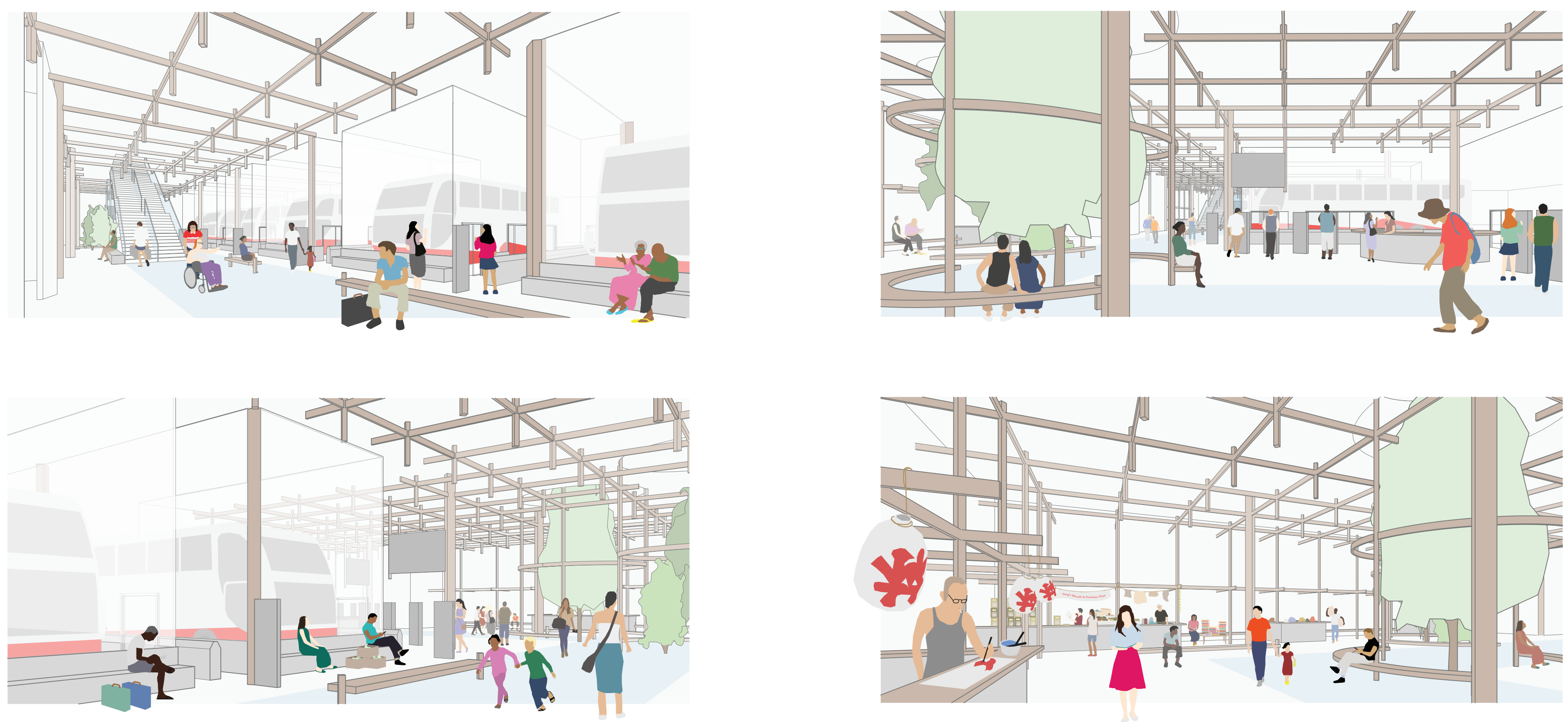


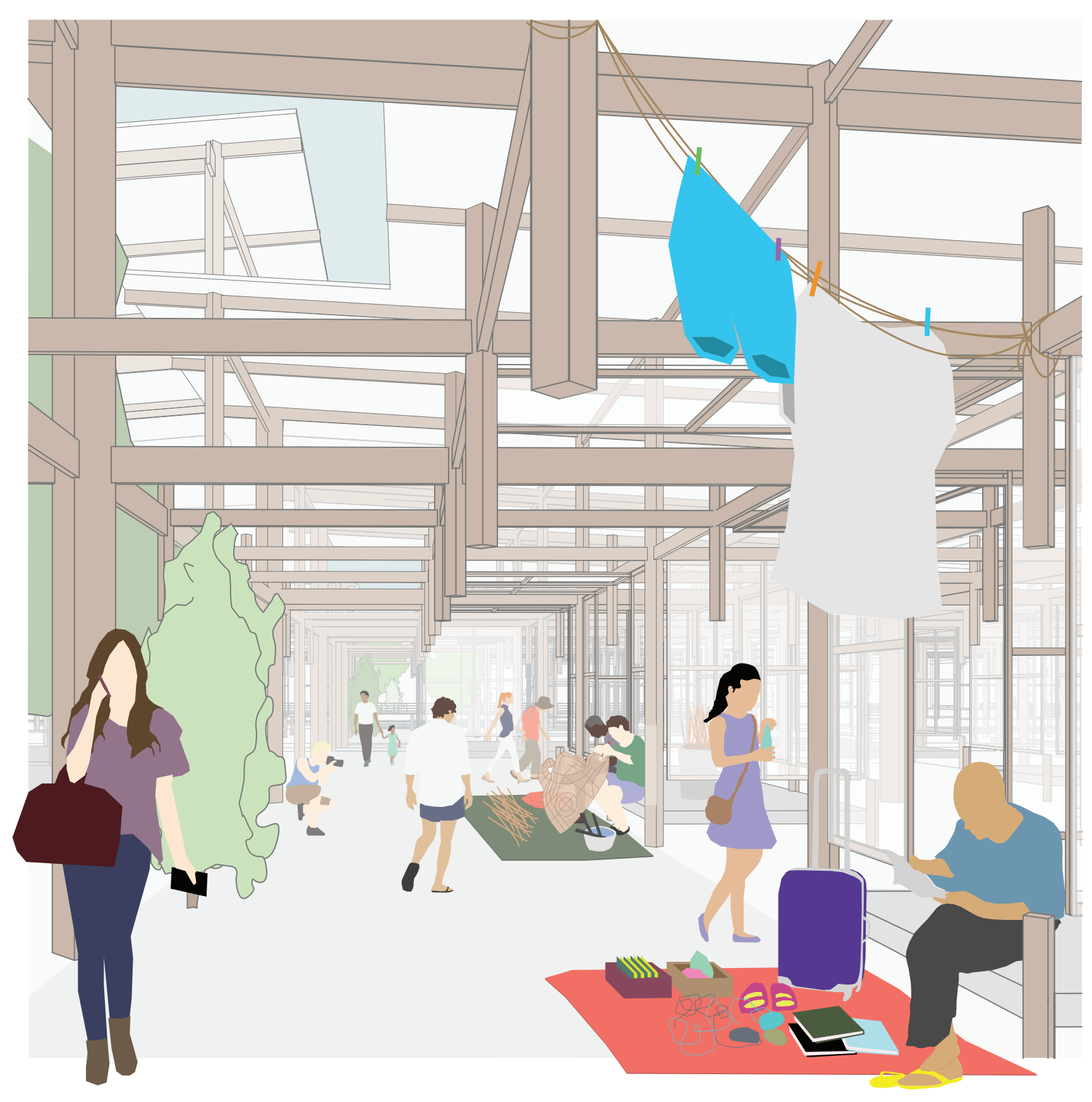

From focusing on developing the preliminary design and addressing the issues aforementioned, a final scheme was executed. It was a response to the Rochor community's evolving surroundings as a wav of allowing the local trades to be conserved and integrated with the future development.

The final design was developed to become a destination for pedestrians in Rochor. It provides amenities that encourage people to stop and stay conditions, a space to socialise and engage with the wider community, as well as a space to sell and buy goods.

Even though it is a public space, the final design could have investigated the financial feasibility of the proiect - to ensure vendors have the ability to afford to lease spaces like this. If this were to be implemented, factors costs. 

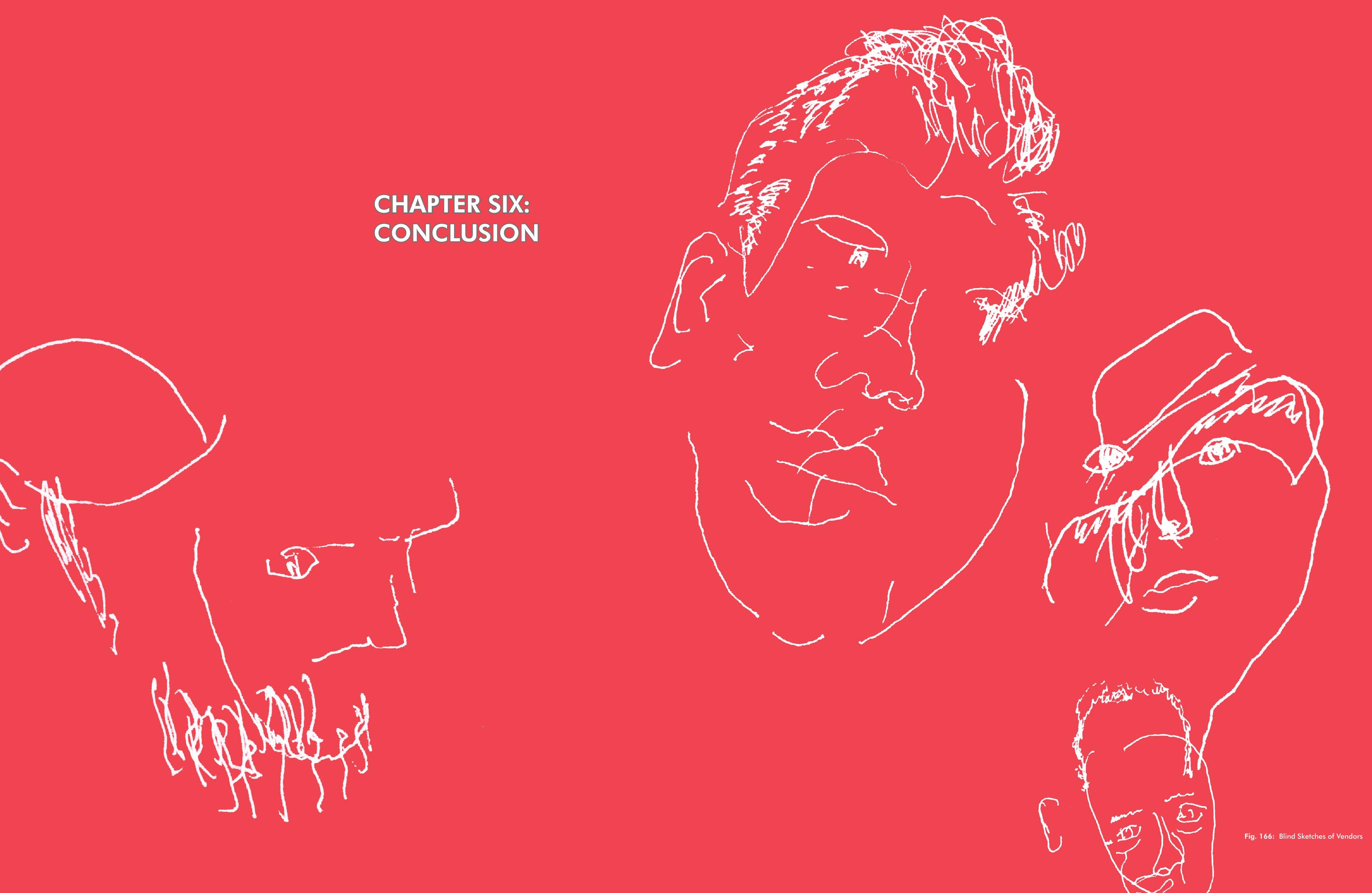
Over the years, Singapore has been performing as a global city in the international economy (Yuen, 2005). Its rapid economic growth - allowing the city state to givelly develon and expand (Yuen, 2005 . Consequently, older buiding a tivies and taditions are vanishing to make way for new developments - rasing the maior issue of beconing a highly modern city that is evermore faceless and lacking in cultural identity (Yuen, 2005). The aim of the research investigation was to explore how the vanishing trades of Singapore can be conserved an integrated with its present and future developments. Certain strategie were used to address this issuc.

The direction of this research investigation was indicated by the literatur reviews. It provided a clear understanding of the different types of heritage - and how this is evoked through memories. These memories opportunity to engage with the community.

em develop social cohesion and a sense of belonging and identity Once the field research was complete, the information gathered was analysed and summarised. This informed the design process as the design guidelines were established. Tools such as sketching and digita modelling were used to explore the various design experimentation. the Sunct hevelop a design outcome which tested the int Johore-Express Bus Terminal.

The outcome of this research investigation addresses how architecture and social inclusion can be used to conserve the local trades of Singapore. Ideally, the next step for this research investigation would be to go back to Singapore and discuss the design outcome with the community. This will allow the community to participate and be more involved with the total design process. If the scope were to be broadened, the researc investagation could examine Singapore's housing issue as a means to strengthen the feasibility of the marketplace proposal - injecting more frequent and sustainable pedestrian volumes as a supporter of the loca community and their trades. From undergoing this, the thought, interests and memories left by the participants were obtained - helping

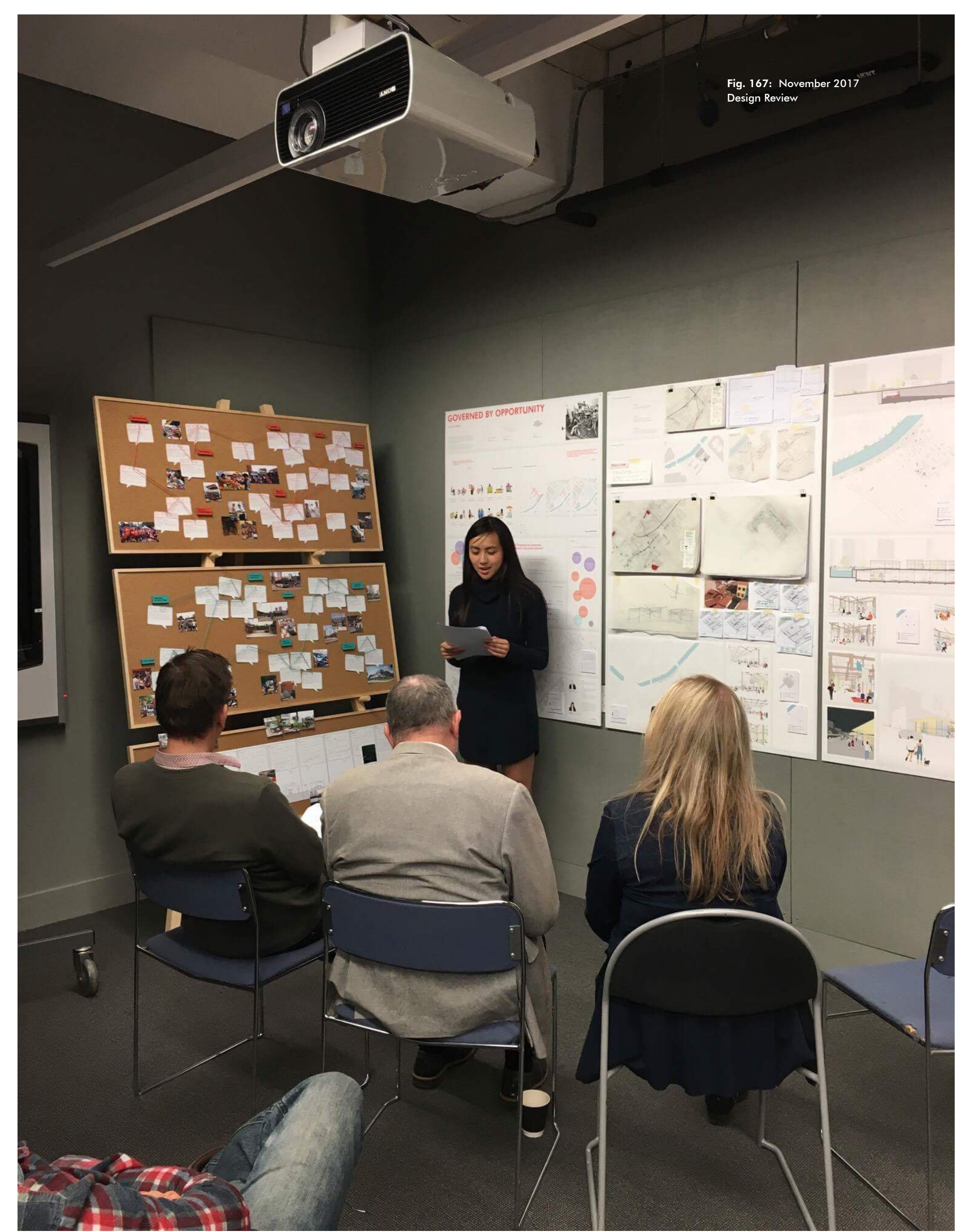


all(zone). (2012, September 28). SZL Market. Retrieved from all/zone): hitp:///www.allzoned
esignall.com/project/architecture/szl-market/

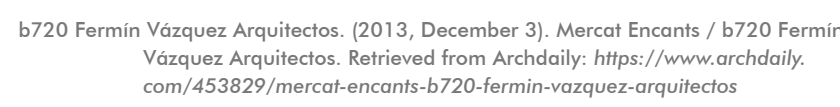

Bennett, J. (2007). Publications: Architectural Aerodynamics: Wind Design Guide. Retrieved

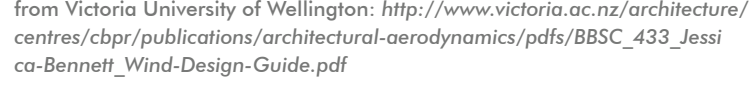

Brown, S. P. (2014, February 18). Process + Product. Wellington, New Zealand.

Carracedo, O. (2016). Ibid./ in the same place. California: ORO.

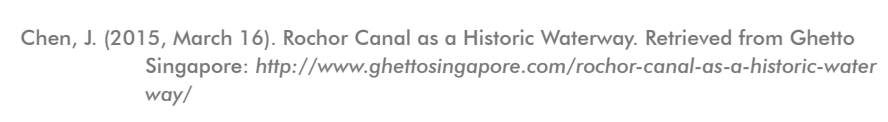

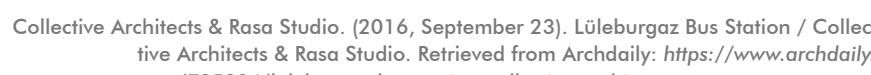
com/795804/Weburgaz-buss-station-collective architects

Harrison, R. (2010). Chapter 1: What is Heritage? Manchester, England.

Kwok, K.-W., Kong, L., Kuo, P., Kwa, C., Lim, W., Tan, B., \& Yoh, B. B. (1999). Introduction: Our
Place in Time: A Preliminary Reflection. In K.-W. Kwok, C. Kwa, L. Kong, \& B.

Land Transport Authority. (2011). Code of Practice: Vehicle Parking Provision in Developmern
Proposals. Singapore.

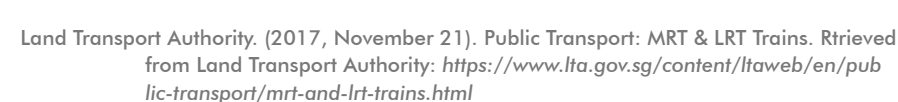

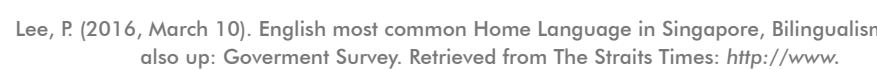

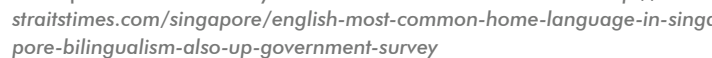

Lowenthal, D. (1979). Environmental Perception: Presenring the Past. Progress in Human

Melcher, K., Stiefel, B. L.., \& F Furest, K. K. (2017). Community-Built: Art, Construction, Preserva
tion, and Place. New York, USA: Routledge.

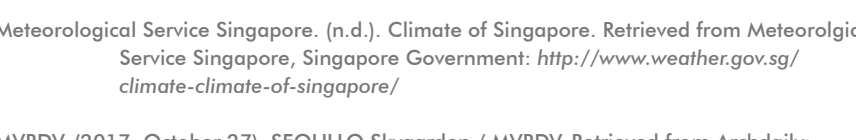

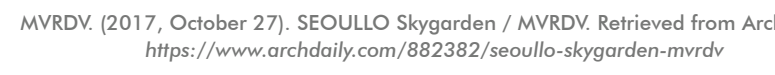

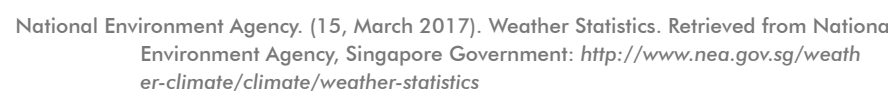

New Zealand Trade and Enterprise. (2005, October). Costs of Setting up an Office in Singa

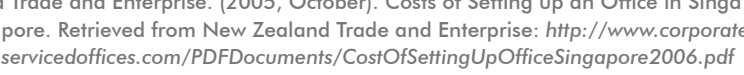
NZTA. (n.d.). Urban Design Principles: Pedestrian Bridges. Retrieved from NZ Transport

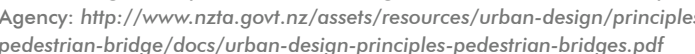

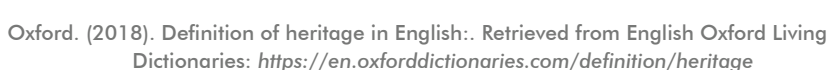

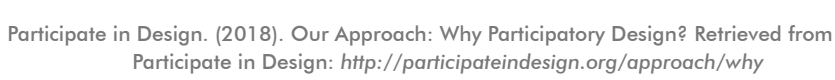

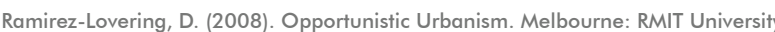
Rapoport, A. (1969). House Form and Culture. Englewood Cliffs, New Jersey, USA: Pren
tice-Holl. Save Sungei Rood Campoign. (2017, June 19). Robinson Petang 2.0: Retain Livelihoods,
Revitalise Histor/ Singapore Schneider, P. (2014). Berlin Now: The City offer the Wall. New York: Farrar, Straus and Seog Be Seog and MMOA. (2017, August 28). Chosunook The Oak / By Seog Be Seog + chosunook-the-ock-by-seog-be-seog-plys-mmoa-studios

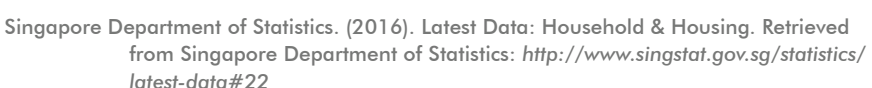

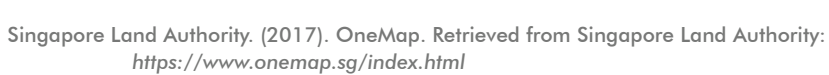

Stiefel, B. L., Faurest, K., \& Melcher, K. (2017). Introduction: Defining Community-Built. In

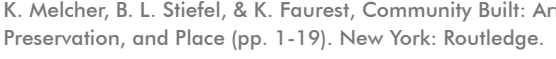

Sum, G. (2013, June). Sustainable Land Transport System: Singapore's Experience. Retrieved
from Sustainable Development: Knowledge Plafform: htps:///sustainabledevel

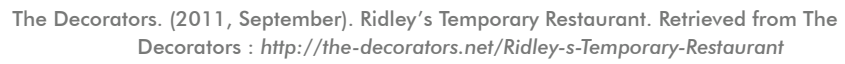

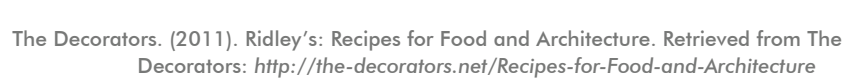

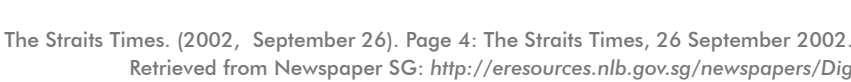

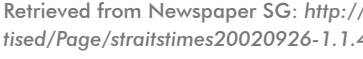

The Straits Times. (2017, May 19). Politits: Singaporo's approach to diversity has created
adistinctive identity ycross ethnic groups: PM Lee Hsien Loong. Retrieved from

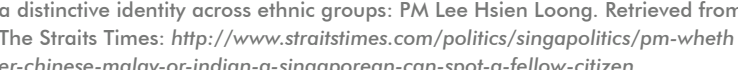

Furner, J. E, \& \& Fichter, R. (1972). Freedom to Build. New York: The Macmillan Compan

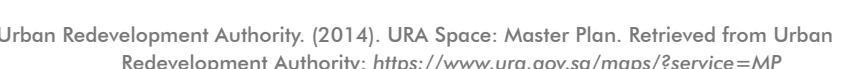
Urban Redevelopment Authority. (2017, November 30). Rochor: Overview. Retrieved from

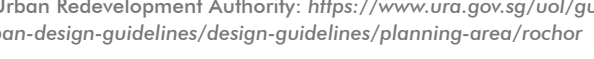

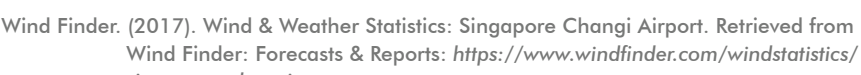
singopore_changi

Yuen, B. (2005). S 


\subsection{List of Figures}

Note: Figures without references are author's own images Image was presented in the November 2017 design review

Fig. 01: People Gathering

Fig. 03: Singapore's $\mathrm{CB}$

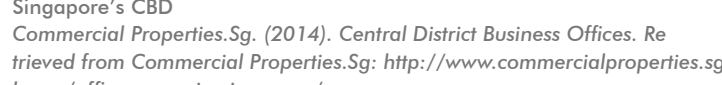

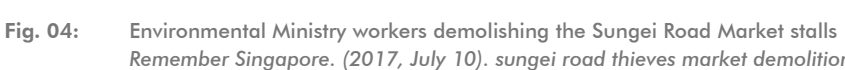
1982. Retrieved from Remember Singgopore hthps
org/2017/07/10/sungei-road-thieves-market-his

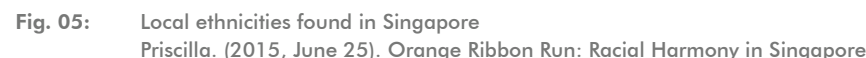

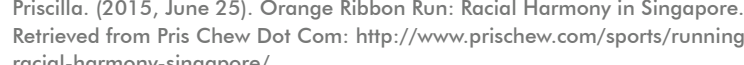
Sunge Road in the 1970

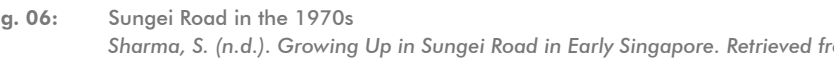
THE PRESURAR, GOOGLE DOODLE HONORS ALESSANDRO VOLTA: hHP://

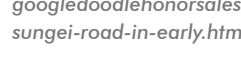

Fig. 08: Sungei Road Marke

Zoccheus, M. (2017, February 14). Decades-old Sungei Rood flea market to shu

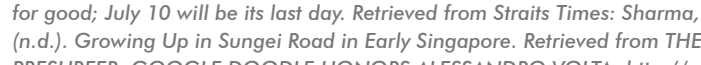
TE DOODLE HONORS ALESSANDRO VOLIA: htPP://googl doodlehonorsolessar
rooddin-early hitml

Fig. 09: Development of Rochor"

Fig. 10: Public Consultation in May 200

Fig. 11: ILUP Diagram

Fig. 12: Methodology Diagram*

Fig. 13: World Map of Existing Case Study Location

Fig. 14: Entrance to Tampines MRT Station from Tampines Mall Wong, I. (2009, April 10). Just Beside MRT TStation, Retrieved from fickriver

ig. 15: Tom Jampines Bus Interchange

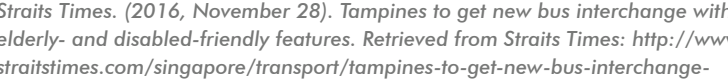

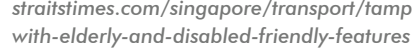

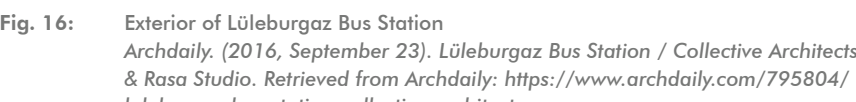

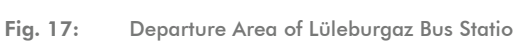

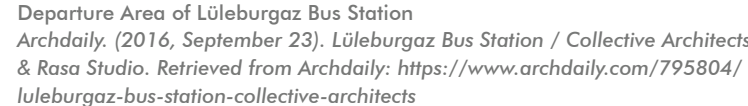

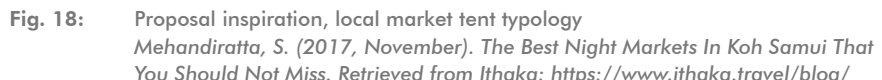

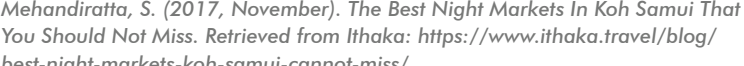

Fig. 19: Proposal inspiration, Deck Art Gallery, Singapore
SG Magazzine. (n.d.). SINGAPORE ART_GALLRY Deck. Retrieved from SG Maga

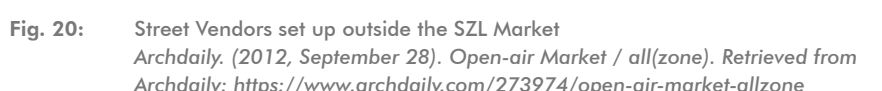

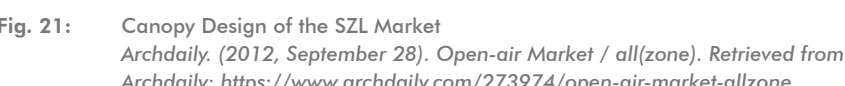

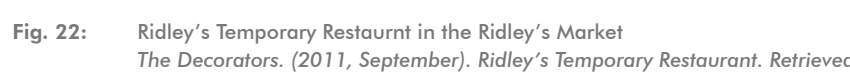

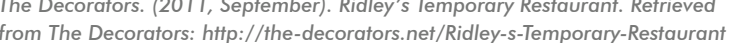

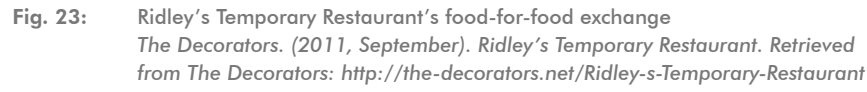

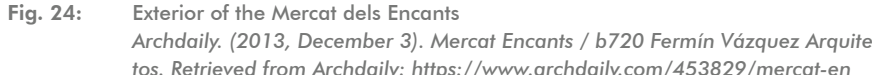

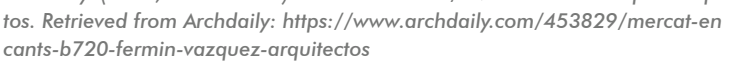

Fig. 25: Canopy Design of the Mercat dels Enco

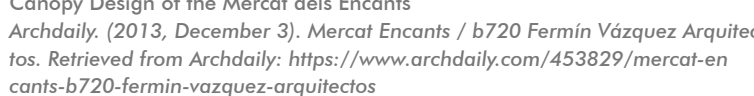

Fig. 26: Map of Singaporor

Fig. 27: Rochor Conal
Centre for Livable Cities. (2015, April 27). Jason Wright: Value of ABC Woters for

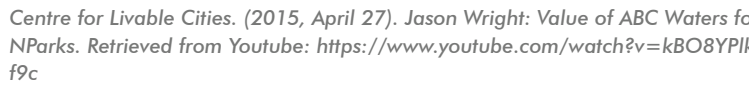

Fig. 28: The future Development of Rochor

Fig. 29: Rochor's Age Group"

Fig. 30: Rochor's Average Income per person (SGD)*

Fig. 31: Rochor's Ethnic Groups"

Fig. 32: Rochor's Literach

Fig. 33: Site Location Pla

E. 34: Existing Singapore - Johore Express Terminal (Proposed Market Relocation)
Land Transoort Gurv. (2013, April 30). Queen Street Bus Terminal. Retrieved

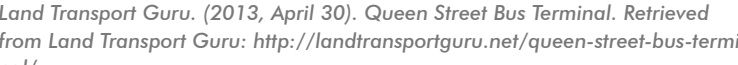

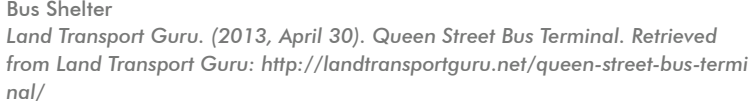

Fig. 36: Bus Sops $\quad$ Land

Fig. 37:

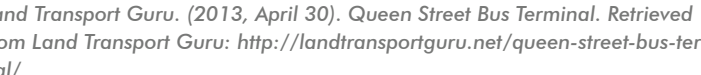

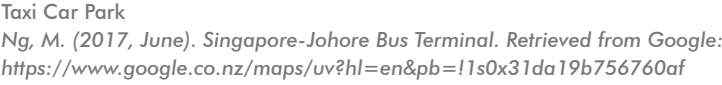

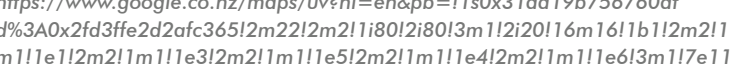

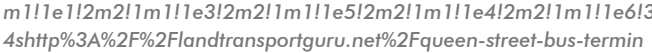

Fig. 38: Taxi Shelter

Fig. 39: Bus Ticket Centre

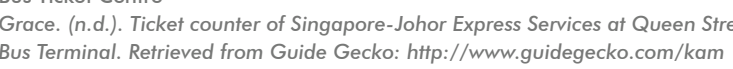
pong-glam/ticket-coun
bust-erminal /pp, 1196

Fig. 42: Singapore's Average Temperature*

Fig. 43: Singapore's Average Sunshine Hours

Fig. 44: Site's Sun Path Analysis

Fig. 45: Singapore's Average Rainfall'

ig. 46: Singapore's Average Wind Speed

Fig. 47: Sires Wind Path Analys

Fig. 48: Rochor's Amenities Plan"

Fig. 49: Rochor's Trafic Movement

fig. 50: 'Sungei Road Market: A Future tor Ste Culture Heritage' Panel Discussion,

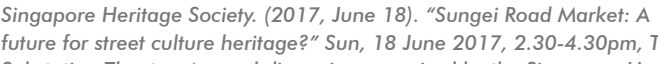
Substation Theatre. A panel discussion organised by the Singupore Herititge

Fig. 51: People waiting for the Coach Bu

Fig. 52: People walking pass the Site
Phom, P. (2016, May). Singop

coogle: hitps: Why

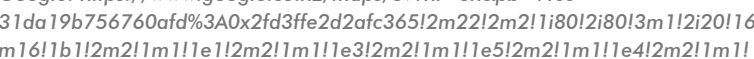

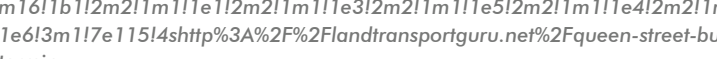

Fig. 53: People walking through the Sito

Fig. 54: People waiting by the Station

Fig. 55: People sitting and waiting for a taxi
Backpacking Mallaysia. (2012). Toxi Stand. Retrieved from Backpacking Malousia:

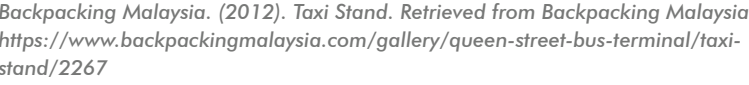

Fig. 56: Ticket Counter for the Coach Buses

57: Construction of the Jelan Besar Station, Sungei Rood

Fig. 58: Eating in the Hawker Centre, Jalan Berseh

59. 59: Shopping in Bugis Street Mall, Bugis Street

9. 60: Walking through the Bugis Street Mall, Victoria Street

. 61: Fishing and Waiting

gi. 62: Eating, Cycling and Walking

Fig. 63: Sitting and Relaxing

ig. 64. Gazing and sleeping

Save Sungei Rood Market. (2017, May 27). Thank you participants of

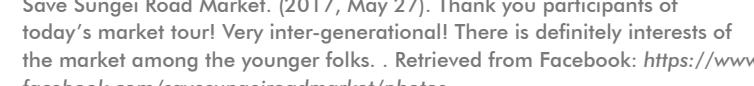

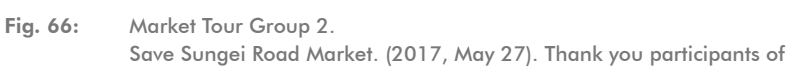

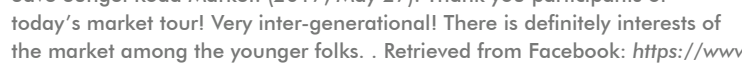

Fig. 67: Market Tour Group 3.

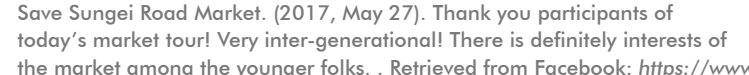

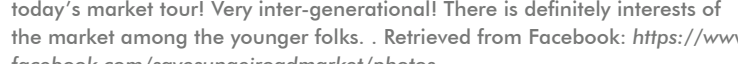

Fig. 68: Marke Tour Group 4.

Save Sungei Rood Market. (2017, May 27). Thank you participants of
today's market tourl Verer

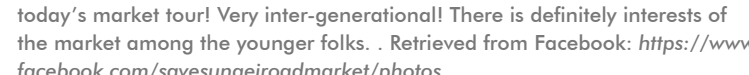

Fig. 69: Lion Dance Performance 1 . Sungei Road vendors may move to Golden Mite

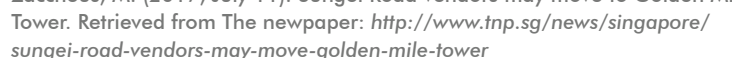

Fig. 70: Vendors Sociallin

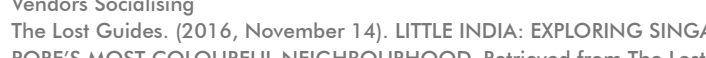
SuRE'S MOST COLOURFUL NEEGHBOURHOODD. Retrieved from The Los

$\begin{array}{ll}\text { fig. 71: Bargaining } & \text { Zecheus, M. (2014, July 31). Sungei Rood flea market will have to go Re } \\ \text { Z Re }\end{array}$

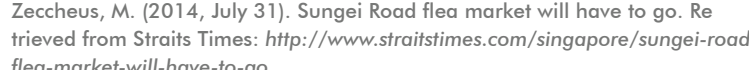

Fig. 72: Vendors' Selfie
Chong, L. (2017, July 11 ). And The Thieves' Market is No More. Re

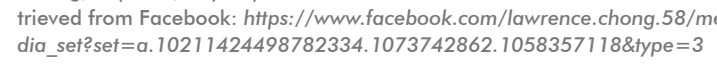


Fig. 73: Shopper Squatiting and Bargaining Asiaone. (2017, Februarr 71$) 7$. 7 things you ought to know about Sungei Road

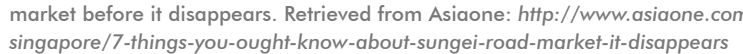

Fig. 74: Squating
Asione. (2017, February 11). 7 things you ought to know about Sungei Rood

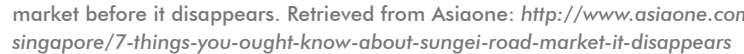

Fig. 75: Vendor and Shopper Socialising
$\mathrm{Ng}, \mathrm{K}$. (2017, July 10). End of a chapter for Sungei Road flea market. Retrieve om Today Online: htpps:///www.toddyonline. com/singopore/end-chopter-

76: Tiger Umbrella, Bicycle and Cha

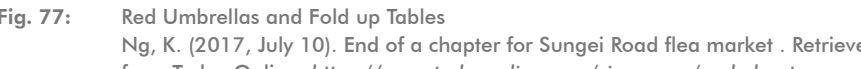

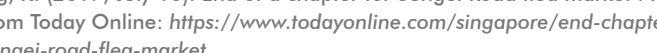

Blue Plastic Tarps and Mats

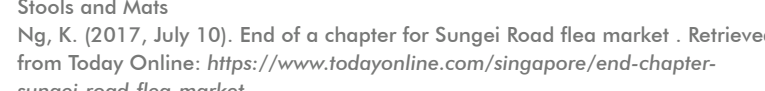
Grits Times. (2014, July 31). Sungei Road flea market will have to go. Re trieved from Straits Times: $\mathrm{htp}$ : //Mww.straitstimes. com/singapore/sungei-rod Un

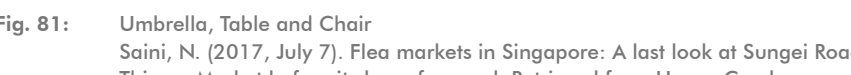
hievess Market before it it loseses for good. Retrieved from Honey Comberis

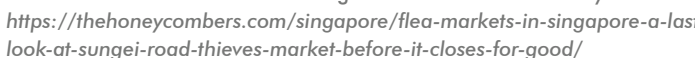

Fig. 82: $\begin{aligned} & \text { Bench and Boxes } \\ & \text { Asione 2017 }\end{aligned}$ Astaone. (2017, February 11$) .7$ things you ought to know about Sungei Road singapore /7-things-you-ought-know-about-sungei-road-market-it-disisppeacrs

Fig. 83: $\quad$ Truck and Chair Saini, N. (2017, July 7). Flea markets in Singapore: A last look at Sungei Rood

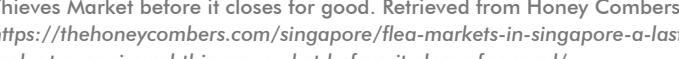

Carts ond Luggages
Xie, S. M. (2016, Jnaury 19). Check out these amazing photos of the Sunge

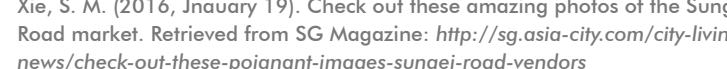

. 85: Umbrella and Hangers

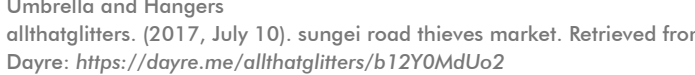

Fig. 86: Blue Plastic Tarps, Boxes and Cart

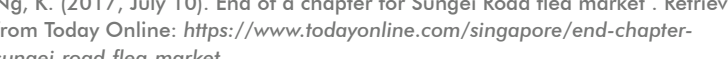
Fig. 88: Stool and Table

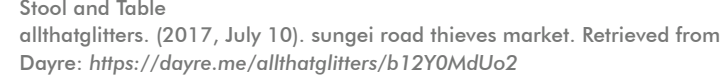

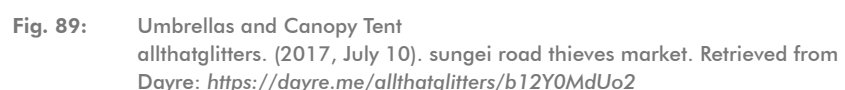

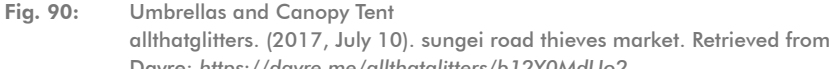

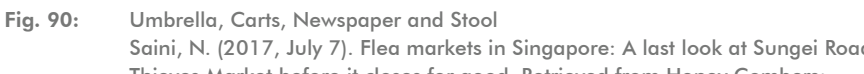

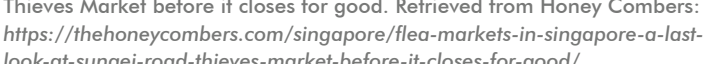

Fig. 91: Motorised Bicycle*

Fig, 92: Small Truck"

Fig. 93: Bicycle and Carrt

Fig. 94: Shopping Trolley and Carrs*

Fig. 95: Pushing and Carrying Goods

Fig. 96: Leff on Site.

Fig. 97: Hanging System that relies on the Existing Corrugated Fence

Fig. 98: Cement Block acting as the Umbrell's's Weight"

Fig. 99: Ties and Knots on to the Existing Corrugated Fence

Fig. 100: Stuffed Bag acting as the Canopy's Weight

Fig. 101: Umbrella on Exising Wire Fence

ig. 102. Canopy Tem

Fig. 103: Vendor setting up his Stall 1 .

Fig. 104: Vendor setting up his Stall 2 .

Fig. 105: Vendor setting up his Stall 3 ,

Fig. 106: Carts left on the side of the Road

Fig. 107: Goods leff on the side of the Pavemen

Fig. 108: Goods left on the side of the Road 2 .

Fig. 109: Rubbish

Fig. 110: Stalls leff behind. Government Cleaners cleaning up and a local passing
through the market

Fig. 111: Chairs ond Government Cleaners cleaning up the rubbish that was left behind

Fig. 112: Red Speech Bubble Questionnaires"
Fig. 113: Selected Red Speech Bubble Questionnaires

Fig. 114: Green Speech Bubble Questionnaires

Fig. 115: Selected Green Speech Bubble Questionnairs

Fig. 116: 'Vendor's ideal Stall' Drawing Exercise'

Fig. 117: Singapore Field Research Qualitative Site Analysis Displar

fig. 118: Design Sketches and Doodles 1 .

Fig. 119: Existing Site Plan, scale 1:500

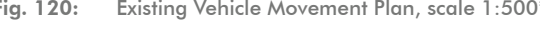

Fig. 121: "Existing Pedestrian Movement Plan, scale 1:500"

ig. 122: Proposed Tratic Motentent Pan, scale 1:500

Fig. 123: Initial Sketches of Proposed Pedestrian Ram

Fig. 124: Pedestrian Ramp lterations and Precedent

Fig. 125: Initial Sketches of Proposed Framework and Preceden

Fig. 126: Enclosed Framework Sectional View

Fig. 127: Open Framework Sectional View"

Fig. 128: Framework's Dimensions"

Fig. 129: Overview Perspective from Rochor Canal-

Fig. 130: Proposed Master Plan

Fig. 132: Proposed Below Ground Plan*

Fig. 133: Courtyord Perspective

ig. 134: Framework Proposal

ig. 135: coungan hommentiven

Fig. 136: Design Sketches and Doodles 2

Fig. 137: Existing site Plan with Areas to be Developed

Fig. 138: New Site Plan with Future Development

Fig. 139: New Vehicle Movement Plan*

Fig. 140: New Pedestrian Movement Plan

Fig. 141: Proposed Troffic Movement Plare

Fig. 142: Initial Above Ground Programme Layout Plan

Fig. 143: Initial Below Ground Programme Layout Plan"

Fig. 144: Sketches of the Framework Refinement and Construction

Fig. 145: Sketches of the Framework Refinement in Elevation

Fig. 146: Refined Above Ground Programme Layout Plan with Pedestrian Movement"

Fig. 147: Refined Below Ground Programme Layou Plan with Pedestrian Movement"

Fig. 148: Refined Sketches of the Canal's edge in Sectional View
199. Digital Modeled Canopy lterations $1-3$ and Precedent

150. Digithad Modeled Canopy lterations $4-6^{*}$

19. 151: Overview Perspective from Arab Street*

Fig. 152: Developed Master Plan"

fig. 153: Developed Above Ground Plan

Th:

fig. 155: Long Sectional View

if. 157: The Conal's Edge*

Fig. 158: Canopy Steps down to the Cand

Fig. 159: Framework used as Market Stalls

ig. 160: Framework used as Educctional Space"

Fig. 161: East Bus Station Entrance from Queen Street

Fig. 162: Bus Stops 01 and 02*

Fig. 163: Information Desk \& Ticket Centre"

fig. 164: Kiosks used as Market Stalls"

ig. 165: Secondary Pedestrian Route from Queen Street

ig. 166: Blind Sketches of Vendors

Fig. 167: November 2017 Design Review 


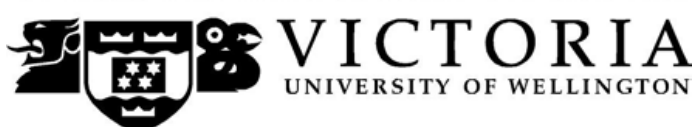

\section{MEMORANDUM}

\begin{tabular}{l|l}
\hline TO & Angelina Ang \\
\hline COPY TO & Fabricio Chicca \\
\hline FROM & AProf Susan Corbett, Convener, Human Ethics Committee \\
\hline DATE & 24 April 2017 \\
\hline PAGES & 1 \\
\hline SUBJECT & $\begin{array}{l}\text { Ethics Approval: 24468 } \\
\text { Governed by Opportunity }\end{array}$ \\
\hline
\end{tabular}

Thank you for your application for ethical approval, which has now been considered by the Standing Committee of the Human Ethics Committee.

Your application has been approved from the above date and this approval continues until 6 March 2018. If your data collection is not completed by this date you should apply to the Human Elhics Committee for

Best wishes with the research.

Kind regards

\section{CONSENT TO PARTICIPATE IN RESEARCH}

Researcher: Angelina Ang - Masters Thesis in Architecture
Victoria University of Wellington, New Zealand

Governed by Opportunity - Participatory Design Research in Singapore

I have read and understood the information sheet of this research project. I was given the opportunity to ask questions and have them answered to my satisfaction. I may withdraw myself and/or any information I IfI wild f for his I understand that any information I provide/produce will be aggregated.

I understand that any information that could identify me will not be used in any reports.

I understand that the information I provide/produce will be used for a Masters thesis and a summary of the results may be used in academic reports and/or presented in conferences.

The information that I provide/produce will be destroyed 2 years after the research finished.

$\square \quad$ I consent to participating in this research project.

¿ I consent the researcher to photograph and/or record me participating in this research project.

$\square \quad$ I consent to any information I provide/produce to be used in this Masters Thesis which will help shape and form the design of a street market.

I would like receive a copy of my questionnaire and/or drawing exercise via. Email.

I I would like receive a summary of the results for this research project via. Email.

Email Address:

Name of Participan

Signature:

Date: 


\section{Sy}

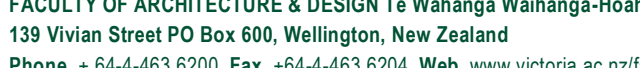

\section{INFORMATION SHEET}

Thank you for your interest in this research project. Please read this information sheet before signing the consent form. If you choose to decline taking part in this research project, thank you for considering and

\section{Who am I?}

My name is Angelina Ang and I am currently a Masters Student in Architecture at Victoria University of thesis.

\section{What is the aim of the Thesis?}

The aim of this thesis is to investigate how architecture and community participation can:

Accommodate for both the Sungei Road Thieves Market and new development.

This research project has been approved by the Victoria University of Wellington Human Ethics Committee: 24468.

\section{What will I be doing?}

Throughout this research project, I will be:

Taking photographs and videos* of the Sungei Road Thieves Market.

$$
\text { Gathering information through questionnaires and/or drawing exercises. }
$$

The information collected will be used to provide a better understanding on how the Sungei Road Thieves Market works

${ }^{\star}$ The faces in the photographs and/or videos will be; avoided, cropped and/or blurred out to protect the people's identity.

\section{How can you help?}

If you agree to take part in this research project I will

Give you a questionnaire to fill out This questionnaire asks about your thoughts and ideas of the market. It will take roughly 5 minutes to fill out.

Give you a small drawing exercise to complete (for vendors only). This exercise involves you drawing a stall with the assistance of the Masters Student (if needed). This will take roughly 10
You may stop the questionnaire and/or exercise at any time, without giving a reason. You may withdraw from Yoreser. If you withdraw, the information you provide/produce will be destroyed.

\section{What will happen to the information you give?}

This research is confidential. This means that the researchers named below will be aware of your identity bu the information will be aggregated and your identity will not be disclosed in any reports. However, you should be aware that in small projects your identity might be obvious to others in your community.

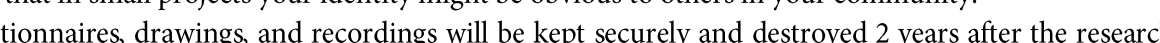

\section{What will the Research Project produce?}

Whe restls of his resench project will be used in my Masters thesis to shape and form the design of a street market. A summary of the results may be used in academic reports and/or presented in conferences.

\section{If you accept this invitation, what are your rights as a research participant?}

You may choose to decline taking part in this research project. However, if you decide to participate, you have

Choose not to answer some/any of the question

A

Wilh

Ask any questions abose $5^{\text {th }}$ of July 2017

Agree on another name for me to use rather than your real name

If you have any questions or problems, who can you contact?

If ou have any questions, either now or in the future, please feel free to contact either:

$\begin{array}{ll}\text { Masters Student: } & \text { Supervisor: } \\ \text { Angelina Ang } & \text { Fabricio Chicca } \\ \text { angange@myvuw.ac.nz } & \text { Senior Lecturer } \\ & \text { School of Architecture at VUW, NZ } \\ & +64044635644 \\ & \text { fabricio.chicca@vuw.ac.nz }\end{array}$

Human Ethics Committee information

If you have any concerns about the ethical conduct of the research, you may contact the Victoria University HEC Convener: Associate Professor Susan Corbett. Email susan.corbett@vuw.ac.nz or telephone +6404463 5480. 
Please fill out the detachable sheets below: 请填写以下的表格:
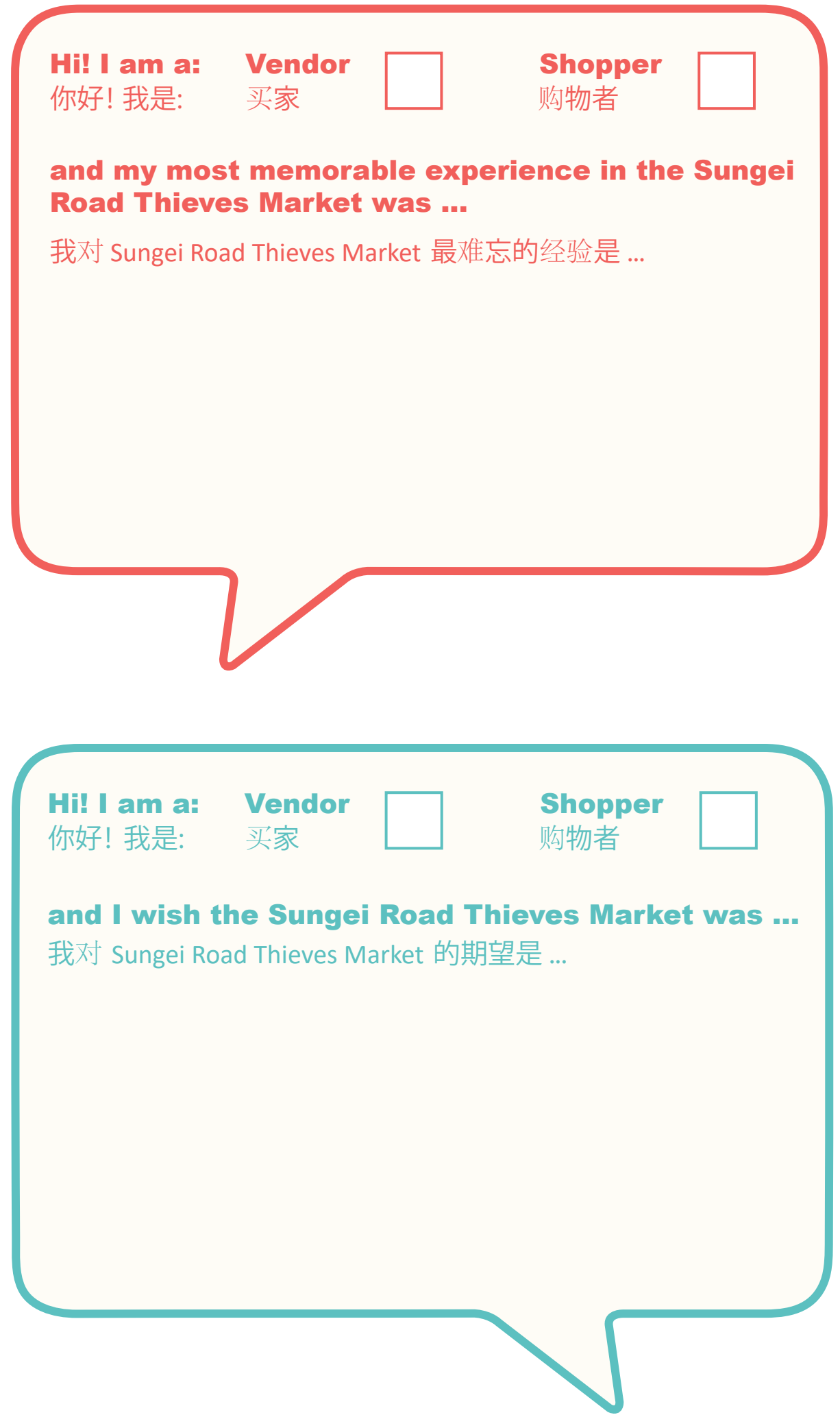

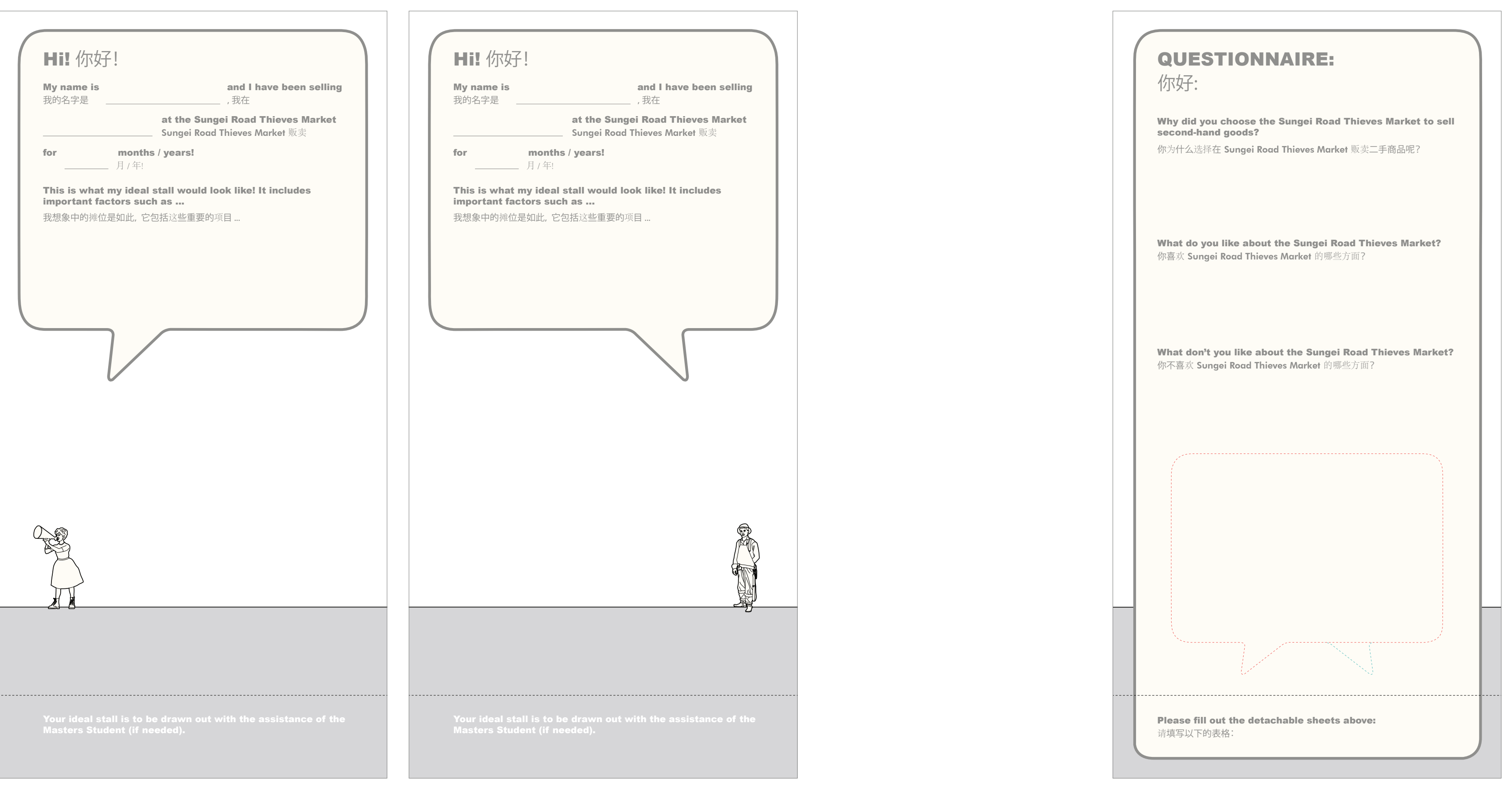
